\title{
A LABORATORY INVESTIGATION OF THE PHENOMENON OF FRICTION AS APPLIED TO FINE-TEXTURED BITUMINOUS PAVING MIXTURES
}

AUGUST 1959

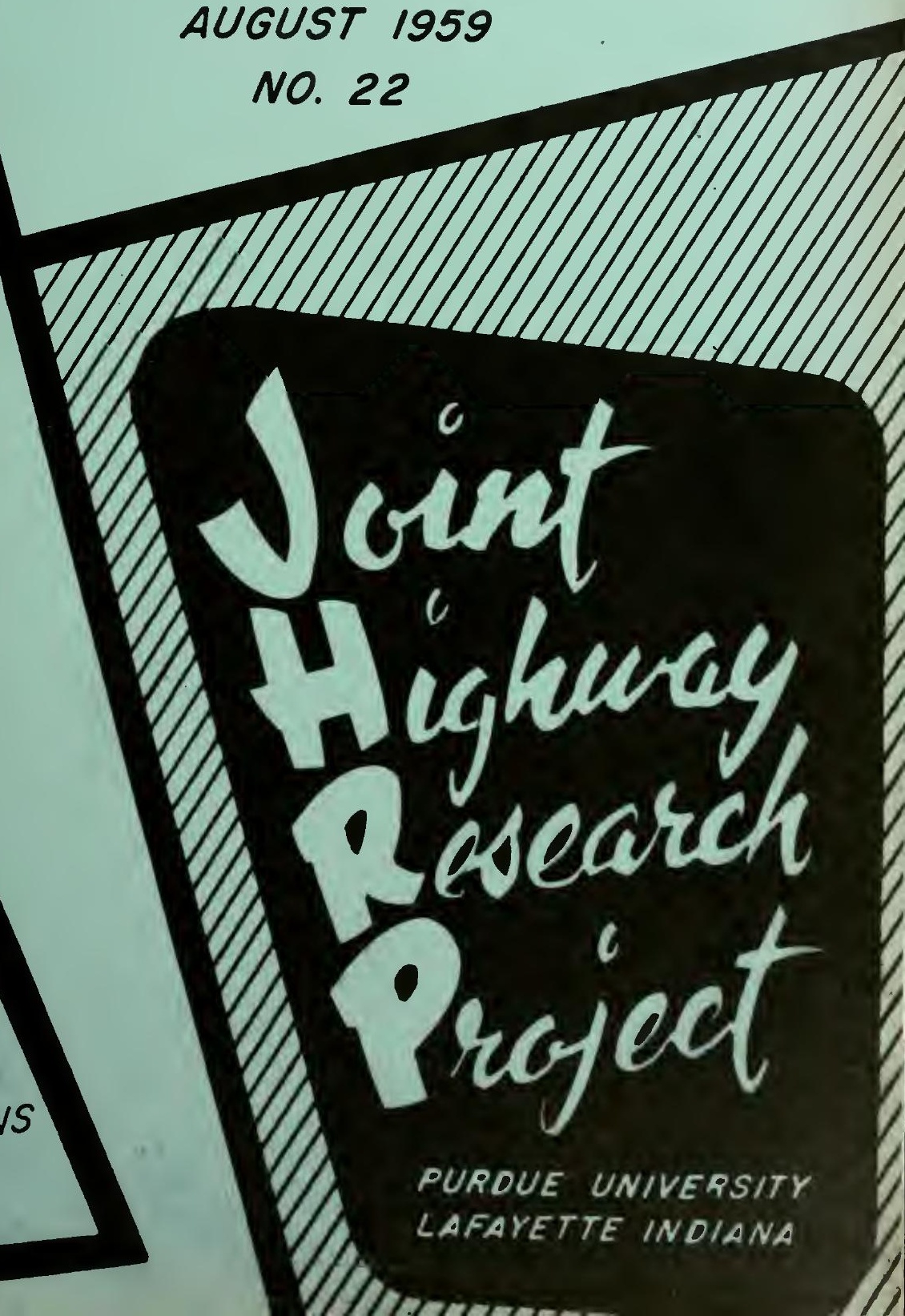





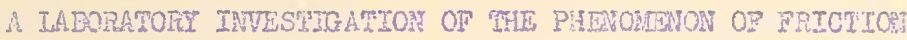

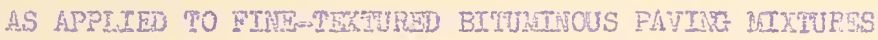

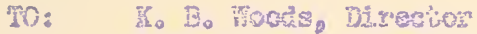
JoInt YIghtwey Fessasch Project

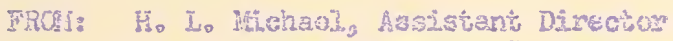
Joins Hightray Fogataroh Project

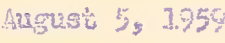

File: 9-6r-10

Pรoject: $0-36053 \%$

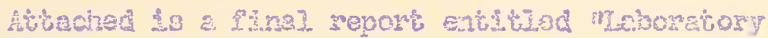

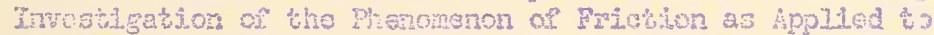

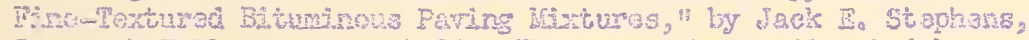

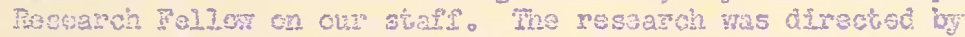

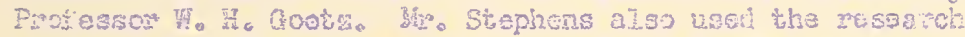

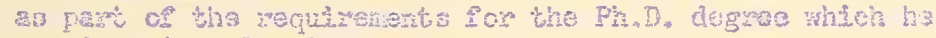

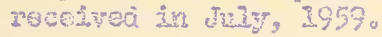

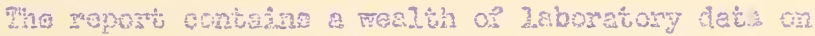

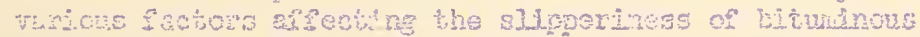

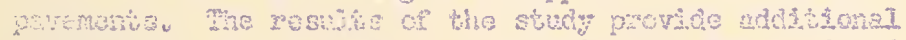

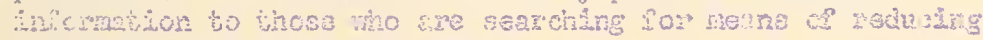

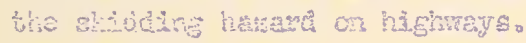

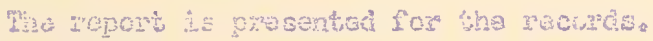

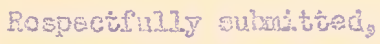

$$
\begin{aligned}
& \text { 2. } 2 \text { restide }
\end{aligned}
$$

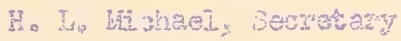

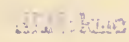

Acticinasust

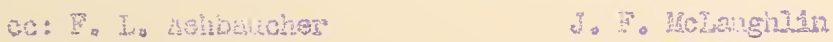

$$
\begin{aligned}
& \text { J. R. Coomen R. D. MLU. E }
\end{aligned}
$$

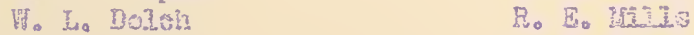

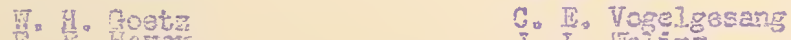

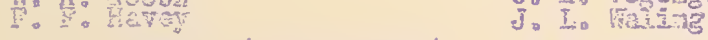

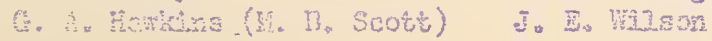

$$
\begin{aligned}
& \text { C. } \therefore \text { Ifonare E. J. Poder }
\end{aligned}
$$


A LABORATORY INVESTIGATION OF THE PHENOMENON OF FRICTION AS APPLIED TO FINE-TEXTURED BITUMINOUS PAVING MIXTURES

\author{
by \\ Jack E. Stephens \\ Research Fellow \\ Joint Highway Research Project \\ Project No: C-36-53J \\ File No: $9-6-10$
}

Purdue University

Lafayette, Indiana

August 5, 1959 
Digitized by the Internet Archive in 2011 with funding from

LYRASIS members and Sloan Foundation; Indiana Department of Transportation 


\section{ACKNOWLEDGMENTS}

This investigation was undertaken by the author while studying at Purdue University under a fellowship financed by the Automotive Safety Foundation. Laboratory facilities, material, and extra labor were provided by the Joint Highway Research Project of Purdue University, Professor K. B. Woods, Director. The author is grateful to these organizations for supplying the assistance required to make this study possible.

The many people who aided this work cannot be individually recognized here, but their help has been appreciated. The author desires to acknowledge especially the support of his major professor and adviser, Professor W. H. Goetz, whose encouragement and faith in this project has aided substantially in the early completion of the work. Lastly, the author wishes to thank his wife for her continual understanding and encouragement and her aid as typist. 
TABLE OF CONTENTS

Page

LIST OF TABLES ................... . . . . v

LIST OF ILLUSTRATIONS .................. . vi vi

ABSTRACT ....................... vili

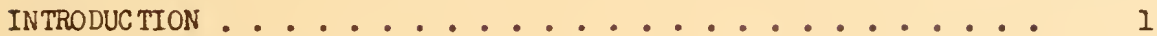

REVIEW OF LITERATURE .......................... 4

Field Investigations ... . . . . . . . . . . . . 4

Laboratory Investigations ............... . . 10

Experimental Results .................. . . 11

Friction of Plastic Materials and Boundary Lubrication . . . 15

THEORY OF FRICTION . . . . . . . . . . . . . . 19

Rigid Material on Rigid Material .............. 19

Plastic Material on Rigid Material . . . . . . . . . . 22

Plastic Material on Plastic Material ............. 24

Lubricated Surfaces (Thick Films) . . . . . . . . . 26

Boundary Lubrication (Thin Films) . . . . . . . . . 26

Rubber Tire on Pavement Surfaces . . . . . . . . . . 28

EFFECT OF GRADATION ON THE SKIDDING RESISTANCE OF FINE

BITUMINOUS MIXTURES .................... 31

EFFECT OF THE QUANTITIES OF CARBONATES AND SILICATES ON THE

SKIDDING RESISTANCE OF FINE BITUMINOUS MIXTURES . . . . . . 38

EFFECT OF AGGREGATE SHAPE ON THE SKIDDING RESISTANCE OF FINE

BITUMINOUS MIXTURES .......................... 45

OPTIMUM SIZE OF ROUGHNESS FOR MAXIMUM SKIDDING RESISTANCE . . . $5 I$

EFFECT OF THE PENETRATION GRADE OF ASPHALT ON THE SKIDDING

RESISTANCE OF FINE BITUMINOUS MIXTURES . . . . . . . . . .

EFFECT OF VARIATIONS IN THE PERCENT OF EXPOSED AGGREGA TE

IN THE PAVERENT SURFACE ON THE SKIDDING RESISTANCE OF

PAVEMENTS 
EFFECT OF AGGREGATE EDGES ON SKIDDING RESISTANCE OF

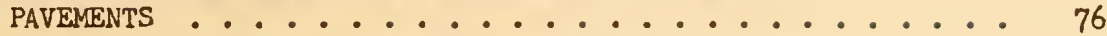

EFFECT OF POLISHING AGGREGATE SURFACES ON SKIDDING

RESISTANCE OF PAVEMENTS ................... 79

USE OF BRUSH SURFACE ANALYZER FOR PREDICTING SKIDDING RESISTANCE OF PAVEMENTS .................... 86

SUMMARY OF RESULTS ......................... 91

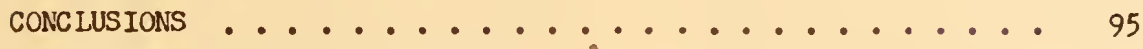

SUGGESTIONS FOR FUTURE RESEARCH .................... 99

BIBLIOGRAPHY . . . . . . . . . . 102

APPENDIX A - MATERIALS ...................... 110

APPENDIX B - TEST PROCEDURES . . . . . . . . . . 114

APPENDIX C - TEST DATA ............. 130

$\operatorname{vITA} \ldots \ldots \ldots \ldots$ 


\section{LIST OF TABLES}

Table

Page

1. Results of Skid Resistance Tests on Gradation Series of Fine Bituminous Mixtures ........... 130

2. Results of Physical and Chemical Tests of Sands . . . 135

3. Results of Skid Resistance Tests on Fine Bituminous Mixes Containing West Lafayette and Richmond Sands . . . . . 136

4. Results of Skid Resistance Tests on Fine Bituminous Mixes Containing Silica and Limestone Sands . . . . . . 137

5. Skid Resistance of Fine Bituminous Mixtures Utilizing Different Penetration Grades of Asphalt . . . . . . 139

6. Skid Resistance Test Results fon Different Contact Areas Between Test Shoe and Limestone .......... 140

7. Relative Resistance Values at Different Pressures for Greencastle Limestone and Medina Sandstone . . . . . . $\mathbb{1}_{4}$

8. Results of Reflected Light Measurements on Fine Bituminous Surfaces .............. 142

9. Skid Resistance of Surfaces Composed of ControlledSha pe Rock Fragments ............... . 143

10. Relative Resistance Values Resulting from Varying the Degree of Polish of Stone Cores ........... 144

11. Summary of Abrasives Used for Polishing . . . . . . . 145

12. Summary of Measurements of Surface Roughness by the Brush Surface Analyzer ............ 146

13. Summary of Sieve Sizes Used for Fine Aggregate . . . . . 147

14. Skid Resistance of Differently Compacted Specimens . . . 148

15. Skid Resistance of Specimens Polished for Different Lengths of Time ............. . . 149 
LIST OF ILLUSTRATIONS

Figure

Page

1. Deformation of Surfaces ............. 21

2. Curvature of Deflected Plastic Surfaces ......... 25

3. Variation in Skid Resistance with Maximum Aggregate Size for Fine Bituminous Mixtures . . . . . . . . .

4. Variation in Skid Resistance with Fineness Modulus for Fine Bituminous Mixtures of Different Maximum Sizes of West Lafayette Sand ..................

5. Variation in Skid Resistance with Fineness Modulus for

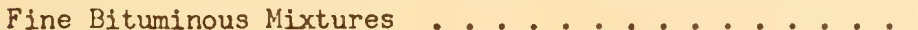

6. Grain Shape and Texture of Six Sands (25x) . . . . .

7. Variation in Skid Resistance with Polishing Cycle for Fine Bituminous Mixtures of Different Materials . . . .

8. Variation in Percent of Insoluble Material with Fineness Modulus for Richmond and Lafayette Sands . . .

9. Variation in Skid Resistance with Fineness Modulus for Fine Bituminous Mixtures Composed of Different Minerals

10. Variation in Skid Registance with Polishing Cycle for Fine Bituminous Mixtures Composed of Round and Angular Silica Sand ...................

11. Variation in Skid Resistance with Polishing Cycle for Fine Bituminous Mixtures Composed of Round and Angular Limestone Sand

12. Variation in Skid Resistance with Aggregate Size for Fine Bitumincus Mixtures Composed of Round and Angular Silica Sand ....................

13. Variation in Skid Resistance with Aggregate Size for Fine Bituminous Mixtures Composed of Round and Angular Limestone Sand 
14. Variation in Skid Resistance with Penetration Grade of Asphalt Used for Fine Bituninous Mixtures ......

15. Variation in Skid Resistance with Degree of Polish for Fine Bituminous Mixtures Made with Asphalts of Different Penetration Grades ............

16. Specimens Studied for Effect of Aggregate Edges and Area on Skid Resistance ......... 64

17. Variation in Skid Resistance with Ratio of Aggregate Area to Pavement Area (Constant Load) ........

18. Core of Richmond Limestone ............

19. Variation in Skid Resistance with Contact Pressure on Limestone and Sandstone .............

20. Variation in Skid Resistance with Ratio of Aggregate Area to Pavement Area (Constant Pressure) .......

21. Variation in Skid Resistance with Reflectance of Fine Bituminous Mixtures ............

22. Variation in Skid Resistance with Polishing Cycle for Rock Cores (Crushed Quartz Abrasive) ........

23. Variation in Skid Resistance with Polishing Cycle for Rock Cores (Core Material for Abrasive).......

24. Photomicrographs of Thin Sections of Rock Cores (90x). 84

25. Brush Surface Analyzer ............ 87

26. Oscillograms from the Brush Surface Analyzer .....

27. Equipment for Molding Laboratory Specimens ...... 116

28. Laboratory Rollers ............... 118

29. Laboratorg Skid Resistance Machine . . . . . . . 119

30. Test Shoe Used in the Laboratory Skid Resistance Machine .............. 120

31. Drill Press Setup for Polishing ......... 124

32. Diagram of Polishing Turntable .......... 125

33. Variation in Skid Resistance with Time of Polishing . . 126 
ABSTRACT

Stephens, Jack Edward. Ph.D., Purdue University, July 1959.

A Laboratory Investigation of the Phenomenon of Friction as Applied to

Fine-Textured Bituminous Paving Mixtures. Major Professor: William H. Goetz.

This presentation recognizes that the friction generated between a skidding rubber tire and a bituminous pavement must be attributed to several causes. In order to better understand friction, and as a start toward the eventual goal of predicting the potential frictional resistance of a pavement before it is built, an effort was made to evaluate each of the causes and to establish their relative importance. An explanation of friction is presented as it applies to the slippage between a rubber tire and a pavement surface.

An extensive series of studies was carried out by preparing specimens from sand mixes of widely varying gradation and testing the resulting surfaces for skid resistance in the machine developed earlier at Purdue University. As a result of these tests, estimates of the size of roughness or surface texture contributing most to skid resistance were made. The optimum height of roughness for maximum skid resistance was estimated as .009 inches at a spacing of 0.018 inches for crushed silica sand. For rounded sands, indications are that the optimum height is less than that for the crushed material. The series of tests on effect of gradation show the possibillty of creating surfaces of improved skid resistance by controlled gradation of the aggregate. For mixtures 
of different gradations using Lafayette sand of sizes smaller than a No. 4 sleve, the minimum skid resistance recorded after two polish cycles was 45 and the maximum 81 . This large variation in skid resistance caused by gradation of the sand could be of great significance in controlling skid resistance of pavement mixtures. Other gradation series based on smaller maximum size Lafayette sand gave changes of similar magnitude.

For economic reasons, a readily avallable mineral is usually used for aggregate in bituminous mixtures. As a result, the aggregate mineral character is subject to change with locality. In most of the field trials for comparing the effect of aggregates, the change in mineral aggregate used has been accompanied by other changes such as a variation in the gradation of the aggregate. In this laboratory study, the actual effect of the ratio of silica to carbonates was investigated by making mixes of the same gradation and.particle shape but with different ratios of silica to carbonates. A range of silica content from five to ninetyeight percent was attained. As the silica content increased, the skid resistance increased at a variable and generally decreasing rate.

Past work has indicated that the aggregate shape has little effect on the skid resistance of coarse-textured bituminous pavements. Effect of shape of sand grains was investigated by comparing naturally rounded sand to material made by crushing coarse material from the same source. The grain sizes for successive mixtures were decreased until the resulting surface roughness of the mix was of the magnitude of that of the aggregate itself. The rapid polish or wear of hard, fine angular silica as compared to the rate of polish of the same material when rounded is pointed out. 
In order to explain partially the variation of skid resistance with aggregate gradation, studies were made on stone cores treated in such a manner as to give varying combinations of surface area of aggregate and length of aggregate edges. Comparisons of results from these specimens were made and some degree of evaluation of the ratio of edges to surface determined. In the range of coarse aggregate sizes, little advantage was gained by increasing either the total length or the sharpness of the edges. However, a large change was found in the relative resistance values when the ratio of the area of aggregate to the total surface area was changed.

Throughout this study the factors of surface area and texture of the aggregate exposed in the pavement appeared to be dominant in the determination of skid resistance. For this reason a study was made of the correlation between skid resistance measured by the laboratory skid machine and the roughness measured by a Brush Surface Analyzer. The results obtained by means of the Surface Analyzer were not entirely satisfactory. However, sufficient visual correlation appears to exist to justify further attempts to evaluate skid resistance by surface measurements.

From this investigation into the skid resistance of fine bituminous mixes, the more important variables appear to be gradation and mineral composition of the aggregate. Varying either of these two factors caused large changes in relative resistance values. The relative resistance values increased as the aggregate gradations were made finer. Increases in the silica content of the aggregate caused the relative resistance values to increase. The magnitude of the 
changes in skid resistance caused by variations in silica content is closely related to fineness modulus or gradation of the aggregate. At low fineness moduli the increase in relative resistance value with silica content is large. However, for sands of coarser gradations in the range of fineness moduli of 3.5 to 5.5 , silica content has a limited effect upon relative resistance values. The area of aggregate exposed in the surface tested is also of importance. The effects caused by adjusting gradation probably include this factor. 


\section{INTRODUCTION}

Skidding has long been recognized as one of the hazards of the operation of motor vehicles. However, the early automobiles had a minimum of trouble with skldding as low power and rough roadways combined to prevent driving above a modest speed. As power increased and smooth pavements were laid on many miles of highways, the importance of skidding as the cause of accidents became more pronounced.

For many states accident records are not sufficiently detailed to permit segregation of skidding accidents. In many accidents not caused by skidding, a high coefficient of friction between the pavement and the tires of the vehicle might have reduced the severity of the accident. Unusually complete accident records avallable for Virginia (54)* show dramatically the importance of this problem. Skidding of some nature was reported in thirty-five percent of the 37,507 accidents reported in 1956. In 1957 the number of reported accidents fell to 34,149 , but those in which skidding was indicated rose to forty-one percent. Skidding was reported to have occurred prior to braking in twelve percent of the 1956 accidents in that state. If skidding occurred prior to braking, it could surely be considered as at least contributing to the cause of the accident.

The increase in percentage of skidding accidents can be explained in several ways. Speeds are higher as is engine horsepower. However, 
the increase in skidding accidents per year is too great to be due to these factors alone. Field tests indicate that some older pavements are polishing under modern high-volume traffic.

There are several means by which automobile skidding accidents can be reduced. Vehicle improvements such as power brakes and driver improvement through driver training and education should be continually emphasized. The design engineer has helped by reducing curvature, by utilizing acceleration and deceleration lanes, and by increasing sight distances. Increased use of alinement features that avoid the need for either sudden stops or changes in direction should be encouraged. Improved means of providing skid resistance by changing tire factors such as shape and material should be investigated. However, the greatest Immediate potential for reduction of the number of skidding accidents appears to be concerned with the pavement surface.

Many agencies have worked on the skid-resistance problem and a wide variety of equipment has been developed for measuring this characteristic of the pavement. However, many field methods of test are inherently incapable of developing further the basic understanding of the phenomenon of friction. Therefore, most of the effort has gone into ways of improving the instrumentation and the operating efficiency of the equipment.

There is increasing concern over the apparent tendency for some types of pavements to polish. However, it is time that efforts be concentrated on the fundamental character of roadway friction. From the practical aspect, the materials engineer needs a method by which he can predict the future action of paving mixes in order to use materials that will retain desirable anti-skid characteristics throughout the 
otherwise useful life of the pavement. Several agencies have started studies of this nature, but the problem is exceedingly complex and new methods of test or at least tests hitherto unapplied to pavements must be tried.

The study reported here is a step in this direction made possible by the availability of a laboratory skid-resistance machine for measuring the effect of various pavement factors. Formulation of a definite theory of design of pavement mixes for increased skid resistance has been complicated in the past by unrecognized and uncontrolled variables in the field measurements of skid resistance. By controlling variables and systematically changing the bituminous mixes tested in laboratory machines, much of the information needed for designing skid resistance into pavements can be obtained.

In this paper the current status of the problem was established by means of a review of the available literature. The phenomenon of friction between different materials is discussed in order to arrive at an understanding as to what factors are important in creating and maintaining skid resistance. The tests which were carried out to evaluate these factors are then explained and the results presented. 
REVIEW OF LITERATURE

Studies which have been concerned with the question of skid resistance of pavements can be divided into two groups. Tests conducted by means of full-size equipment on pavements in place on the roadway make up the larger group. Various laboratory tests using small-scale pavement sections or small-scale equipment, and tests using simulated tires make up the second group. Early studies were generally of the fullscale field type or group one. The texture of the road surface at the time of many of the early tests was not the same as found today because of changes in construction methods and the polishing action of modern, high-volume traffic. Also, the conditions of test were not those that might be desirable today. Therefore, great care should be used in interpreting the data and trends presented in older studies, giving careful consideration to the conditions of test such as velocity, tire pressure, etc. However, general principles have not changed and much of the modern skid-resistance equipment is a relatively direct outgrowth of that used by the early experimenters.

\section{Field Investigations}

As early as the late 20's, T. R. Agg (1,2) made measurements of sidewise friction coefficients and found that a range of 0.60 to 0.85 covered most dry pavements. However, these values were based upon data obtained by sliding a model 'T' Ford touring car chassis sideways with 
a block and tackle. This indicates that an extremely slow rate of motion was used and the value obtained was probably the static coefficient. In fact, some of the lateral coefficients of friction found were based on such small movements, that very possibly the effect studied was that of resistance of tires to lateral deformation rather than lateral friction of tires on pavement. If this were true, the coefficients found were higher than the true coefficient of friction.

R. A. Moyer (60) carried out one of the early studies on skid resistance of pavements. For this work, Moyer built a two-wheel trailer which was pulled behind a truck. The hitch was arranged so that the traller could be towed normally or in such a way that the wheels of the trailer rolled at an angle to the direction of travel. The trailer brakes were activated from the truck and normally locked only one wheel. A dynamometer was incorporated into the hitch in order to measure the drawbar force required to maintain the test speed with the wheel locked. When desired, water could be fed from tanks in the truck bed to sprinkler bars ahead of the trailer test wheel. Results of these tests were published in 1934 and indicated high values for all high-type bituminous surfaces.

The National Physics Laboratory, London, England, worked on developing a method of skid testing based on the use of a wheel skewed to the direction of travel (4). This was accomplished by altering the sldecar mounting of a motorcycle in such a way that the sidecar wheel could be swiveled with respect to the line of travel. Tests were conducted by getting the motorcycle up to the desired test speed and then rotating the movable wheel to the test angle. The measure of friction 
used was the force required to maintain the wheel at the test angle and represented a coefficient of friction applicable to a skidding direction intermediate between the longitudinal and the transverse direction. This method of test has been further developed by the Road Research Laboratory of the Department of Scientific and Industrial Research and Ministry of Transport, London, England. Many tests have been performed and data are available for a wide variety of conditions and pavements (4).

The use of stock automobiles with a minimum of modifications has been advocated by several agencies. The use of trailer-type eauipment does impose certain artificial conditions upon skid resistance as compared to the skidding of self-powered motor vehicles and the use of automobiles may more nearly reproduce the true conditions. Purdue University has worked extensively with this method of skid testing of pavements and the State Highway Department of Indiana has continued this type of testing (37). The Ford sedan used was modified by the addition of electrically-operated power brakes intended to insure instant locking of all four wheels. Measurements of skid resistance were accomplished by driving the car onto the pavement to be tested and locking the wheels so that the car skidded to a stop. A Wagner stop meter gave the speed of the vehicle at the point of application of the brakes and the distance traveled in stopping. For wet-pavement tests, a water truck sprayed the pavement prior to testing.

A variety of this type of test has been developed in which the car is not allowed to skid to a stop as the brakes are only applied for one or two seconds (22). The rate of deceleration is measured by a 
decelerometer mounted in the car. Theoretically, it is possible to convert the measurements to coefficients of friction.

Many additional variations of these basic methods of measuring skid resistance are reported in the literature. It is impossible to enumerate all of the possibilities, but a few of the more significant are included. The Road Research Laboratory expanded the idea of the skewed-wheel motorcycle sidecar into an adjustable wheel supported in the rear seat area of a motorcar (22). The wheel can be raised when the vehicle is traveling from place to place and lowered through the car floor for testing. The wheel can be used straight or skewed, making it possible to correlate results from skewed, free-turning tests with those obtained by straight, locked skids.

A simple two-wheel trailer was constructed by the city of Paris in 1936 (47). Both wheels of the trailer swivel about kingpins under the action of levers controlled from the towing vehicle. Thus, at any time during the travel of the trailer, the wheels can be swiveled and the increased drawbar pull required to maintain the test speed recorded. By the use of suitable pressure cells, the sidewise coefficient can also be measured. In order to make large numbers of tests economically, the French also developed the 'Stradographe' which is an apparatus consisting of two wheels and guide members mounted upon a hitch underneath a van in such a way that the load to the wheels can be held constant (47). The wheels can be swiveled to $15^{\circ}$ or raised clear of the pavement. Provisions are made for reading the sidewise force developed when the wheels are swiveled and for measuring the towing force required. 
The trailers developed in this country are nearly all intended for longitudinal skid measurements. Minor differences in instrumentation, economy of construction, and general structure account for development of the different trailers (31). That under development by the National Advisory Committee of Aeronautics at Langley Field provides for controlled rate of slip $(84)$. This is done by having a gear chain between the two trailer wheels, giving a positive ratio between the angular velocities of the two and thus forcing one to slip at a given rate. This same idea has been incorporated into most of the longitudinal skid equipment in use in Europe (22). The city of Paris first tried a slip of ten percent of the distance traveled, but has now revised their machine to use ninety percent as the rate of slip. This new machine makes use of a front-wheel-drive vehicle with the slipping wheel driven by a gear reduction unit powered by one of the rear wheels. A machine formerly in use in Sweden operated at a preset rate of slip. This was accomplished by driving the test wheel by a take-off on the transmission acting through a gear box. The use of this machine has been discontinued in favor of one which forces the test wheel to slip at a rate independent of speed by incorporating a test wheel coupled to a drive wheel of a different diameter (22).

In recent years several skid-resistance tests which are not carried out by true automotive type equipment, but by simulated tires, have appeared. At least three of these are in the form of pendulums and resemble the Charpy or Izod impact machine used for measuring the strength of metals. The French (22) and the British (45) machines consist of pendulums pivoted on an adjustable horizontal axle carried 
by a portable standard. The horizontal axle is adjusted to permit the simulated tire on the head of the pendulum to exert the desired pressure on the pavement. The pendulum is then released from a set height and the work done against friction computed by observing the loss in energy of the pendulum as evidenced by the reduced height of the back swing. The National Crushed Stone Association portable tester is similar except that a bicycle wheel is used for the pendulum (34). By removing the tread from part of the perimeter of the tire on the wheel, it can be made to operate as a pendulum. As the tread remaining extends for a much greater length than the rubber on the European pendulums, the bicycle wheel comes to rest with the tread still in contact with the pavement. The angle through which the wheel rotates is considered an arbitrary measure of slipperiness.

Both the State of California (4I) and the Laboratorie del Transporte of Madrid (43) have developed skid-resistance machines based on the rate of loss of angular momentum of a free-spinning wheel. A motor is used to drive a rubber-tired wheel until the angular velocity corresponds to the desired speed of test, at which time the motor drive is disconnected and the wheel set down on the pavement under test. The Spanish machine permits the wheel to coast to a stop on one area of pavement while measurements of torsion in the axle and of deceleration are made. The California apparatus operates in a similar manner with the major difference being that the wheel is free to travel along the pavement under the restraint of calibrated springs. The distance that the wheel travels in using up the stored angular energy is a measure of the skid resistance of the pavement. 


\section{Laboratory Investigations}

The pendulum type and the rotating, free-wheel type of test machine can both be used either in the field or in the laboratory on specially prepared test specimens. Several machines have been developed especially for laboratory use and do not lend themselves to fleld testing. One such machine has been used by the Kentucky Highway Department $(40)$ and consists of a standard drill press driving a rubber ring against the pavement sample. The machine in use at Purdue University measures the torque transmitted to a fixed rubber shoe by a rotating six-inch pavenent sample $(75,76,78)$. The laboratory of the Tennessee Highway Research Program uses a full-size automobile wheel for studies of parement (87). The wheel is forced to spin in contact with the pavement sample and the power required to maintain the original speed is taken as a measure of pavement slipperiness.

Several other forms of laboratory tests have been used to simulate the action of tires on pavement. Orchard (66) rotated the pavement much as Shupe (78), but used a small tire to represent the braked wheel. The National Crushed Stone Association has conducted tests at a scale intermediate between full-size field tests and the small laboratory tests. Pavements were constructed in a 14 -foot diameter circular track and compacted and polished (34). However, the advantage of a largescale test was lost by measuring the resulting slipperiness with the National Crushed Stone Association bicycle wheel. The tire companies have studied skid resistance as development work for better tires. The Goodyear Tire and Rubber Company has made tests in which the pavement 
was placed on the surface of a revolving drum and rubber-tired wheels were spun in contact with the drum (65).

\section{Experimental Results}

Comparisons of the results of these different methods of measuring skid resistance are difficult to make as, to some extent, results are a function of equipment used in the measurements. This effect of equipment is demonstrated very vividly by the results of a comparison study of Virginia pavements made in conjunction with the First International Skid Prevention Conference. Statistical analysis showed excellent correlation between the measurements made with two cars using the stopping-distance measurements. However, the results of the tests by six trailers did not correlate with each other nor could any simple additive factor be found to relate the different equipment. Goetz and Rice (30) listed the factors that could affect skid resistance or test measurements. If test results are to be correlated, most of the variables listed in this paper must be controlled.

Skid-resistance trends presented by Moyer (61) in the early 30's seem to be true today. Most investigators have found a lower coefficient of friction for wet pavements. However, Moyer (58), Martin (48), and Foster (20) report pavements which had higher friction values when wet than when dry. Very possibly the cooling effect of water accounts for this apparent nonconformity. Studies on the effect of temperature are incomplete due to the difficulties encountered when attempting to measure the actual temperature at the contact zone of the tire. Indications are that frictional resistance falls as temperature rises, with the change probably due to softening of the rubber. 
The effects of speed in skid resistance are variable depending to a large extent on other conditions and the range of speeds considered. Most studies show that speed has little effect on the skid resistance of dry pavements. The experimental results on wet pavement show some disagreement. Moyer notes (60) that the greatest changes in (coefficient of friction) occur when speeds are low, but Stinson and Roberts ( 81 ) found pavements which were most sensitive to changes at high speeds. Bradley and Allen (10) indicate a sharp decrease in for smooth tires on wet bituminous pavements. At speeds over $100 \mathrm{mph}$ on wet airport runways, Giles and Lander (26) found exceedingly low coefficients of friction. Results of trailer tests published by Whitehurst and Goodwin (86) indicate that $\mu$, when measured on dry pavement, increases with speed.

Moyer (6l) originally found little change in $\mu$ with tire pressure or load. However, Moyer repeatedly points out increases in with increased area of contact.

Polishing and weathering are closely related for many aggregates. Giles, Sabey, and Lander $(28,26)$ and others report lowest values of $\mu$ in late summer and highest in late winter. This increase in winter may be a temperature effect or an actual increase due to weathering of the aggregate. The seriousness of aggregate polish is reflected in data presented by Michael (53) which show over a fouryear period an increase of over fifty percent in stopping distance from $30 \mathrm{mph}$ for one Indiana pavement. Giles and Sabey $(25,28)$, Whitehurst and Goodwin (86), and others have reported skid resistance measurements which indicate progressive polish of pavements. 
Over the years, pavement texture has received much attention (68). Moyer (60) states a gritty or sand-paper texture is best, but that some consideration must be given to tire condition and water films before making general statements. Bleeding of asphalt always results in slippery pavements. Croce (12) states that the skid resistance of a bituminous pavement decreases when an excessive proportion of fine-grained bituminous mortar is in the surface. Moyer $(59,62)$ has reported results that indicate angular aggregate is superior for skid resistance to round aggregate.

Gough (32) has presented interesting comparisons which indicate the relative importance of pavement versus tire characterisitcs. For the same tire, the best to poorest road surfaces gave a range of coefficients of friction of 1.0 to 0.2 . For the same road, the best to poorest tires gave a range of coefficients of friction of 0.55 to 0.2 . Noman (64) reported a thirty-three percent change in stopping distances for supposedly identical tires. Moyer (58) raised the question of excessive skid resistance. As part of the tread must slip during nomal rolling, friction above that required for control would cause additional wear.

Bird, Scott, and Miller $(3,4)$ have made comparisons of transverse friction measurements to longitudinal braking friction messurements. Both types are useful, but they feel that the transverse coefficient is a better measure of the slipperiness of a pavement surface. Recently, Brown, Milliman, and Otto (11), Skeels, Stonex, and Finney (80), and Finney and Brown (19) have proposed including a traffic index or factor when skid-rating pavements. Comparisons of polishing characteristics 
of aggregates and pavement types without adjustments for traffic volume could be very misleading.

Only a small amount of information is available about actual attempts to build skid resistance into pavements. The early investigators were so busy measuring existing pavements that they seem to have had little time for applying their results. Finney and Brown (19), working in Michigan, found no variation in skid resistance due to source of asphalt. Martin (49) found all tar surfaces more skid resistance than asphalt ones. McKesson (51) agrees that excess asphalt may cause slippery conditions and explains the excess as due to poor mix design (lack of voids), vapor pressure from below, insignificant cover, or loss of cover.

Aggregate gradation in the range of sizes down to $\frac{1}{4}$ inch seems to have little effect on skid resistance of bituninous pavements. Morgan (55) states that a preponderance of particles between the No. 40 and the No. 200 sieves will lower friction. Dillard and Alwood (16, 17), in a recent investigation of deslicking mixes, found sands with 40-95 percent passing a No. 40 sieve gave good skid resistance. Reufer (70) found sands with 40-85 percent finer than a No. 40 sieve were effective and resisted polish well because particles were ejected.

The nature of the aggregate used deserves more attention than has been forthcoming in the past. Sandstone generally gives good skid resistance (88). Limestones vary from good to poor and may polish under heavy traffic (63). Blending of hard materials with polishsusceptible limestones for improving skid resistance has not been very successful (17). Non-glassy slag, which is usually relatively skid 
resistant when new, frequently loses this resistance rapidly (13, 19). An attempt was made in France to restore the skid resistance of the aggregate by sand blasting (13). The results were not encouraging as the improvement was short-lived.

In the past few years several states have used skid measurements to anticipate slippery locations and thus indicate where deslicking procedures should be attempted. Virginia (54) and England (27) have pioneered in relating high-accident locations to skid resistance of the pavement. Some efforts are being made toward including skid resistance in contract specifications for new work (24). Zuk (90) has shown mathematically that a single absolute determination of $\mu$ is not sufficient for use in the prediction of skidding accidents. If the coefficient of friction is the same under all wheels, skidding will be straight and may be controlled by the driver. However, the driver may lose control if $\mu$ is different under part of the wheels and the vehicle spins under the effect of an unbalanced moment. Ideally, $\mu$ should be measured independently in each wheel track.

\section{Friction of Plastic Materials and Boundary Lubrication}

While the problem of friction between rubber and pavements is largely a highway engineering problem, it is not to far removed from the general problem of a plastic material sliding over a solid. Denny (I4) studied friction between rubber-like and solid materials and concluded that friction between rubber and a solid was made up of two components. One part was considered as independent of contact area, but as a function of the contour of the surface of the solid and of the load. The second was then related to the surface asperities of the two 
materials. Moyer (56) suggests much the same separation by considering friction as due, in part, to a basic portion varying with material and normal load and a second portion caused by mechanical interlock.

Schallamach (74) considers that rubber, when under load, will deform to match the contours of the pavement and that the area of contact is then a function of load and the modulus of the rubber. Bowden and Tabor (9) computed area of contact considering two surfaces of the same material, one plane and one spherical. They found the area of contact to vary as the cube root of both the load and the radius of curvature and inversely as the cube root of the modulus of elasticity. Lodge and Howell (44) studied contact area assuming contact to exist.when surfaces are separated by less than ten angstroms. Although, for constant load, pressure decreases when area increases, Derieux (15) has been able to show that $\mu$ increases with area for a constant load and increases with pressure for constant area. Markwick and Starks (46) experimentally measured pressure distribution caused by loaded tires on differently-shaped objects. Giles (23) jabbed differently-shaped pieces of stone into rubber repeatedly in order to evaluate shape factors.

Friction between materials is greatly affected by temperature. Bowden (8) used two sliding materials as a thermocouple and messured dry-sliding temperature approaching $750^{\circ} \mathrm{C}$. Possibly, at the peaks of the asperities, the temperatures were even higher and welding of the two materials occurred which resulted in a "slip-stick" type of motion (7). Hample (38) attempted to duplicate the high temperatures encountered in skidding by heating the pavement. This has an abnormal effect as under the true conditions the heat is not transferred to the surface of the rubber but is generated within. Gough and Parkinson (33) found 
that repeated loads raised the temperature of rubber. High temperatures have several effects upon rubber. Hysteresis decreases as temperature rises as shown by Giles and Sabey (29). Roth, Driscoll and Holt (69) found high temperatures tend to bloom the surface of the rubber and lower the coefficient of friction. The high temperatures developed during skidding are prevented from dissipating by the low conductivity of both the rubber and the asphalt pavement $(21,67)$.

The work required to roll a small ball and that to slide an equivalent ball along the same material under load are very nearly the same (18). Greenwood and Tabor $(35,82)$ used $1 / 8$-and $1 / 4$-inch steel balls on rubber and subsequent theoretical calculations verified their experimental work. Sabey (71) compared spherical asperities to conical and found conical gave better skid resistance though subject to more rapid polishing. Superiority was explained by the higher unit pressure on the cones.

Blok (5) has explored the subject of boundary lubrication in great deta1l. His work was intended for metals, but seems to have some application to skid problems. Lubrication wedge formations occurred ahead of the asperities unless either the supply of lubricant was low, the viscosity was low, the speed was low, or the load was very high. At the interface between water and a solid material the viscosity of the water is different from that at a point well within the water. Bowden and Bastow (6) give fifty angstroms as the maximum distance within a water mass at which the viscosity of the water is affected by conditions existing at the surface. Grime and Giles (36) have plotted curves showing the time rate of reduction of thickness of molsture 
films. In an extreme case, Trout (84) found that water puddles were sufficiently elastic to cause tires at high speed to plane over the surface.

The exact action of the surface of a tire rolling from a nonloaded position to a loaded position is very complex. Photos taken by Skeels, Stonex, and Finney (80) show the tread changing dimensions laterally. McConnell (50) points out that the tire must usually be slipping in a longitudinal direction as the rate of travel per rotation varies continuously from zero for a splnning wheel to an infinite value for a locked, skidding wheel. 
THEORY OF FRICTION

Friction is normally defined as the force required to slide one object over the surface of another. Loosely interpreting the term surface to include all surfaces of sliding, whether they are internal or external, we can subdivide friction problems into five general classes based on the material from which the surfaces are made:

1. Rigid material on rigid material

2. Plastic material on rigid material

3. Plastic material on plastic material

4. Lubricated surfaces (thick films)

5. Boundary lubrication (thin films)

\section{Rigid Material on Rigid Material}

The type of friction involving rigid material on rigid material has been measured repeatedly. In this case, friction is due to mechanical interlock of irregularities on the surfaces of the two materials. Each material is held together by molecular bonds of various types which have very short ranges of influence due to the extremely small size of the molecules. If the surface molecules of the two materials could be brought sufficiently close together, molecular bonds would be established across the interface between the formerly unbonded molecules. The distance through which such bonding can be established will increase as the available energy increases. Two surfaces mechanically 
dressed until they appear flat to any available instrument probably would appear, at a molecular scale, as sawtooth surfaces. When placed together, the teeth would partially intermesh and give interference to any sliding motion. See Figure 1. Should sliding action be forcefully maintained, some of the peaks would be sheared off, some deformed or pushed into low areas out of the way, and some fused or welded to peaks on the second surface. This latter action would cause a "slipstick" motion as the welds were formed and broken.

Some authors believe that the temperatures reached at points of conflict may be well into thousands of degrees. Due to the very small. moss heated to this degree, the heat is instantly diffused into the general mass of material immediately beneath the surface and the overall area of contact undergoes only a relatively small change in average temperature. The small change in temperature that can be measured during the duration of friction on such a surface would not appear adequate to cause any significant change in the characteristics of the material. However, the temperature of varying parts of the surface has been excessively high, and after an extended period of sliding it would seem probable that all parts of the surface have been subjected to temDeratures sufficient to cause important character changes. Metals have been observed to weld together.

At the interface between two rigid materials, as the normal load is increased, the peaks of one material tend to be forced more and more deeply into the second. However, between rigid surfaces even under high loads, only the higher peaks and those on high areas are in contact and appreciable areas remain untouched. The theory that the coefficient of friction between two surfaces is an inherent property of 
Rigid-Rigid

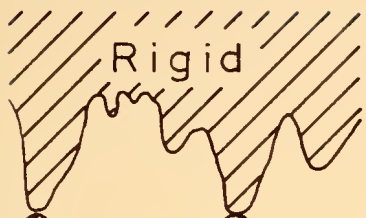



a. Light Load
Plastic-Rigid
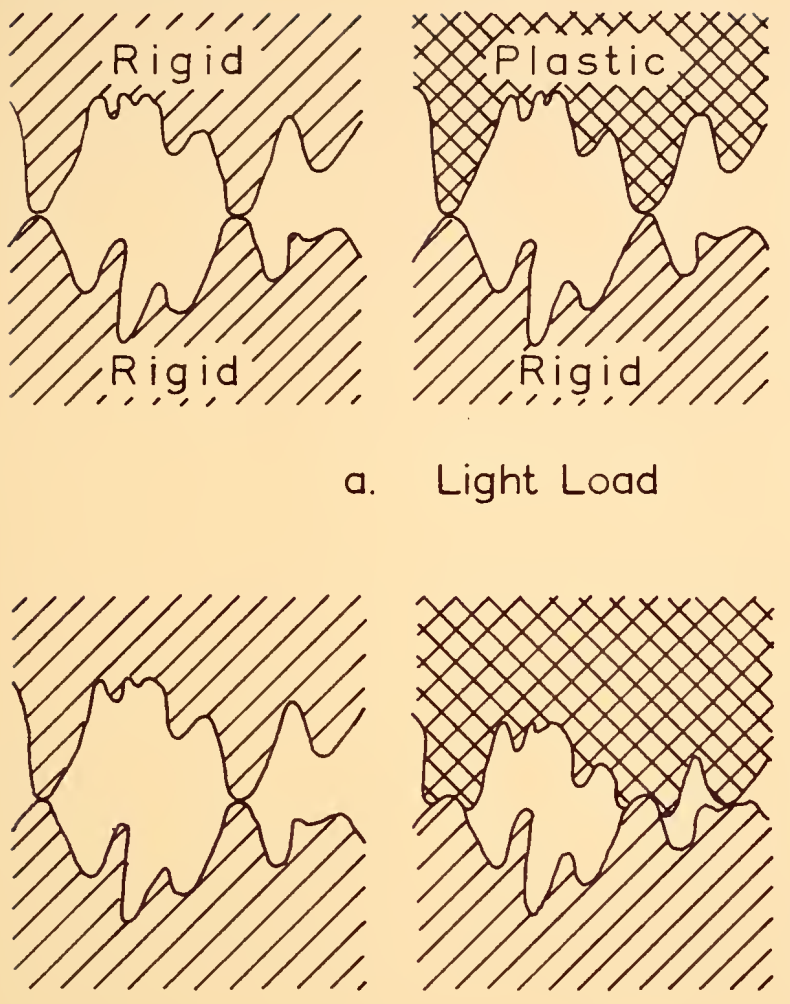

b. Medium Load
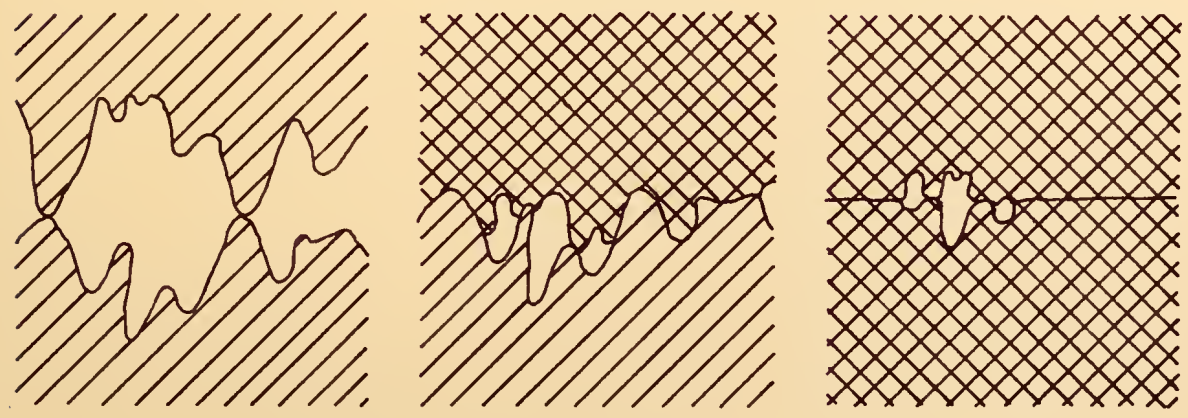

c. Heavy Load

Plastic-Plastic

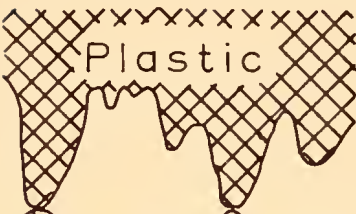

28

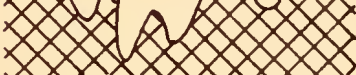
$\times 1 \times x$

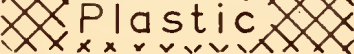

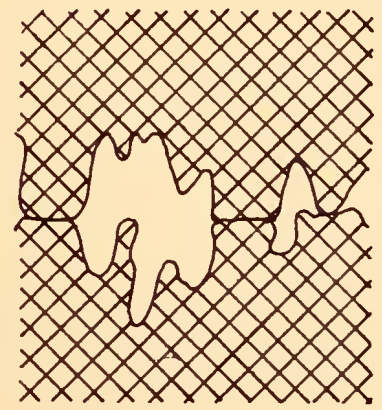

FIG. 1 DEFORMATION OF SURFACES UNDER LOAD 
the two materials of which the surfaces are made could indeed have some physical basis. A single material made of one type of molecule takes on a particular structural form or structural lattice. Once in that form, the exterior of the material at the molecular level would present the same aspect to another material regardless of other conditions. Of course, such a statement must be regarded realistically by accepting the condition that rougher surfaces will have higher apparent coefficients due to excessive interlock or interference on a macro scale which may overshadow that on the micro scale.

\section{Plastic Material on Rigid Material}

Friction between a plastic material and a rigid material acts in a manner similar to that between two rigid surfaces. At low normal loads, the same phenomenon continues with a possible shift as to the relative importance of deformation, shearing, and welding of the peaks. As normal load increases, the peaks are forced deeper and deeper into the opposing material (Figure 1), thus increasing the resistance to sliding. However, unlike the rigid-rigid condition, the plastic material will conform to the contours of the rigid material and prevent the extreme local pressures of rigid-rigid friction. Despite the lack of extreme pressures, the resistance to sliding may be higher for the plastic-rigid combination than for the rigid-rigid because mechanical interlock occurs over larger areas and more work is required to shear, deform, or otherwise overcome the resulting resistance to motion.

It is of interest that most plastic materials exhibit a hysteresis loss during deformation and rebound. Thus, if an object, is slid across a sheet of rubber while carrying a normal load sufficiently 
large to cause an indention in the rubber, the amount of work that the rubber does on the trailing edge of the object while rebounding is always less than that done by the leading edge of the object while plowing across the rubber. The energy lost cannot just disappear, but has probably changed into heat to cause a change in temperature of the surfaces. At high sliding velocities, the rate of rebound of the plastic material may have an appreciable effect upon the coefficient of friction.

Hypothesizing that the surface of the rigid material is made up of peaks and depressions and that under static conditions the plastic conforms to the rigid terial, then each area of the plastic material which is depressed by a peak in the rigid material must rebound when moved to a depression. As lateral speed increases, the possibility of complete rebound of the plastic material between the peaks decreases, and the coefficient of friction should decrease. That is, a plastic which cannot rebound rapidly enough to regain its original level between peaks of roughness on a moving load will take on much of the character of a stiffer plastic. As most plastic materials are pliable in all directions, and as the force supplied by a peak in the rigid material when sliding is taking place must have components both parallel and perpendicular to the motion, it is logical that all areas of the surface of the plastic material are in constant motion of a transverse nature with respect to the direction of the principal motion.

In friction between plastic and rigid materials, both stress and temperature are distributed differently from that in rigid-rigid friction. As the plastic material deforms, shear stress will increase to a maximum at a depth equal to the amount of penetration of the peaks 
of the rigid surface into the plastic. Temperature rise will be caused by both friction on the surface and internal friction of rearranging or deforming of the plastic immediately within the surface. The maximum temperature will then occur within the plastic surface instead of on the surface.

For each plastic material, there must be a minimum radius of curvature to wich the surface can conform. See Figure 2. It is possible that the minimum radii for concave and convex bending are different. As these radii are determined by the modulus of the plastic and the tension of the surface, they may vary slightly with pressure. The plastic would then be able to conform to the contour of a solid surface composed of large radil curves. As the surface roughness becomes smaller, the surface tension in the plastic prevents complete penetration of the plastic into the depressions of the solid. If the asperities of the solid are reduced in size until the radius of the peaks is smaller than that which the plastic can follow, the areal type of contact will disappear and the friction between the materials will be similar to that for rigid-rigid contact. See Figure $2 b$. If the projections are made infinitely sharp (no radius at vertex), the plastic cannot bend this short and, although each tip is in contact, there will be an annular area immediately around the tip where no contact occurs. See Figure 2c. If the vertical pressure is increased, this area can be reduced but not eliminated.

\section{Plastic Material on Plastic Material}

Friction between two materials of equal plasticity may well be less than that between the same plastic and a solid. The deformation 
MINIMUM

CURVATURE

OF PLASTIC
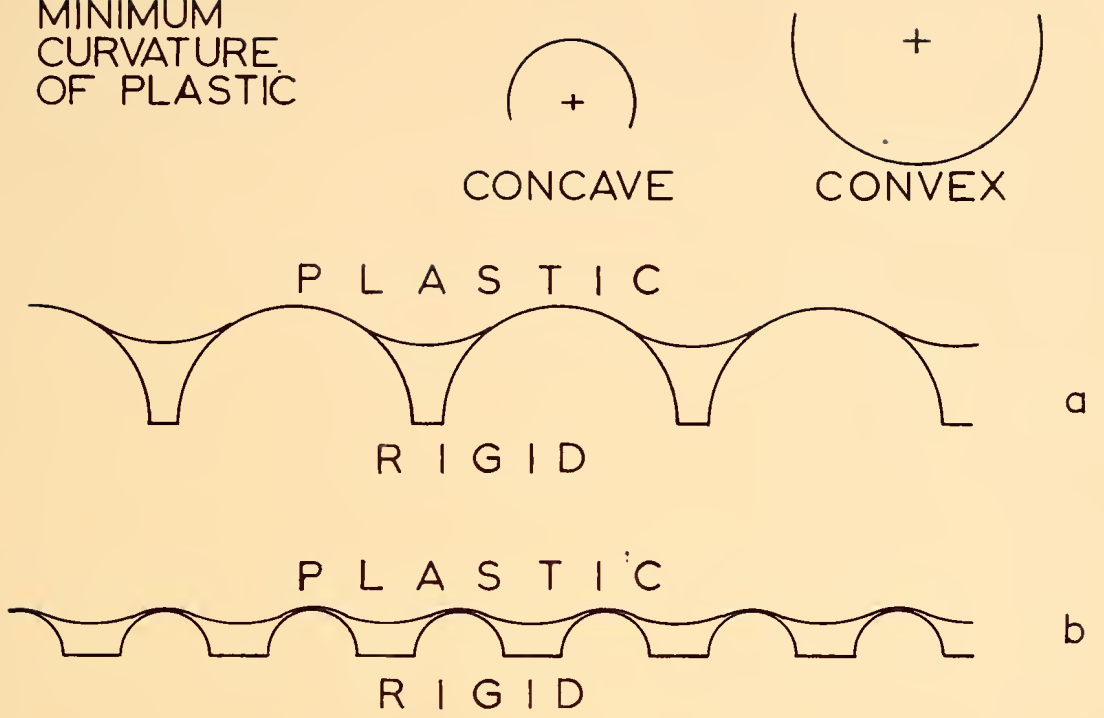

$P L A S T \mid C$

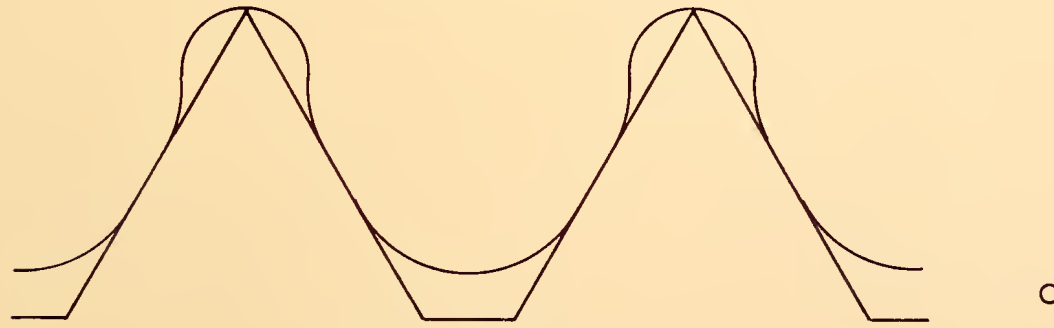

$R|G| D$

$P L A S T I C$

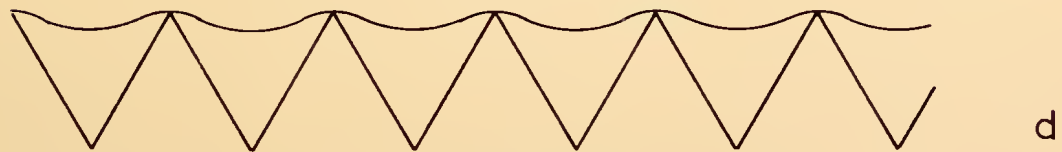

$R|G| D$

FIG. 2 DEFORMATION OF PLASTIC MATERIAL BEARING ON RIGID MATERIAL 
occurring in either of the plastic surfaces of the plastic-plastic condition is less than that of the plastic surface in the plastic-rigid situation and would, therefore, account for less energy when sliding occurs. As both surfaces share the deformation in plastic-plastic contact, penetration, lateral deformation, energy, and other deformationbased quantities for one surface will be much less than that for the plastic surface of the plastic-rigid case. Although both surfaces must be considered when estimating friction, that part of the friction between two plastic surfaces due to interference could be less than that occurring between one plastic and one rigid surface ( all surfaces of equal roughness). Under dynamic conditions this reduction in deformation would mean a reduction in rebound as peaks pass and, therefore, less effect of speed on the coefficient of friction for plastic-plastic friction as compared to plastic-rigid friction.

\section{Lubricated Surfaces (Thick Films)}

Surfaces separated by thick films of a liquid, or hypothetical surfaces within a liquid, will slide over one another relatively easily. Although the surfaces are completely in contact, the ease with which the molecules can be displaced prevents any great build-up of frictional resistance. At modest speeds, assuming no contact of the solid surfaces, the frictional coefficient will be that due to the vicosity of the liquid.

\section{Boundary Lubrication (Thin Films)}

Boundary lubrication is defined as occurring when liquid film thickness is less than that required to prevent direct mechanical 
interference of the peaks of the surfaces separated by the film. Probably the greater part of the friction occurring under such conditions is due to this mechanical interference. As the film is further reduced, the friction will approach that of the unlubricated surfaces. Once film thickness is reduced to the range of thicknesses corresponding to boundary lubrication, the viscosity of the lubricant has little direct effect upon the frictional resistance. However, the degree to which a normal force may force the surfaces together and thus increase direct interference is governed by the ease with which the liquid may be forced out from between the surfaces. This is a function of liquid viscosity. The range of film thicknesses at which viscosity no longer governs the coefficient of friction will also depend on the character of the surfaces. This is true because the amount of liquid which must be expelled for a given increase in direct interference will depend upon the density and size of peaks on the surface. There is some change in liquid viscosity with film thickness, but the magnitude of this change probably is not of importance unt1l the film is in the fifty angstrom range.

Boundary lubrication has a greater effect on the reduction of sliding friction for plastic-solid surfaces than for solid-solid conditions. There are many interfacial voids when two solids are in contact and, if this entire volume were filled with liquid, the direct interference of peaks could still occur. Due to the manner in which a plastic material deforms to follow the contours of a solid surface, there is a smaller volume of voids in the interfacial zone that can be filled with water without reducing the normal pressure and the friction than 
for solid-solid surfaces of the same roughness. Therefore, if the lubricating effect is to be avoided, the pressure in any trapped liquid must be relleved. This can be accomplished by reducing the viscosity of the liquid to permit more rapid drainage, by altering the surfaces to prevent sealing of pockets, by providing porosity in the materials, or by a combination of these methods.

The minimum curvature to which the plastic surface can bend will have an effect on boundary lubrication. Areas of the surfaces not in contact due to curvature limitations will not exert pressure on the liquid and are, therefore, ineffective in reducing the thickness of the lubricant film. In fact, round, peaked asperities with a radius below that which is critical for the plastic, may cause lower frictional resistance when boundary lubrication exists and speeds are increased. The zone of no contact around the asperity is of nearly negligible thickness, (see Figure 2d) and flow of liquid would be very slow. The infinitely sharp peak (see Figure $2 \mathrm{~b}$ ) would be accompanied by very high pressure and would tend to thrust through any liquid film. However, if the plastic is to be protected from tearing, these sharp peaks must be close enough together to limit the maximum pressure. When sufficiently close, the heights become small and a thin film drowns the peaks causing thick film lubrication.

\section{Rubber Tire on Bituminous Pavement}

An attempt to apply the concepts presented above to the problem of the friction between a rubber tire and a road surface quickly shows the complexity of the problem. Some conditions applicable to each of the five classes of possible friction appear to be present. 
Considering the first class, one would not normally class a rubber tire as a rigid material, yet at high speeds the mbber may not have time to deform into the crevices of the surface and may thus act much as a rigid material (82). At modest speeds, the tire and pavement probably fit the second or plastic-rigid class of friction. At exceedingly low speeds the rubber tire and the bituminous pavement might both be considered as plastic. During inclement weather, imperfections in the pavement will pond water sufficiently deep to cause areas which at high skid speeds act as if lubricated by thick films. The remainder of the wet pavement would come under the classification of boundary lubrication.

The tire manufacturer must deal with the factors associated with rubber characteristics such as rate of mubber rebound, ratio of elasticity of rubber to pavement and surface drainage by tread design. The highway design engineer can aid in skid-resistance problems by providing adequate cross-slope and other factors to insure rapid runoff of surface water. The materials engineer should then design a pavement material sufficiently stable to prevent rutting and shoving, which might provide low spots for ponding water, and which has a surface texture that will resist boundary lubrication.

Skidding resistance can be considered as made up of an attraction between the materials which varies with both the material and the normal load, and a direct mechanical interference which varies with the surface conditions and the normal force. As all pavements provide adequate frictional resistance when dry, the chief problem is how to control the effect of water films. One approach would be the selection 
of aggregate with a surface texture that always permits drainage of surface water from the interfacial zone of the tire-pavement contact. Sandstone is a natural choice for this condition but durability experience has been poor. Due to the stmucture of sandstone, at any degree of wear, whether due to expulsion of particles or actual wearing away of the surface, some of the voids will be of such a size that water can escape. At this size, however, tire rubber will not deform to a radius short enough to permit the mibber to seal the volds. Aggregate polish, which is of current interest to several agencies, probably is a gradual reduction in relief of the stone surface which is accompanied by an increase in resistance to surface drainage. Desirable aggregate characteristics would then be hardness or resistance to wear coupled with non-homogeneity as an aid to maintaining roughness when wear occurs. Internal drainage of the pavement mix would also aid in reducing boundary lubrication by releasing the water pressure under tires. Providing drainage by internal porosity may tend to reduce durability to weathering. Conceivably, a gradation of fine aggregate could be developed which would incorporate most of the advantages of sandstone. 


\section{EFFECT OF GRADATION ON}

\section{THE SKIDDING RESISTANCE OF FINE BITUMINOUS MIXTURES}

Surface texture or roughness can be thought of as existing at two levels when referring to bituminous pavement. The gradation of the aggregate establishes the general texture or overall surface roughness. In skid-resistance probiems, the texture of the aggregate surface itself is superimposed on the general contours provided by the gradation. Both have an effect on the skid resistance, and the contribution of each toward the overall skid resistance must be evaluated.

In an attempt to appraise the effect of gradation, approximately f1fty gradations were prepared from Lafayette sand. After two minutes in the mixer, each specimen was molded in the frame shown in Figure 27 as explained in Appendix B. These specimens were polished in the drill press shown in Figure 31 of Appendix B. The polishing used consisted of two minutes with No. 000 crushed quartz and two minutes with No. 00000 crushed quartz. In making these specimens it was necessary to vary the asphalt content as the gradation changed. As the purpose of these tests was to measure the polish resistance and skid resistance of various gradations, it was necessary to use an asphalt content sufficiently high that the surface of the mix did not ravel during the polishing, yet low enough that asphalt did not bleed or flush to the surface and conceal the character of the surface. For this reason many of the gradations were repeated several times before an asphalt 
content was found that fitted the conditions. Only results from samples that were felt to be within these conditions are included. The asphalt content varied from five to ten percent by weight of the aggregate. Wet skid resistance was measured by means of the machine developed by J. Shupe (78) and results are expressed as relative resistance values as read from the oscillograph on this machine.

The experimental results are tabulated in Table $I$ of Appendix C and shown in Figure 3. In this figure, the relative resistance value for each mix is plotted against the maximum size particle in the mix. Two symbols have been used to separate the points into two groups; one represents mixes consisting of three consecutive sieve-size particles and the other includes mixes of more than three sizes. All of the aggregate used was natural West Lafayette sand.

A band which includes all of the three-size mixes shows a definite trend, within the size range covered by the experimental mixes, for the relative resistance value to increase as the maximum size aggregate decreases. At the larger maximum size aggregate, mixes with additional fine sizes were used to make four- and five-size mixes. Addition of these fine sizes raised the relative resistance value of the mixes utilizing material passing No. 4 and No. 8 sieves as the maximum sizes. Some notice should be made of the possible relationship between the highest relative resistance values found at each maximum size. When appreciable amounts of No. 30-50 and No. 50-100 size materials were added to the mixes based on No. 4 and No. 8 as maximum size, gradations were achieved which gave the same relative resistance values for Nos. 4, 8, and 16 maximum size mixes. The minimum size for these mixes was the same, indicating that perhaps the 


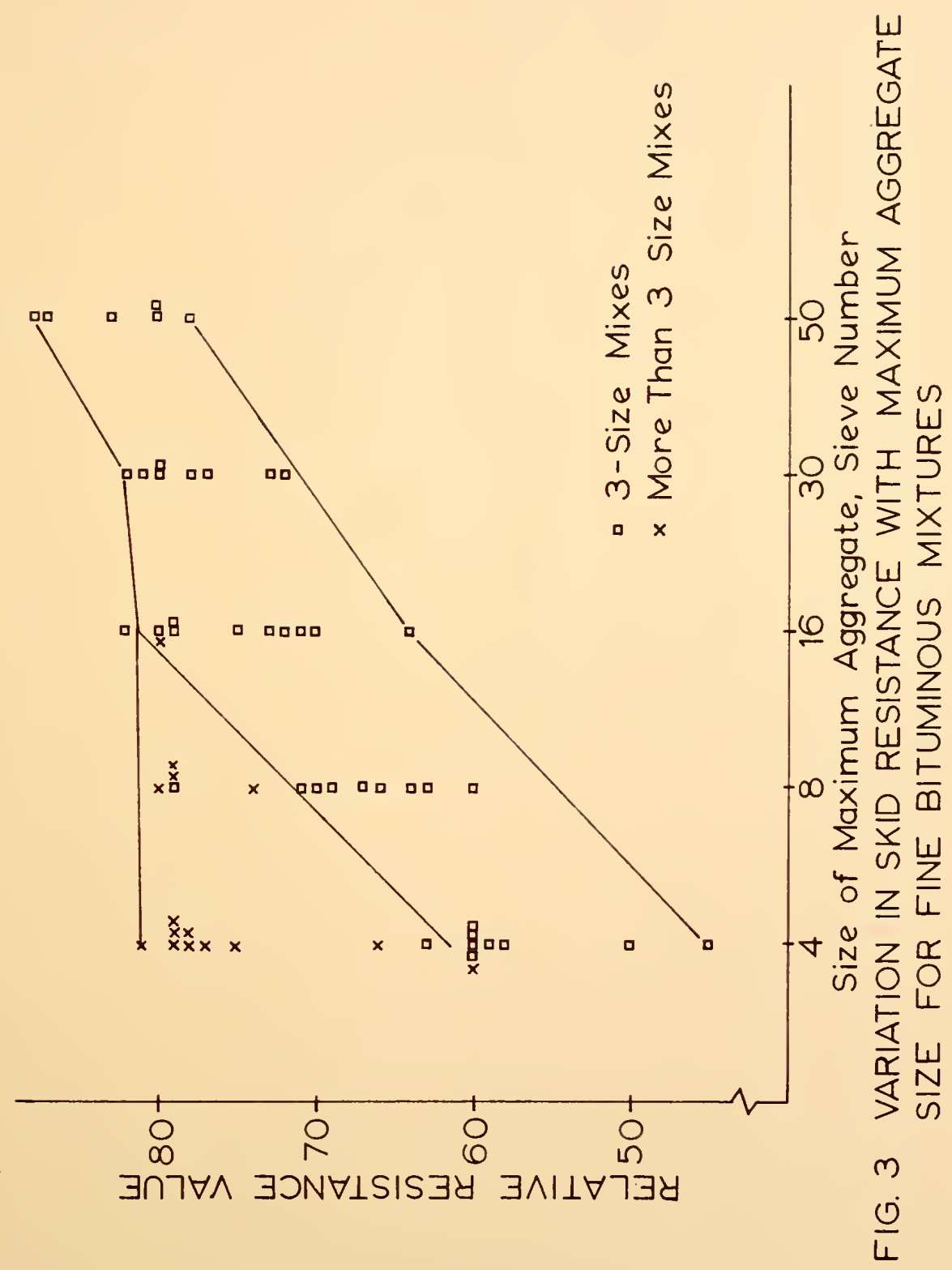


fine size is representative of the skid resistance.

Attempts to relate the relative resistance value of the mixes to the fineness modulus, computed as the summation of the cumulative percents coarser than sieves Nos. 8, 16, 30, 50, 100 and 200 divided by 100 , met with only partial success. Although all tests considered together did not give a clear relation between fineness modulus and relative resistance value, such a relationship can be developed for mixes containing the same maximum particle size. The relative resistance values for each maximum size have been plotted against fineness modulus to develop Figure 4. A straight line has been fitted, by the method of least squares, to each segment of the data in this figure. This gives a family of lines showing the relationship of relative resistance values to fineness modulus for each maximum size. The scatter of the points in this figure may be due to slight variations in the condition of the rubber shoe at the time of test or due to the inherent character of $\mathrm{f}$ ineness modulus which permits a variety of gradations for any particular modulus. When the percent of the maximum size present in the mix falls below some minimum quantity, the effect of this size probably becomes very small and the next smaller size could be considered as the maximum size present.

Change of maximum size is a continuous-type variable, so the lines obtained in Figure 4 should compose a compatible family of lines. For comparison purposes, the five lines are shown in Figure 5. These lines, fitted to the data by the method of least squares, appear to substantiate each other well. The small discrepancies within this family of lines are due probably to effects other than 


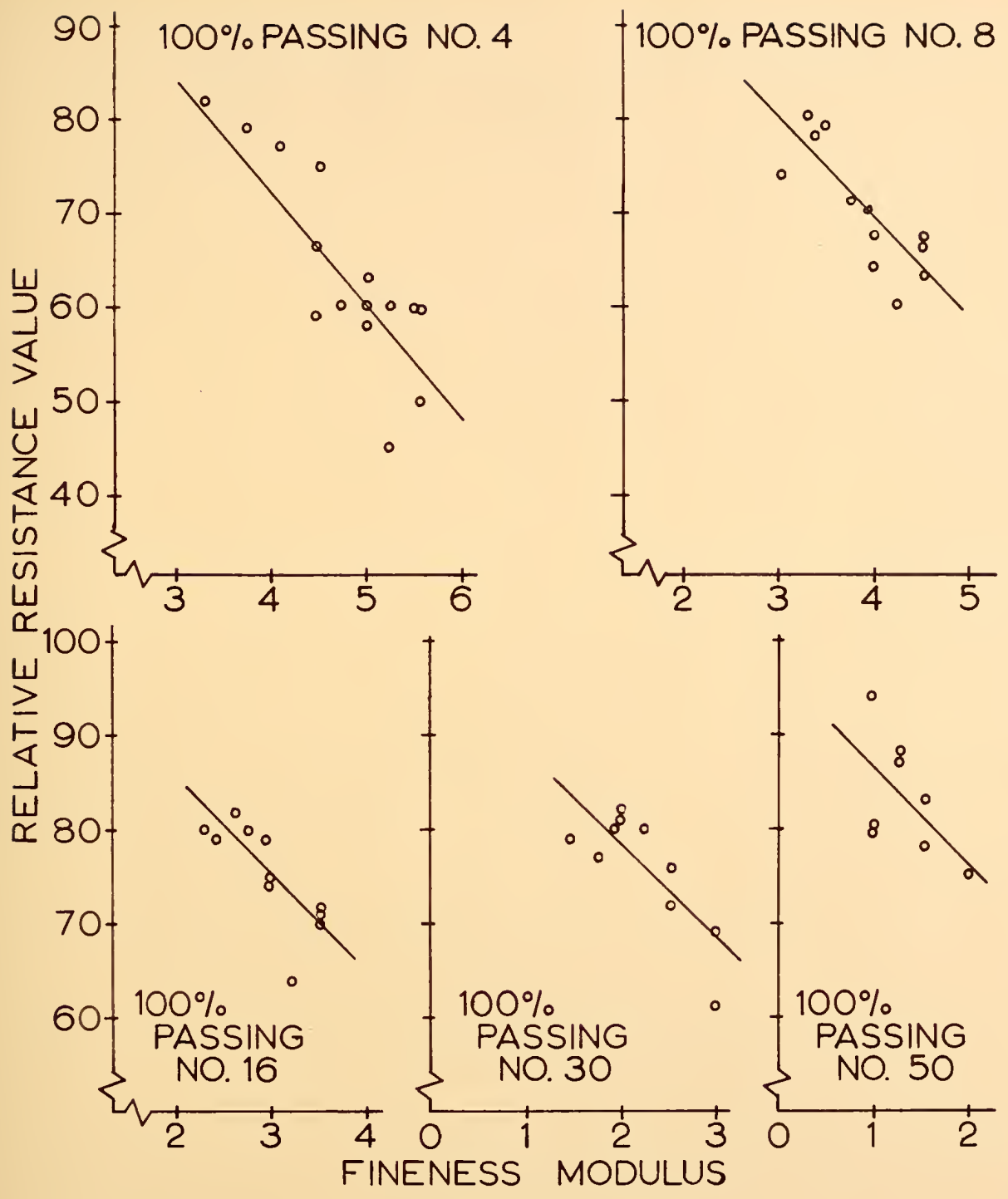

FIG. 4 VARIATION IN SKID RESISTANCE WITH FINENESS MODULUS FOR FINE BITUMINOUS MIXTURES OF DIFFERENT MAXIMUM SIZES OF WEST LAFAYETTE SAND 


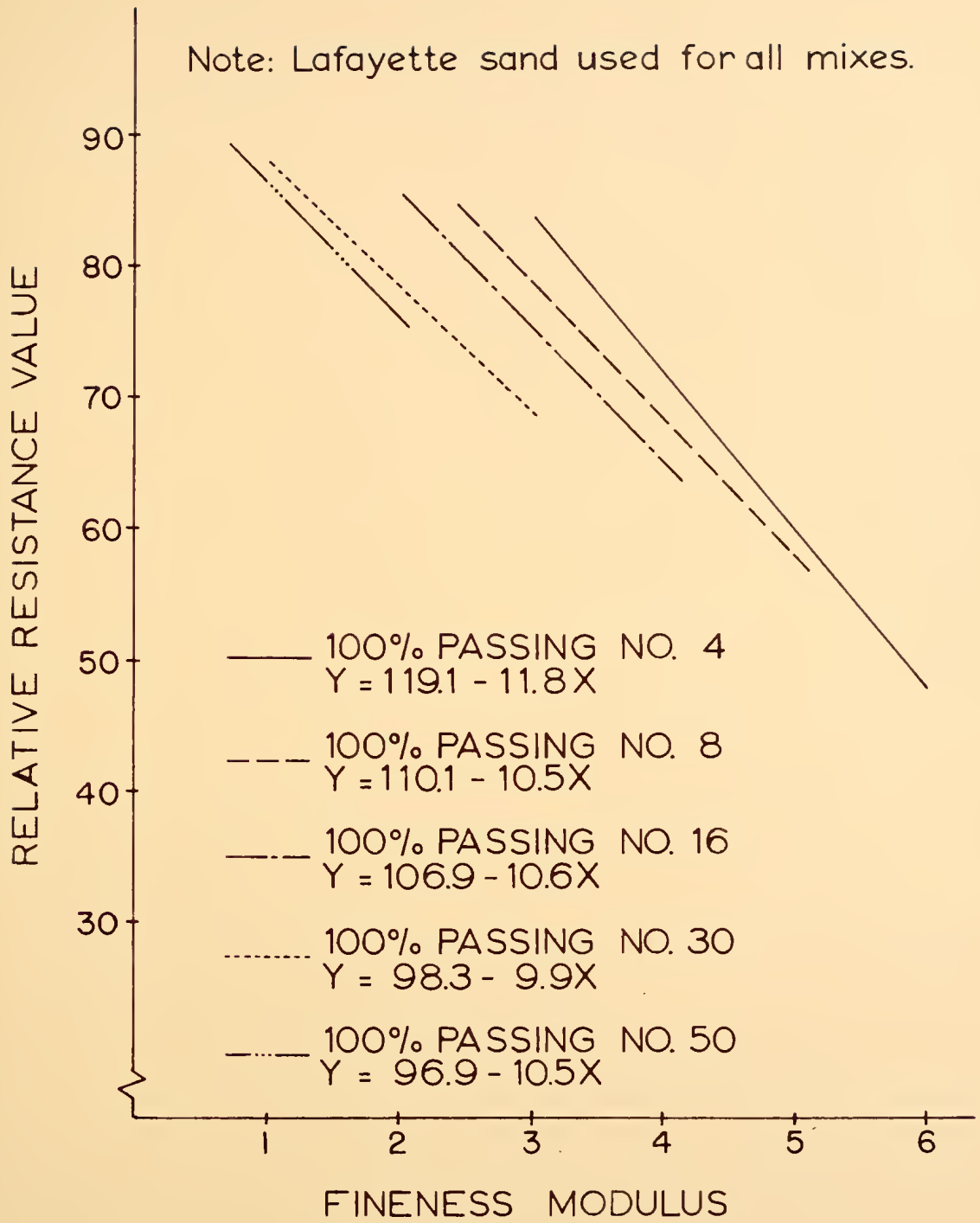

FIG. 5 VARIATION IN SKID RESISTANCE WITH FINENESS MODULUS FOR FINE BITUMINOUS MIXTURES 
gradation. Theoretically, for a given gradation of Lafayette sand, one should be able to enter Figure 5 and predict the relative resistance value for the resulting surface. 


\section{EFFECT OF THE QUANTITIES OF CARBONATES AND SILICATES}

ON THE SKIDDING RESISTANCE OF FINE BITUMINOUS MIXTURES

One possible method of increasing the resistance of pavements to the polishing action of traffic would be the careful selection of aggregates to insure the use of hard, resistant particles. Several state highway organizations have recently introduced specifications providing for deslicking mixes based on the use of silica sand. In many areas sand of high-silica content is not readily avallable and would be expensive. As very little is known about the true reasons why surfaces made of silica sand have shown a high skid resistance, several comparisons were made with other materials in an attempt to determine the relative merit of silica sand.

The materials chosen for this purpose were a very high-silica sand from Chillicothe, Ohio, sand from the Lafayette, Indiana area, sand from the vicinity of Richmond, Indiana, and limestone sand from Greencastle, Indiana. The latter was artificially rounded in the laboratory. These materials are shown pictorially in Figure 6 and the percent insoluble in acid is listed in Table 2 of Appendix C. The acidinsoluble material in the graded aggregate ranged from ninety-nine percent for the high-silica sand to three percent for the limestone sand. It is not entirely correct to refer to silica content of the aggregate when discussing the tests reported here as other minor constituents may be included. Each aggregate was placed in warm hydrochloric acid 


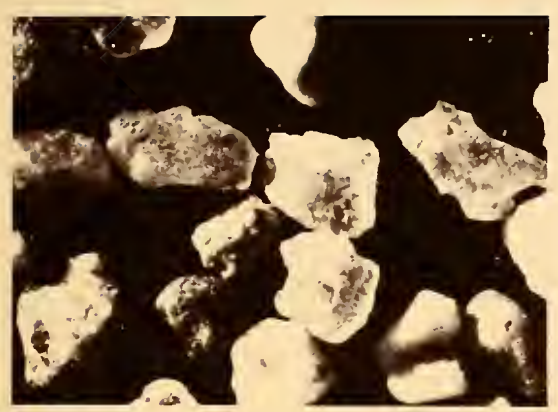

LAFAYETTE SAND

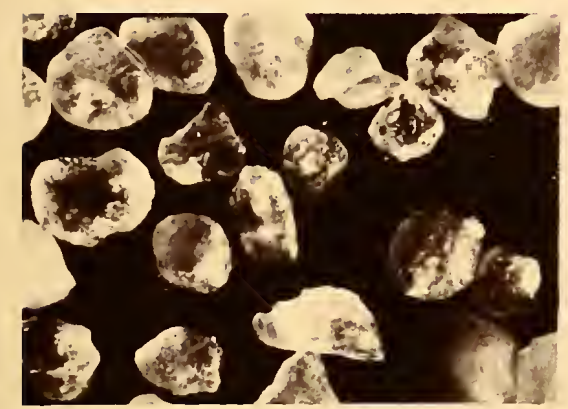

SILICA . SAND

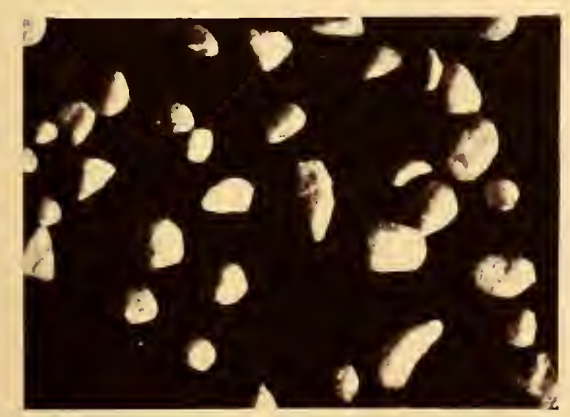

CRUSHED AND ROUNDED LIMESTONE SAND

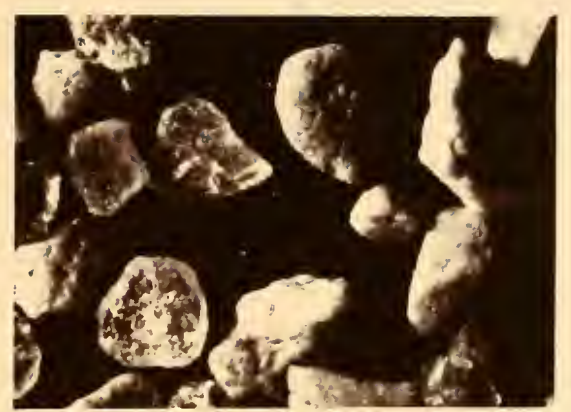

RICHMOND SAND

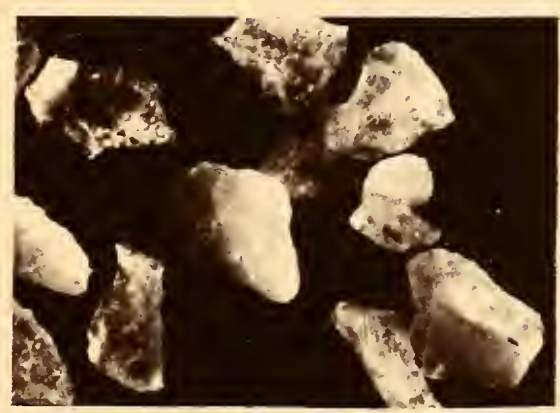

CRUSHED SILICA SAND

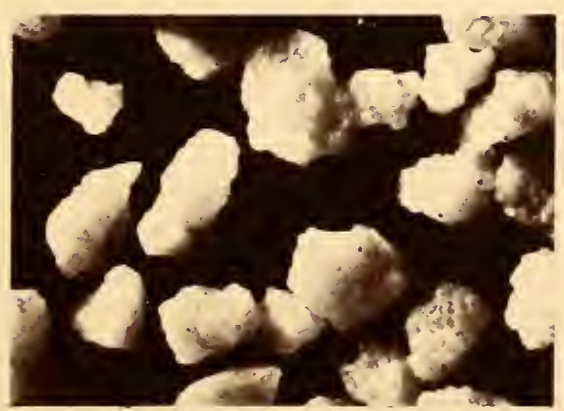

LIMESTONE SAND

FIG. 6 GRAIN SHAPE AND TEXTURE OF SIX SANDS $(25 X)$ 
solution for twenty-four hours, after which the acid was washed out, the residue dried and reported as the percent of the original material insoluble in acid. The silica content of the sands used varied with the size of particle tested. Physical constants for the total sands and silica content by size fractions are tabulated in Table 2 of Appendix C.

The limestone sand as supplied by the producer was of an angular form. In order to remove shape variations from the test results, this sand was worn round in the laboratory. This was accomplished by tumbling the sand for 35,000 revolutions in the Los Angeles rattler without the normal charge of steel shot. Angular silica sand was prepared by crushing the naturally rounded silica sand obtained from Chillicothe, Ohio. The specimens were batched, mixed, polished, and tested as described in Appendix B. Several gradations were used of each material. The polishing used consisted of four minutes with No. 000 crushed quartz and four minutes with No. 00000 crushed quartz.

The relative resistance values measured after different cycles of polish for the glacial sands are listed in Table 3 of Appendix C and plotted in Figure 7. Data for silica and limestone, both rounded and angular, are tabulated separately in Table 4 and are included in Figure 7. Since several gradations were used for each material, a range of relative resistance values was found for each material at each degree of polish. This spread is shown by the bands delineated for each material in Figure 7.

Certain trends are readily apparent from Figure 7. Of the materials tested, silica generally gave superior skid resistance. Regardless of polish cycle or gradation, limestone sand always gave the 


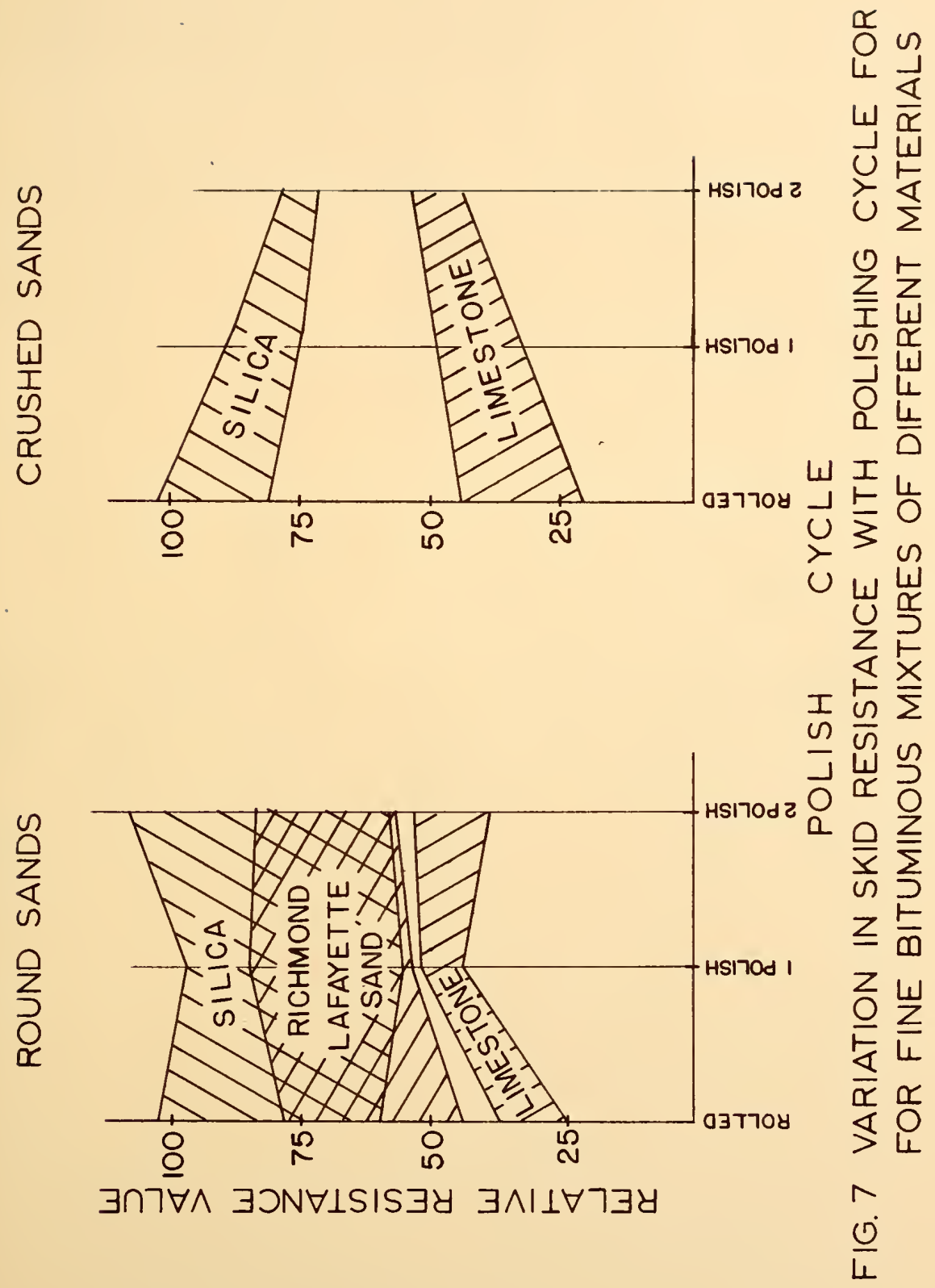


lowest relative resistance value. The relative resistance values for the sands from Richmond and West Lafayette, Indiana, fell above the limestone band and in the lower part of the silica band.

As the silica contents of the Richmond and West Lafayette sands varied for different size fractions, a detailed comparison must include gradation. The percent of silica in each mix was computed by multiplying the percent of each size fraction in each mix by the percent silica in the size fraction and totaling the results. The variation in the percent silica for the mixes is shown as compared to fineness modulus for Richmond and West Lafayette sand in Figure 8. This variation for the silica and the limestone sands is not shown as they did not vary in silica content with changes in gradation.

In Figure 9 the relative resistance values after the second polishing crcle has been plotted against fineness modulus. Each of the four rounded sands is represented in this figure. Both silica content, Figure 8 , and relative resistance value, Figure 9 , for the Richmond and the Lafayette sands increased as the fineness modulus decreased. However, the relative resistance value of the silica and limestone sand mixes for which the silica content remained nearly constant also increased with a decrease in fineness modulus. As the rate of increase of the relative resistance value is nearly the same for all the sands, this change is not due to the increase in silica. Apparently, the effect of the silica content is shown by the relative position of the curves in Figure 9. As could be expected, the curve for the highsilica sand is in general above all others and the limestone curve is well below. The two glacial sands do not fit well into the otherwise ordered array of data. 
At a fineness modulus of 5.5 the silica contents of the two glacial sands were 30 and 56 percents; yet, both produced mixtures that were equal to or above the high-sillca sand mixture in skid resistance. When the fineness modulus decreased to 2.5 , the silica contents of these same sands are 57 and 79 percents and the relative resistance values are slightly over half-way from that of limestone to that of the high-silica sand. At all fineness moduli there is a large difference in the silica content of the two glacial sands, but the relative resistance values remain close. It can be concluded that the relative resistance value increased with increasing silica content, but at a variable and generally decreasing rate. 
EFFECT OF AGGRECATE SHAPE ON

THE SKIDDING RESISTANCE OF FINE BITUMINOUS MIXTURES

The possibility of using sharp, angular or crushed aggregate for increasing the skid resistance of pavement surfaces has been considered many times. Little actual test data are available to substantiate such possibilities, but limited tests by Shupe (78, 79) indicate that after several polishing cycles, round aggregate may supply more skid resistance than angular. His explanation for this apparently little understood result was that the round aggregate compacted more readily and hence gave greater densities and thus had more aggregate in contact with the test shoe. As crushed stone or artificial sand could be used for sand deslicking mixes, some comparisons should be made between crushed aggregates and rounded material from the same source.

The data tabulated in Table 4 of Appendix C, and used for a comparison of the effect of mineral content, are adequate to make a comparison between shapes. To facilitate such a comparison, these data have been replotted in Figure 10 where curves have been drawn for individual mixes. Silica sand from Chillicothe, Ohio, composed all of the mixes represented in Figure 10. For each gradation, two specimens were tested, one of natural sand and one composed of crushed material. The abscissa of this figure is polishing cycles completed prior to skid testing. 


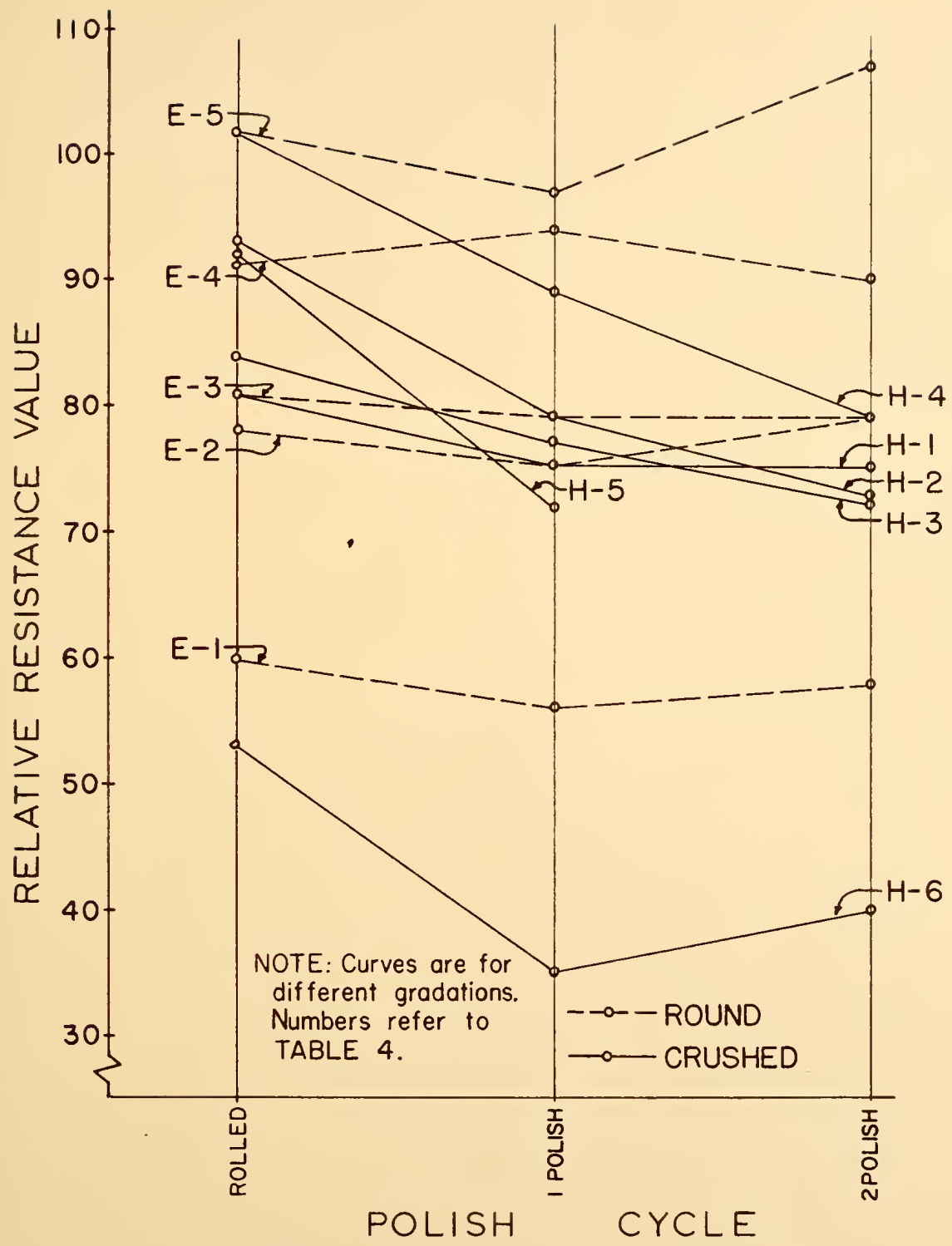

FIG. 10 VARIATION IN SKID RESISTANCE WITH POLISHING CYCLE FOR FINE BITUMINOUS MIXTURES COMPOSED OF ROUND AND ANGULAR SILICA SAND 
Figure 11 is similar to Figure 10 but represents data from Table 4 of Appendix C for limestone sands. Due to the small range of relative resistance values found for the limestone sand, all of the curves of relative resistance values versus polishing cycle for this material fell in the same portion of the figure. For this reason the curves were plotted by pairs consisting of a curve for a specimen of angular limestone sand and one for rounded limestone sand, both of the same gradation. The scales for the separate parts of this figure are the same.

A comparison of the resistance to polish of the two materials, silica and limestone, show's some striking differences. The relative resistance value for round or natural silica, Figure 6, is affected very little by polishing. Regardless of gradation, the curve of relative resistance value versus polishing cycle, Flgure 10, is flat. The relative resistance value for all gradations of crushed silica, Figure 10, decreased with polishing. However, the initial relative resistance value was much higher for crushed silica than for natural silica. All but one of the mixes using either rounded or angular Iimestone showed initially an increase in relative resistance value as polishing progressed.

For fine mixes, differentiation between polish and wear is very difficult. The term wear usually implies removal of material. The term polish then implies smoothing up of the surface without appreciable removal of material. When discussing the very fine textures found on the surfaces tested in this study, the two terms become nearly symonymous. The amount of material removed by polishing was 

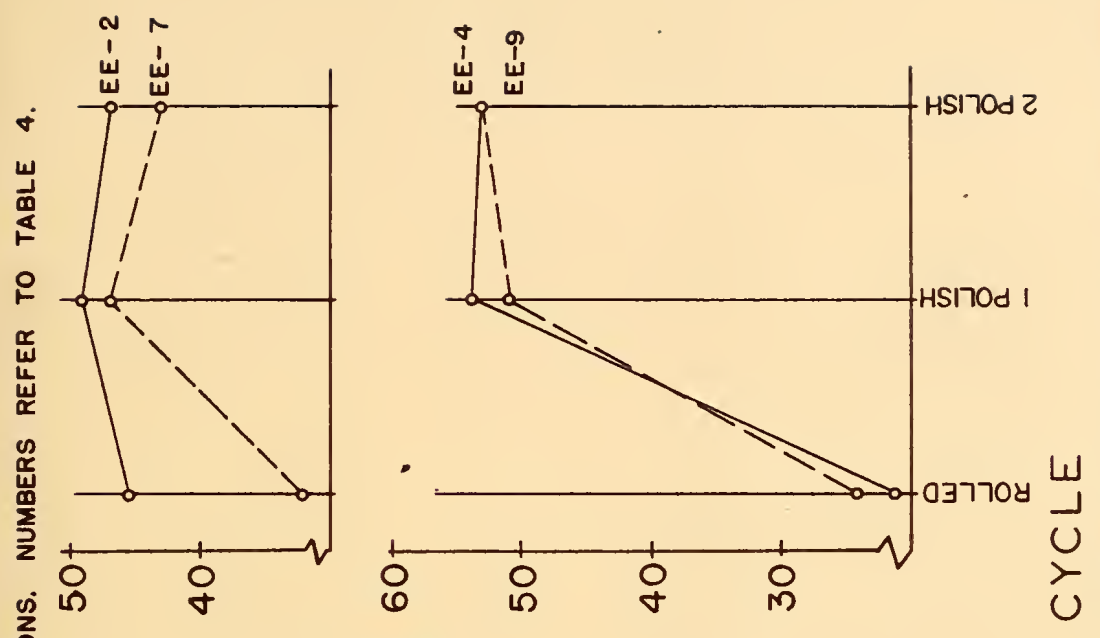

竞
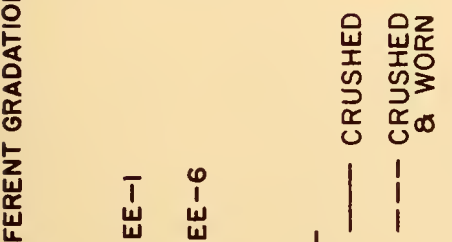

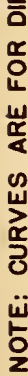
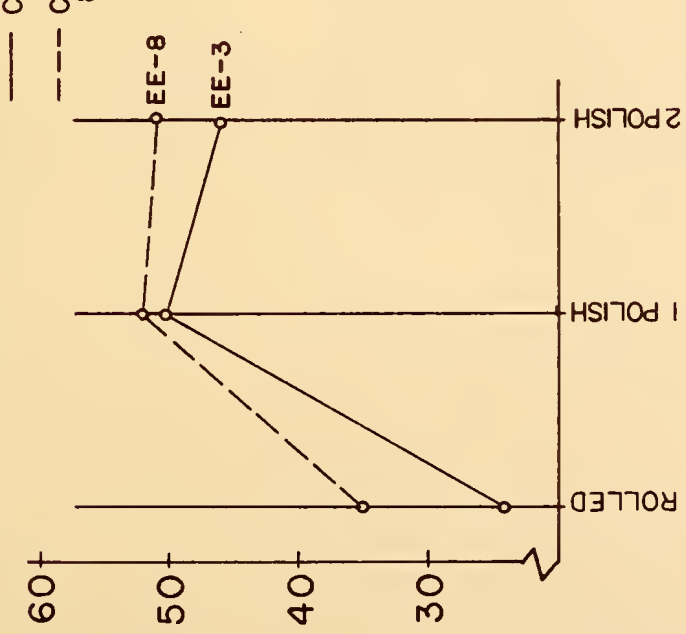

0

㞸号

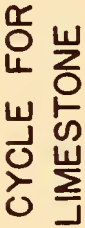

운

票

U

잉

$\stackrel{n}{3}$

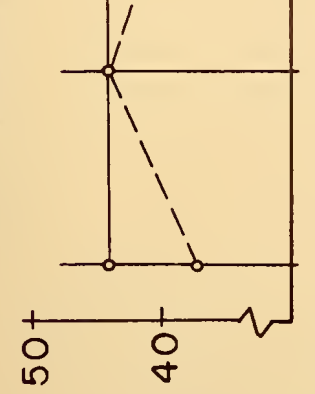

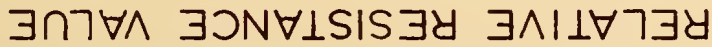

$\frac{0}{4}$ 
large in comparison to the aggregate size. If a corresponding amount of material were removed from a coarse aggregate mix, it would be considered wear. Unless otherwise noted, the terms wear and polish will be used interchangeably in this paper.

The natural silica sand, Figure 6, when in the surface of the specimen gave a rolling surface much like that shown in Figure $2 a$. There were few sharp points to grab into the rubber and contact pressures were modest. The initial relative resistance values were good, and polishing did not make any significant changes because there were no edges to be polished away. The angular silica in the larger sizes gave a surface much like that illustrated in Figure 2c. The sharp points gave a relatively high contact pressure and initially the relative resistance values were high. However, polishing with abrasive dust quickly removed the extreme sharpness and the shape of the particles approached that of the round sand. The angularity of the crushed sand interferes with the rearrangement of the particles at the time of molding and the actual amount of sand exposed in a unit area of surface is less than for specimens molded of round sand. As the shaprness is polished from the angular sand, the surface resembles that of the natural sand but with less aggregate area in the surface. The relative resistance values for the polished, crushed sand are then lower than for the polished, round sands.

The limestone sands act in much the same way but the rate of wear is much more rapid. The exposed angular edges of the crushed IImestone were greatly reduced by the steel rollers, making the relative resistance values of the rolled but unworn specimens nearly the same whether rounded or angular. The contrast in sharpness between the 
crushed limestone and the rounded limestone is not as distinct as between the crushed and round silica sand. Grinding the limestone in a rotary type grinder created large quantities of fine dust. During the sieving of the ground limestone nearly one-half of the total material passed the No. 200 sieve. After similar treatment only five to ten percent of the crushed silica had passed the No. 200 sieve. Apparently the material that would have to remain as projections on the crushed limestone if sharp edges were to be formed, broke off as small distinct particles.

The limestones gave higher relative resistance values after one polish cycle than when tested as rolled. The polishing wore down the irregularities, thus permitting more intimate contact and more skid resistance. The irregularities were not strong enough to contribute much to the skid resistance. Consequently, the increase in skid resistance due to better contact and greater area was more than the reduction due to the wearing away of the angularity. For fine limestone aggregate mixes, further polishing had little effect as the total relief of the unpolished surface was small and by the end of four minutes of polish, the particles were either worn to a flat surface or expelled. Further wear lowered the elevation of the surface but did not change its character. 
OPTIMUM SIZE OF ROUGHNESS FOR MAXIMUM SKIDDING RESISTANCE

An optimum size exists for the roughness that will give maximum resistance to motion for each plastic material when sliding on a rigid surface under set conditions of temperature, normal load, rate of sliding, and type of lubrication. Evaluating such a factor is of interest as a possible basis for the choice of aggregates for paving mixtures. If the internal structure of some particular aggregate anproximated this size, then it would be a good choice for providing and retaining skid resistance.

In the preceding shape study, the aggregate size became smaller with successive mixes of the same type material. As the maximum aggregate size decreased from No. 4-8, to No. 8-16, No. 16-30, and on down to No. 30-50 sieve-size crushed silica, the relative resistance increased steadily as can be seen in Table 4 of Appendix C. The relative resistance for the next finer mix, maximum size material between the No. 50 and the No. 100 sieves, fell sharply below that for the preceding mix. Using the crushed quartz abrasive for fine aggregate permitted molding an even finer specimen with No. 100-200 sieve material as the maximum size present. The relative resistance of this mix was the lowest of all the crushed-silica mixes.

Figure 12 illustrates graphically the relationship between particle size and relative resistance value. The data of Table 4 of Appendix $C$ show the nature of this relationship to be the same at all 


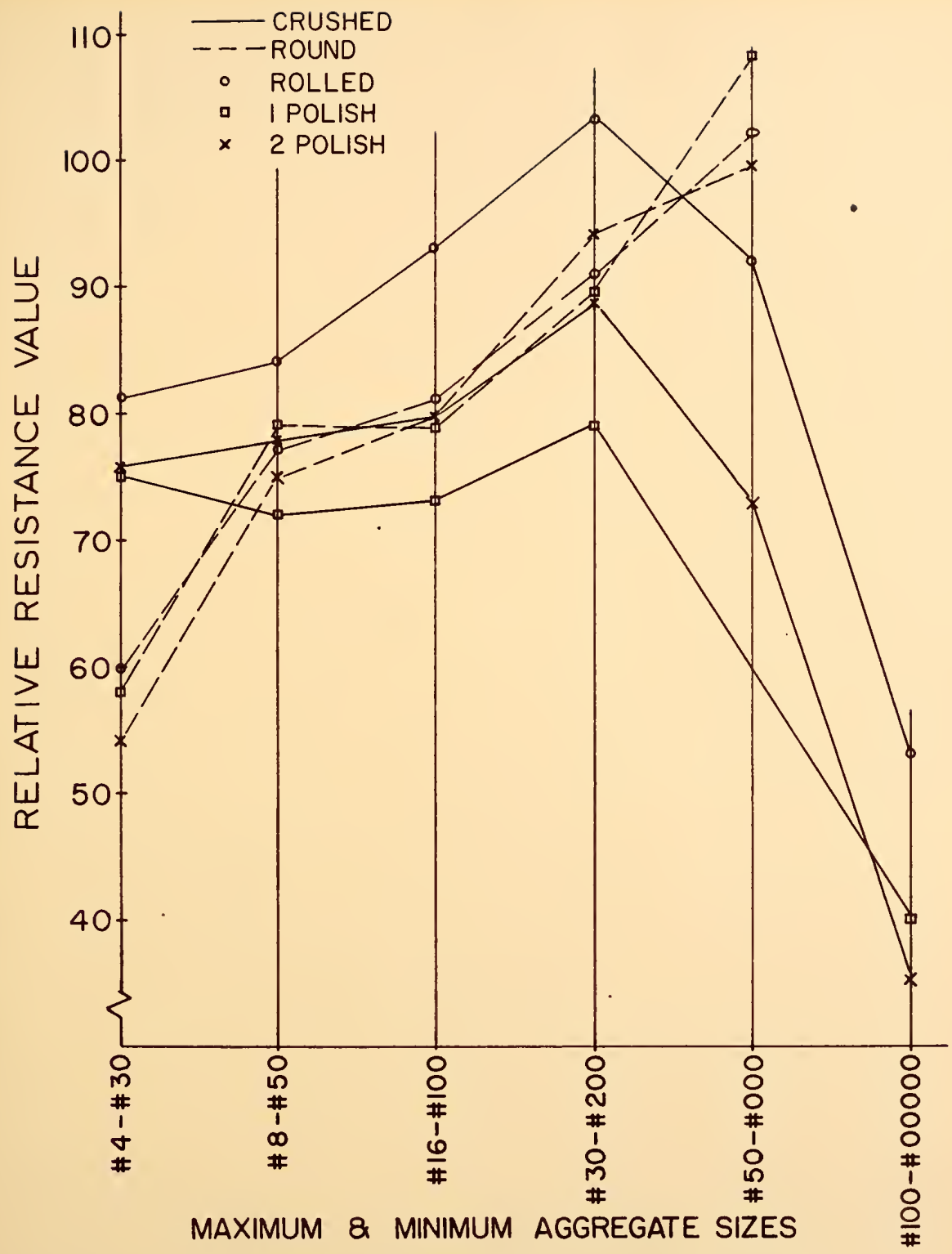

FIG. 12 VARIATION IN SKID RESISTANCE WITH AGGREGATE SIZE FOR FINE BITUMINOUS MIXTURES COMPOSED OF ROUND AND ANGULAR SILICA SAND 
degrees of polish carried out in the laboratory, and the curves in Figure 12 include all degrees of polish. Curves are included in this figure for round silica, but as no source for the small sizes of round silica could be found, an optimum relative resistance was not found.

The effect of size of particle for fine limestone mixes on the resulting relative resistance values is shown in Figure 13 which is plotted from the data of Table 4 of Appendix $C$. The range of this curve was limited by a lack of fine, rounded limestone.

Each of the mixes used was made up of seventy percent of one size particles and fifteen percent each of the next two finer sizes. Ideally, for establishing surface texture, one-size mixes would be best, but it was found to be nearly impossible to hold such surfaces together under the severe action of the test shoe. However, the size of the texture or relief of the material as molded must approach onehalf of the diameter of the particles used.

The existence of an optimum relative resistance value for the crushed silica is shown by Figure 12. The curves for relative resistance value of round silica in Figure 12 and those for polished limestone in Figure 13 rose continuously as the material used became finer. However, if the tests could have been continued, an optimum value would have been found.

The controlling particles used in the mix, which gave the optimum value for the crushed silica, passed a No. 30 sleve and were retained on a No. 50 sieve. The approximate average diameter of these particles is 0.0175 inch. No particles of this size were 


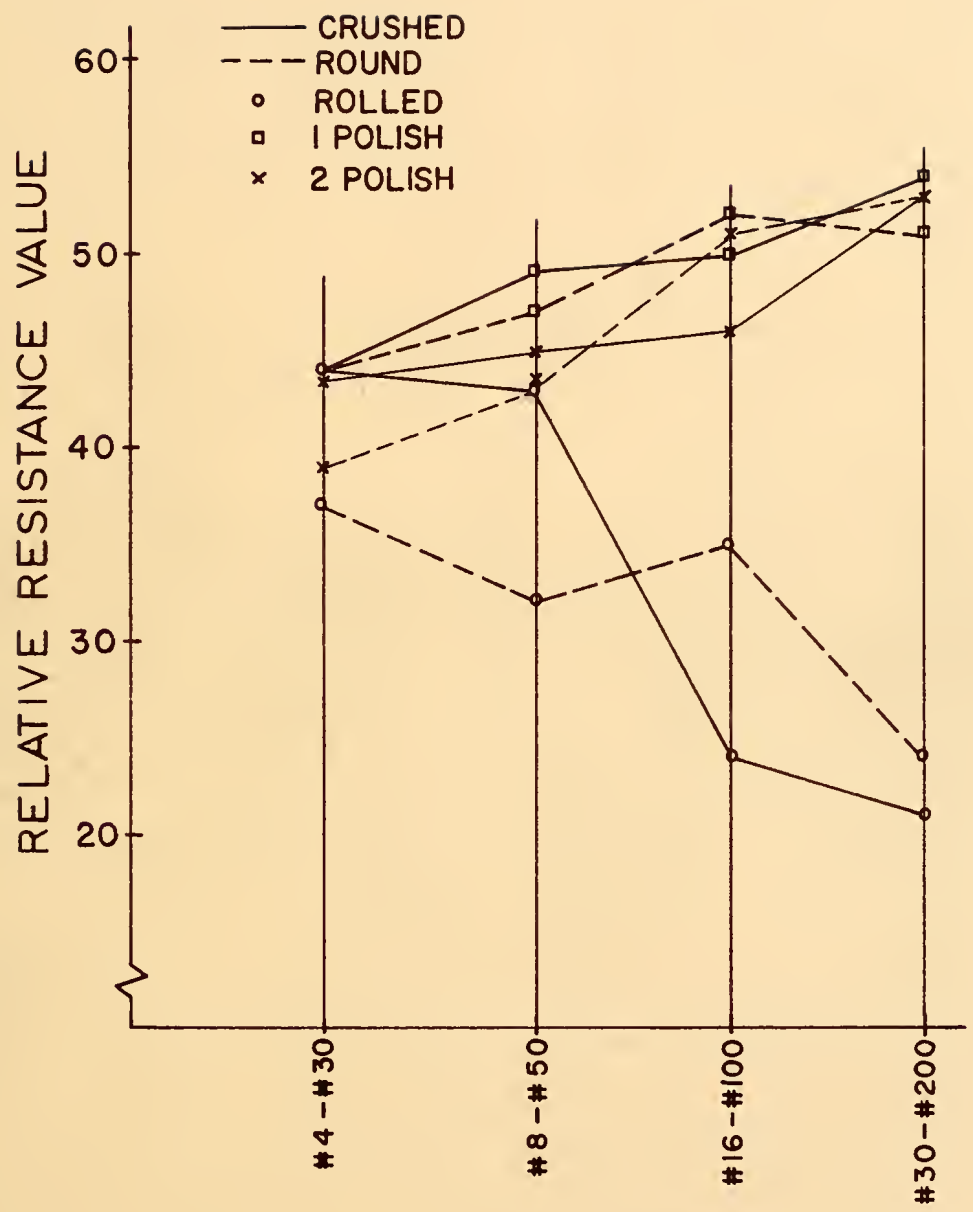

MAXIMUM \& MINIMUM AGGREGATE SIZES

FIG. 13 VARIATION IN SKID RESISTANCE WITH AGGREGATE SIZE FOR FINE BITUMINOUS MIXTURES COMPOSED OF ROUND AND ANGULAR LIMESTONE SAND 
present in the next mix. This then ind1cates that asperities approximately 0.009 inch high provide the best resistance to skidding for crushed silica. The rounded silica-sand mixes reached a relative value about equal to the optimum found for crushed silica but at a smaller aggregate size. However, whether or not that size corresponded to an optimum size for maximum relative resistance was not determined.

There has been much speculation in recent years on the interaction of water films, roughness, and mubber characteristics as they affect skid resistance. The possibility exists that water trapped in the surface roughness of the pavement must be expelled by pressure from the deforming tire before high frictional resistance can be developed. As the texture of this surface roughness becomes finer, the resistance to water flow through the torturous paths remaining causes increasingly higher pressures. As the water is expelled, the rigidity of the rubber causes the water pressure to fall rapidly and even under static load all of the water cannot be removed. Therefore, before attempting to find ways of providing for removal of the water, it should be determined if water in the void snaces between the peaks of the asperities on the pavement surface is indeed the factor which reduces the skid resistance of fine-textured pavements when wet.

At high speeds, the short time the rubber is in contact with the pavement may prevent the water from being expelled. However, the time effect may be greater as applied to the rubber material than as applied to the water. At a speed of $60 \mathrm{mph}$ the tire slides eighty-eight feet per second, and if the roughness is of the magnitude of 0.009 inches in 
height, giving a spacing of 0.018 inch, each element of tread area 0.018 inch wide would pass over 58,667 asperities per second. A longitudinal section of the surface of the rubber would deform approximately as a sine wave vibrating with a frequency of 58,667 cycles ner second. There would seem to be some question whether the modulus of deformation of the rubber is such that the amplitude of this wave of deformation will approach the static deformation. If the material can recover completely in $1 / 58,667$ of a second from the deflection caused by an asperity, the resulting friction could depend on the ease with which the water can escape. If the rubber cannot keep up this pace, the sliding rubber would act much as a rigid material sliding on the pavement and more rapid removal of the excess free water would not aid greatly in increasing friction.

It is conceivable that free water standing on the pavement provides a supply of water to be partially adsorbed by the rubber. Driving on pavements which appear dry (may have adsorbed water on the surface) causes sufficient heat to build up within the tire rubber to drive adsorbed water from the rubber surface. Under the cooler conditions resulting from wet pavements, a film of water may remain on the rubber. The friction which can be developed between two layers of adsorbed water is probably lower than that between a layer of adsorbed water and a dry surface.

Another possibility is that some water remains in the small volumes around the surface asperities where the rubber cannot flex sufficiently to contact the aggregate surface (see Figure 2c). As the mubber slides past an asperity, this non-contact area will be maintained and water, if present, would not be expelled. 
Approximate calculations indicate that a very high pressure or length of time is needed to expel the water from the voids of a pavement whose surface is made of a mix utilizing No. 4 to No. 8 material similar to the coarsest mix in Figure 12. Not only did this mix give a high relative resistance value, but the values for finer mixes were even higher. An approximate value for the velocity required in the water for escape is given by the equation:

$$
v=\frac{K P}{4 I}
$$

Where $K$ is permeability; used as $6 \times 10^{-7} \mathrm{~cm}^{2}$ as found by McLaughlin and Goetz (52)

$P$ is pressure driving the water; used as 500 psi, which is far greater than that which can be maintained for more than a fraction of the contact $t$ ime

4 is the viscosity of the water; used as $2 \times 10^{-5}$ lb-sec per $\mathrm{ft}^{2}$

$L$ is the distance the water must travel; used as 3.5 inches or the radius of a circle of area equivalent to the contact area

The value so obtained is $v=95$ inches per second which means that the time required by the water to travel 3.5 inches would be 0.037 seconds. At $30 \mathrm{mph}$ the tire contacts a section of the pavement, assuming the contact radius is $3 \frac{1}{2}$ inches, for 0.013 seconds, and at $60 \mathrm{mph}$ for 0.0065 seconds. Neither of these times is long enough to remove the water if the conditions assumed for calculation are correct. As both the permeability and the pressure were assumed conservatively high, this calculation would seem to show that the removal of free water is not the critical factor.

Strong support for this conclusion is seen in the relative resistance values obtained from the Purdue laboratory skid-testing machine. Water is applied to the surface of the pavement through each radial slot of the testing shoe. At 2,500 rpm and 16 slots, only 0.0015 
second is available in which to expel the water from under a segment of the test shoe. The maximum distance to a non-pressurized edge is approximately one-third that for a true tire, giving an overall comparison of time weighted for distance of one-third that actually occuring in the field at $30 \mathrm{mph}$, or about that for $90 \mathrm{mph}$. The best textures tested with this machine have consistently been fine mixes ut1lizing particles in the range of 0.0176 -inch and smaller diameters. Very few mixes with maximum sizes in this range have been tested due to difficulties experienced in mixing. However, the removal of water from the surfaces molded did not seem to be a critical problem. In fact, the removal was so complete that many of the surfaces tended to overheat. 


\section{EFFECT OF THE PENETRATION GRADE OF ASPHALT \\ ON THE SKIDDING RESISTANCE OF FINE BITUMINOUS MDXTURES}

For fine sand mixes, the rigidity with which the sand particles are cemented into the surface could have an effect on the skid resistance. If small grains of sand become dislodged under traffic and are rolled under skidding tires, the surface will be scored or otherwise roughened. For skid-resistance comparison tests of pavement textures, the more critical tests would be those in which the sand particles were not pulled from the surface but allowed to remain and to become polished. The grade of asphalt could be one of the controlling factors in the retention of the sand particles.

For this reason several mixes of different gradations of Lafayette sand were prepared using different grades of asphalt. These mixes were prepered and polished as explained in Appendix B. The asphalt content varied with aggregate variation but not with asphalt grade. Results of this series are presented in Table 5 of Appendix $C$ and illustrated by Figures 14 and 15. The skid-resistance values taken during and after the accelerated polishing procedure did not indicate that a relationship exists between skid resistance values, degree of polish, and penetration grade of asphalt. It is recognized that very little if any weathering of the asphalt can occur during the shortterm polishing performed in the drill press. The possibility exists that the effect of asphalt grade on skid resistance of mixes containing coarse aggregate might be different than that for fine mixes. 


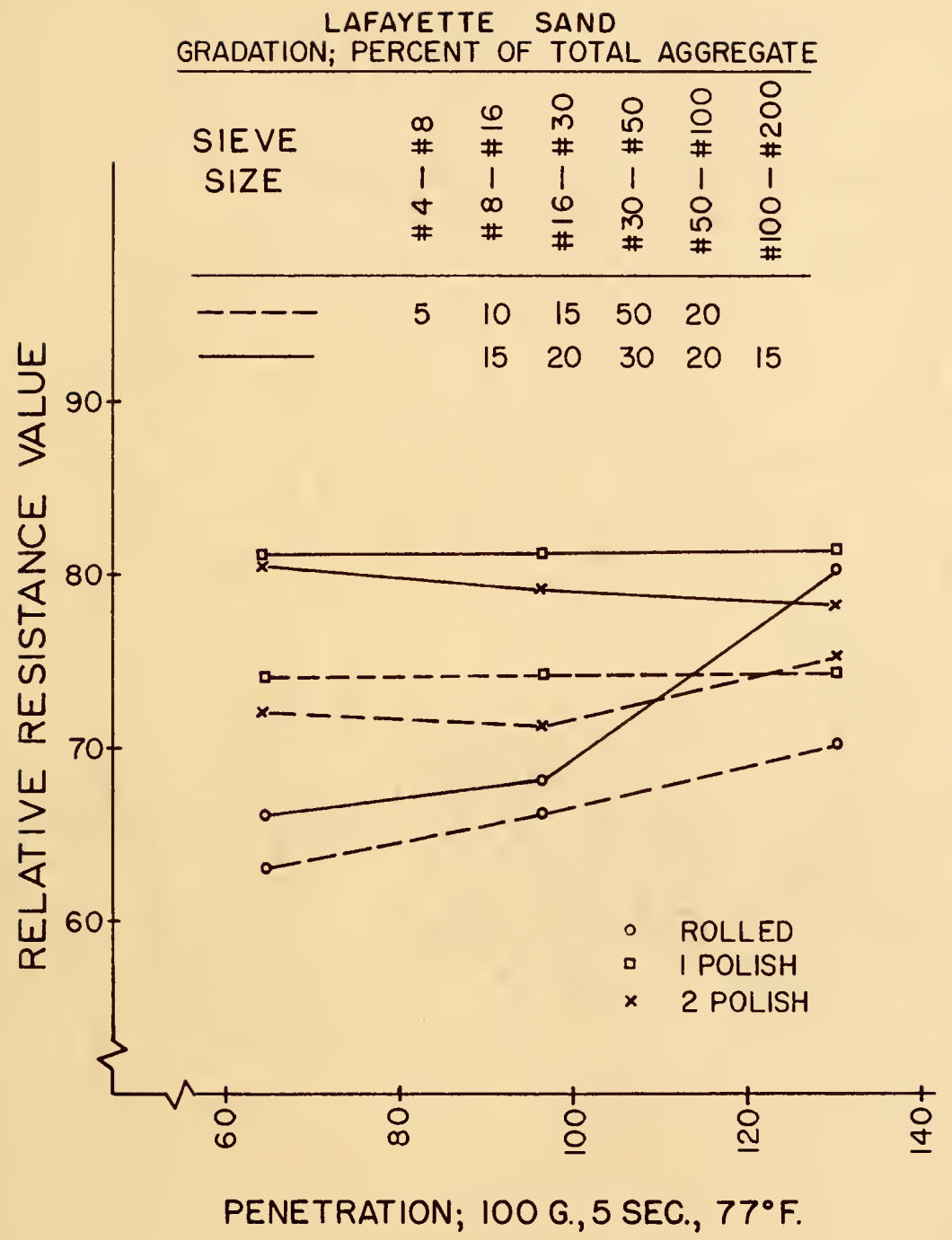

FIG. I4 VARIATION IN SKID RESISTANCE WITH PENETRATION GRADE OF ASPHALT USED FOR FINE BITUMINOUS MIXTURES 
LAFAYETTE SAND

GRADATION; PERCENT OF TOTAL AGGREGATE

\begin{tabular}{|c|c|c|c|c|c|}
\hline $\begin{array}{c}\text { SIEVE } \\
\text { SIZE }\end{array}$ & $\begin{array}{c}\infty \\
\# \\
1 \\
\sigma \\
\#\end{array}$ & $\begin{array}{l}\frac{\omega}{\#} \\
1 \\
\infty \\
\#\end{array}$ & $\begin{array}{l}0 \\
m \\
\# \\
1 \\
\underline{\varphi} \\
\#\end{array}$ & 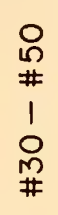 & $\begin{array}{c}\circ \\
\text { 음 } \\
\text { \# } \\
\text { 음 } \\
\#\end{array}$ \\
\hline---- & 5 & 10 & 15 & 50 & 20 \\
\hline & & 15 & 20 & 30 & 20 \\
\hline
\end{tabular}

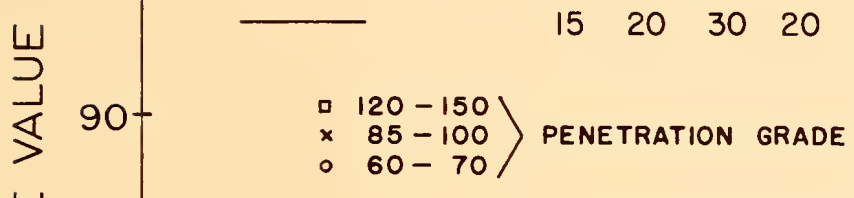

$\frac{u}{2}$

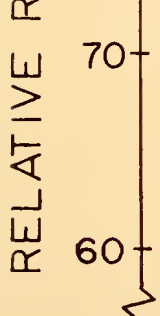

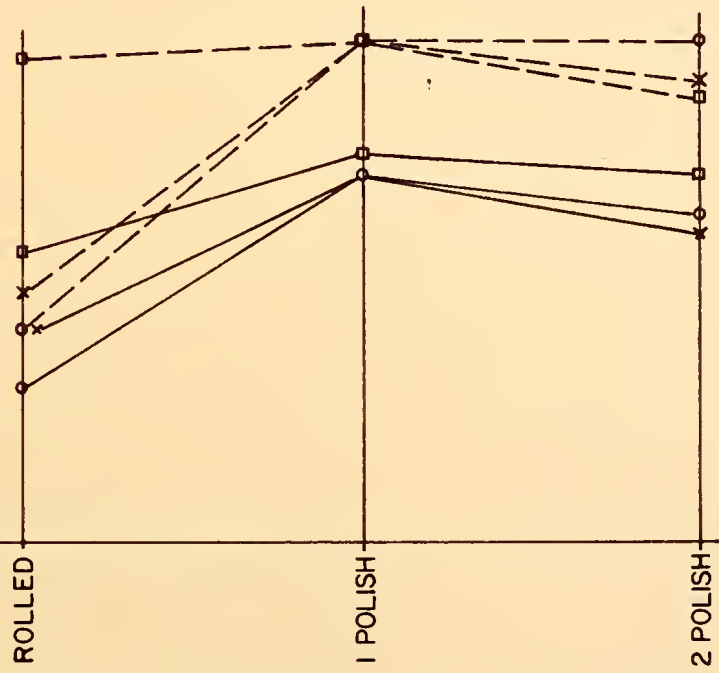

POLISH

CYCLE

FIG. 15 VARIATION IN SKID RESISTANCE WITH DEGREE OF POLISH FOR FINE BITUMINOUS MIXTURES MADE WITH ASPHALTS OF DIFFERENT PENETRATION GRADES 
EFFECT OF VARIATIONS IN THE PERCENT OF EXPOSED AGGREGATE IN THE PAVEMENT SURFACE ON THE SKIDDING RESISTANCE OF PAVEMENTS

Pavements made from mixes of different gradations show a large variation in the percent of surface made un of exposed aggregate. If one is willing to accept surface texture of the aggregate as one of the factors determining the skid resistance of pavements, then area of aggregate exposed in the surface is of great interest. To oversimplify this concept, if a loaded rubber block were supported upon a single conical projection, it would be penetrated to some set depth. If the same loaded block were then placed upon two cones identical with the first, penetration would be more than one-half of the former amount. This can be explained by observing that resistance to penetration does not vary directly with the penetration, but more nearly as a higher power of the penetration. Some such relationship should be expected, since the cross-section of the cone increases with depth.

The pressure distribution on the surface of the cone of roughness must change with depth of penetration into the rubber. The greater the depth of penetration, the farther from the tip of the cone the effective center of lateral pressure on the cone will be. This effect is due to the large lateral deflection required at the surface of the rubber for the larger penetration. Should the rubber block be pushed sidewise, the force required to overcome frictional resistance would be greater for the two-cone situation than for one-cone as the 
resistance for each cone is over one-half that for one cone alone. This principle can be expanded to many projections and, finally, for a given tire contact area, to the concept that the greater the area of stone within the contact, the greater the resistance to sliding.

In an attempt to show the effect on skid resistance of the area of aggregate exposed in a pavement surface, several specimens were planned of Greencastle limestone for which the contact area could be varied. For the first, sma 11 rock cores 0.66 inch in diameter were placed in a radial pattern in the specimen (see CO-1, Figure 16). By locating the cores in this manner, the length of the edge of each core normal to the direction of skidding remained constant regardless of the amount of wear. For the first skid test, there were no flat areas on the cores and the area of contact was unknown. The rubber shoe must have conformed sufficiently to the curvature of the crests of the cores to carry the load.

The specimen was then polished repeatedly in the drill press for 15-minute intervals with No. 000 crushed quartz. The relative resistance values and the areas of the flats worn on the cores as measured after each polish are recorded in Table 6 of Appendix C. Figure 17 represents the variation in relative resistance value as the contact area of the limestone under the test shoe changed. For these particular data, the total area of the test shoe and the total normal load were held constant.

In order to adjust the curve shown in Figure 17 to a constant pressure condition, relative resistance values were measured on certain specimens at different normal loads. The specimens used were the small limestone-core specimen at the last stage of polish as 
RS-8

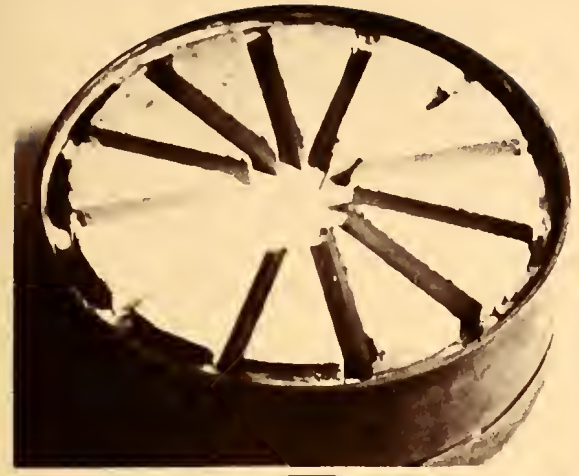

CU-1

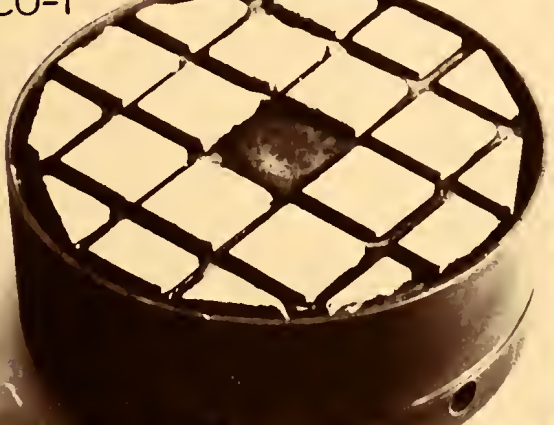

CU-2

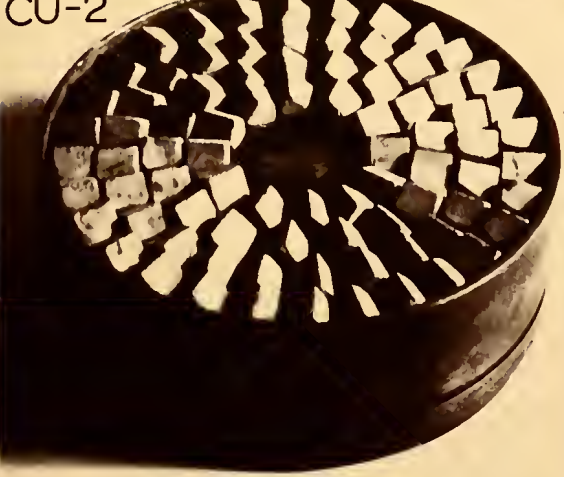

RS-16
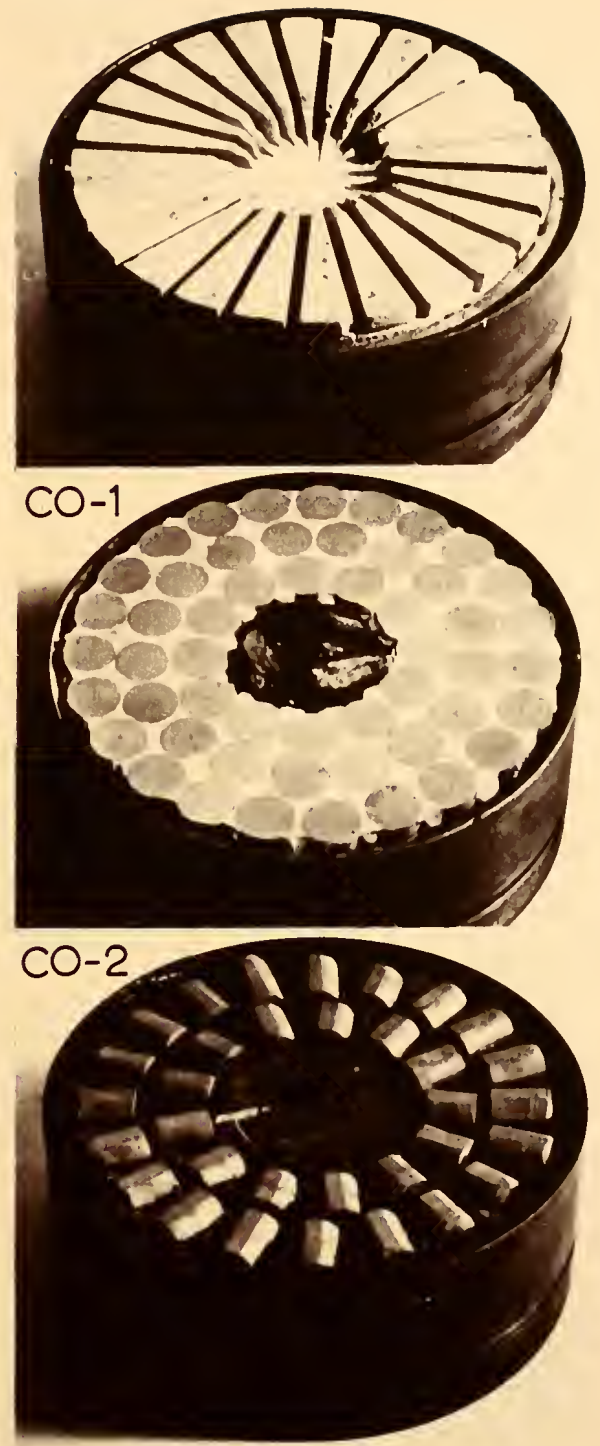

FIG.16 SPECIMENS STUDIED FOR THE EFFECTS OF EDGES AND AREA ON SKID RESISTANCE 


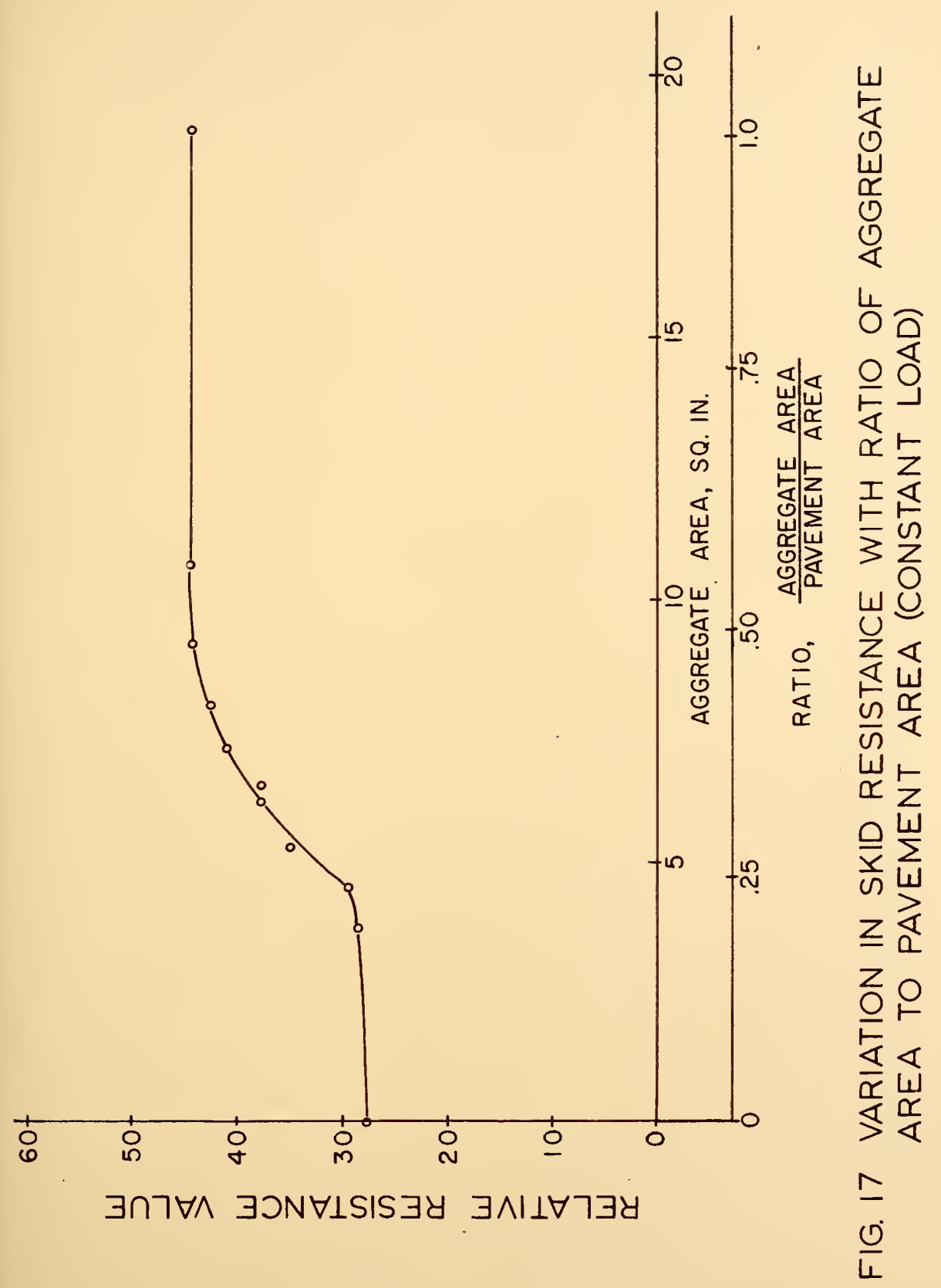


described before, a solid limestone core, and a solid sandstone core, both similar to that shown in Figure 18. The tests were then repeated at the same loads but with the machine turned off and the motion supplied by turning the specimen very slowly with a lever. The dependency of skid resistance upon pressure is shown in Figure 19. The ordinate of this diagram is contact pressure and was determined as the load on the test shoe divided by the area of aggregate under the test shoe corrected for the lack of contact on the slots in the shoe. This factor could also be considered as load divided by rubber-aggregate contact area.

Under static conditions at a pressure of about $50 \mathrm{ps}$, the relative.resistance values for both the limestone and the sandstone tested were the same. At pressures less than $50 \mathrm{psi}$, the static relative resistance values for the limestone were higher than those for the sandstone. The relief of the polished sandstone is more than that of the polished limestone. At low pressures the rubber is not forced down into the depressions of the sandstone and the contact area is less than for the limestone. At pressures above $50 \mathrm{psi}$ the rubber is forced sufficiently into the rubber to increase the contact area and to raise the static skid resistance above that of the Iimestone.

The sample made of small cores had less aggregate in contact with the rubber than the solid cores. The relative resistance for this specimen under the static condition was always below that of the solid specimen. The increase in relative resistance when the pressure was increased on the small limestone cores corresponded to that for the solid limestone. 


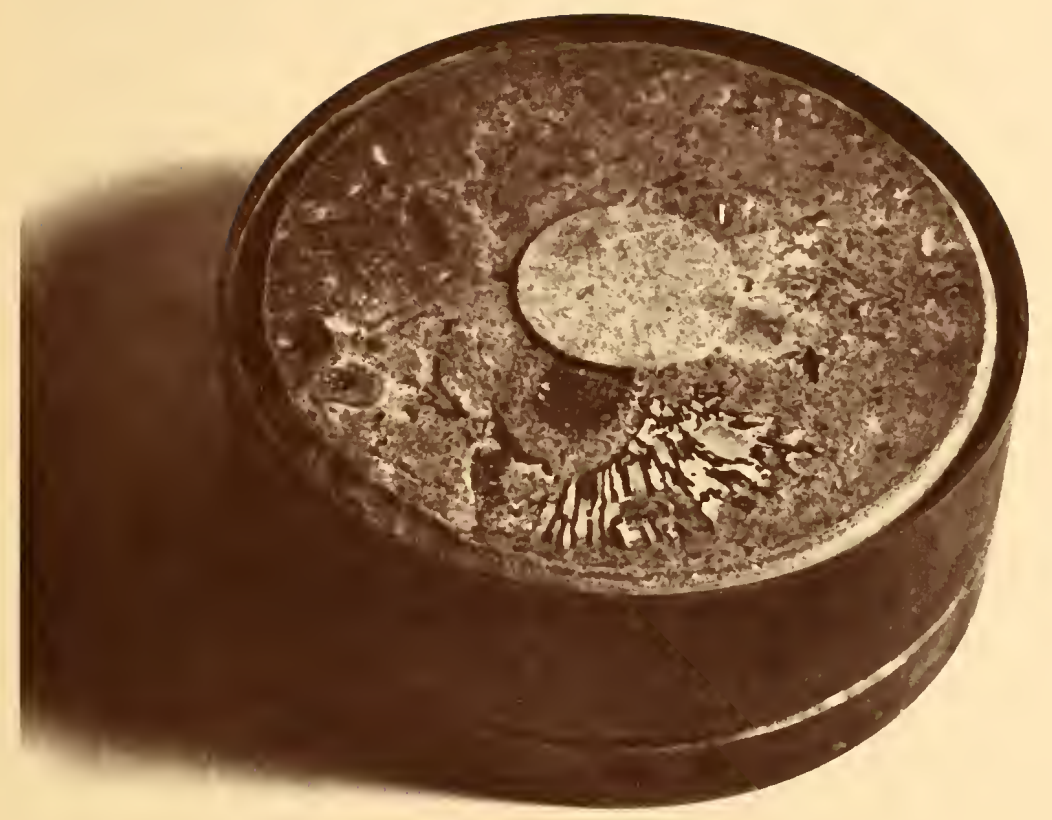

Figure 18. Core of Richmond Limestone 


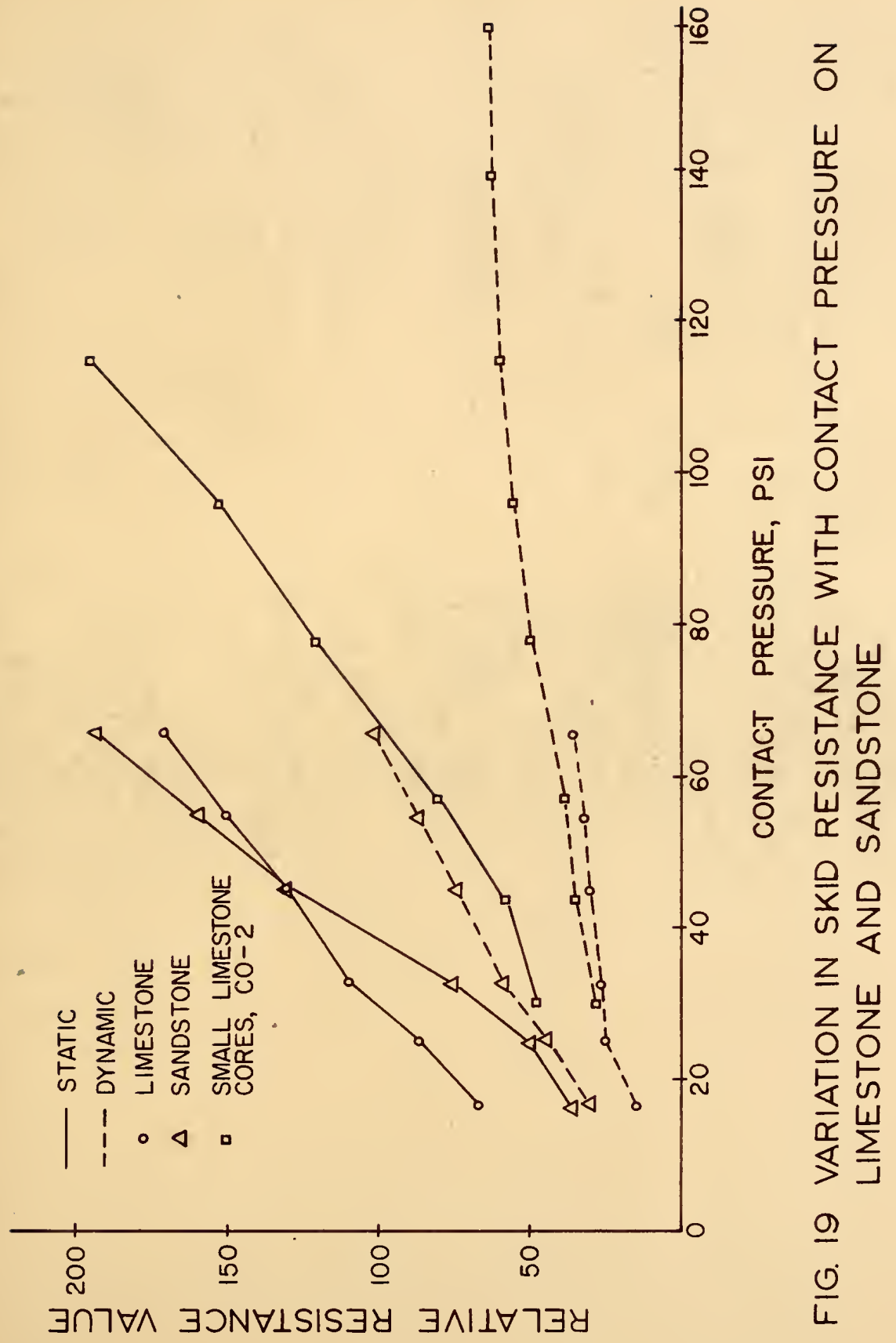


For the dynamic condition the relative resistance values of the sandstone were always well above those for the limestone. However, the dynamic relative resistance values for the sandstone were well below the static values. At all pressures the introduction of motion reduced the relative resistance of the sandstone. At the highest pressure used, this reduction approached fifty percent of the static value. This same change from static to dynamic conditions reduced the relative resistance values of the solid limestone core by about seventy-five percent and the composite specimen of small limestone cores by about fifty percent. Again the rate of increase of relative resistance value with increased pressure was nearly identical for the solid limestone core and the composite specimen of small cores.

Special notice should be made of the change in relative resistance values for the two limestone specimens as conditions change from static to dynamic. Under static conditions the relative resistance values for the solid core specimen were substantially above those for the specimen made of separate small cores. Yet, under dynamic conditions, the values for the composite specimen were consistently above but nearly the same as those for the solid specimen. Possibly the explanation for this latter relationship was the added time available for rebound in the rubber as the shoe passed the void area between the small cores.

This inter-core space had an average width of $3 / 16 \mathrm{inch}$. As the mubber of the shoe passed over these inter-core spaces, a much longer rebound time was available than when passing over the small voids of the Iimestone surface roughness. During this time the rubber penetrated into the spaces by a rebound process and part of the skid resistance was due to mechanical interference. 
Using an average rate of change of relative resistance of 0.2 relative resistance value units per one psi change in contact pressure, the values found when using constant total load were converted to a constant pressure of $28 \mathrm{psi}$. The resulting relative resistance values are shown in Table 6 of Appendix $C$ and in Figure 20. In this figure, relative resistance values at constant pressure have been plotted against areas of aggregate in contact with the test shoe. The relative resistance values used here were not measured directly but were found by combining Figures 17 and 19, and must be considered as approximate. For convenience in using this figure for estimating relative resistance values of limestone mixes, the abscissa is also given as a ratio of the aggregate area in contact with the rubber surface to the total pavement area. Relative resistance values corrected to 28 psi for specimens CO-1, CU-1, RS-8 and RS-16 are shown for comparison purposes on Figure 20 and will be discussed in later paragraphs.

For both the constant-load curve of Figure 17 and the constantpressure curve of Figure 20, a large increase in relative resistance value occurs as the area ratio increases from about 0.2 to about 0.5 . These results indicate that the skid resistance of any paving mix made entirely of Greencastle limestone which has less than fifty percent of the surface made up of exposed aggregate can be increased by redesigning the mix to increase the area of stone in contact with the tire.

Three similar specimens were prepared of $\frac{1}{2}-i n c h$ cubes of Greencastle limestone. Plaster of paris was the cementing medium for two of these, and asphalt was used in the other. One edge of each cube was placed up and oriented in a radial direction similar to the small ifmestone cores. When completed the surfaces of these specimens were 


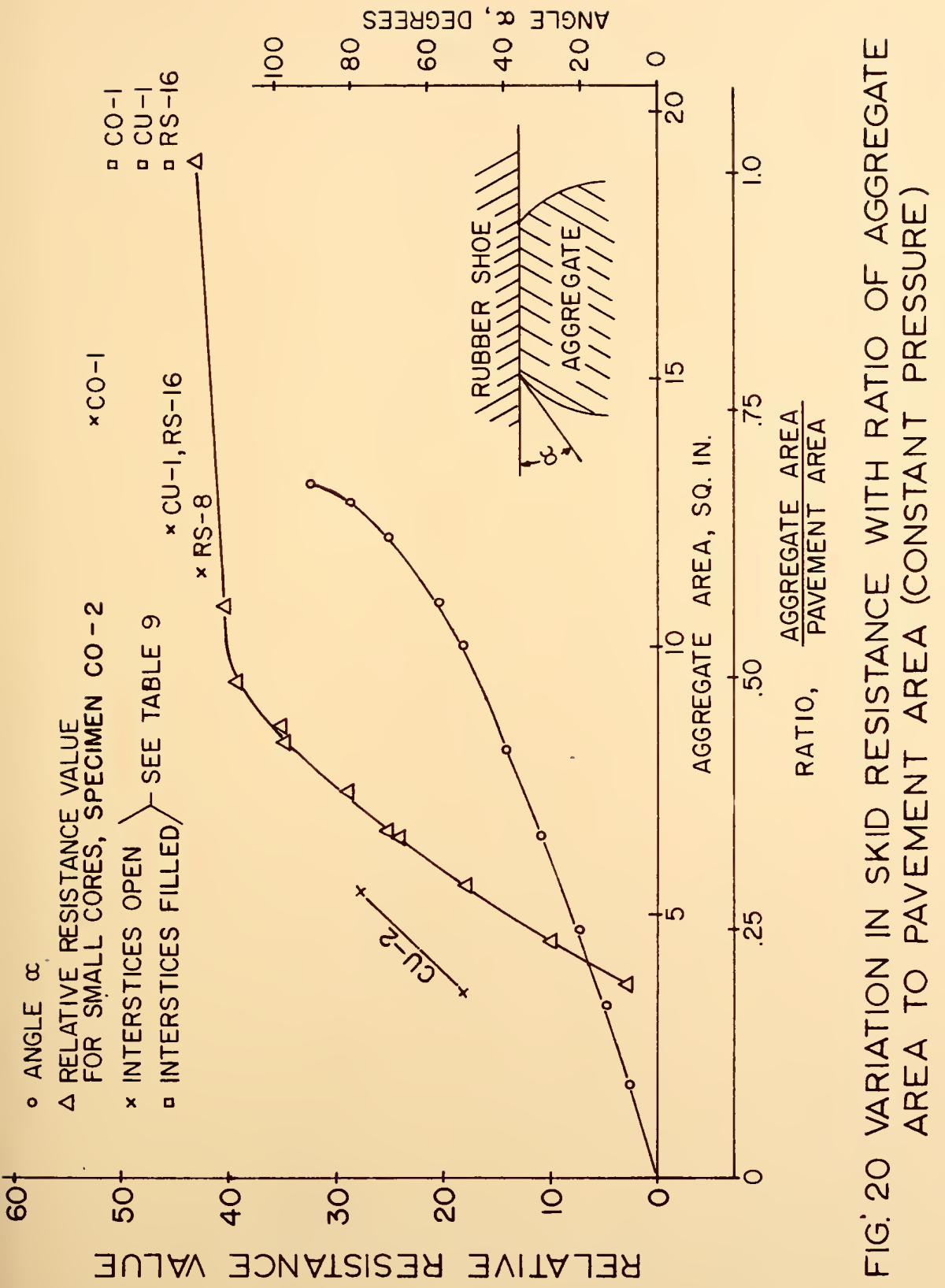


covered with small sharp ridges as seen at CU-2 in Figure 16. Skid tests destroyed the first two small-cube specimens. Shear forces applied to the top of the cubes by the testing shoe pulled the small cubes from the plaster of paris used as a backing. The third specimen, backed with hard asphalt, withstood several polishing cycles.

Results obtained for relative resistance values of the small-cube specimen CU-2 appear in Table 6 of Appendix C. These values were adjusted to a pressure of 28 psi as described previously and then plotted on Figure 20. Although the points representing specimen $\mathrm{CU}-2$ are few in number, the same trend of increase in relative resistance with increase in aggregate area which characterized specimen $C 0-2$ is apparent.

In an effort to substantiate the relationships developed by means of the controlled-area samples, measurements of the area of aggregate exposed on the surface of some of the fine mixes were made. For these measurements, a strong light beam was projected onto the surface at an incident angle of $60^{\circ}$ and the reflected beam picked up by a RCA 920 photoelectric-cell positioned to receive the $60^{\circ}$ reflected beam. The face of the tube was located three inches from the surface measured. The output of the photoelectric-cell was read on a DuMont oscilloscope. A flat limestone surface of the same material and polish as that used in the mixes was used for calibration. The scope was adjusted to read -50 for no reflection and +50 for the reflection from the limestone. This gave a probable range of readings for the mixes made of this limestone of -50 to +50 or 100 units.

The oscilloscope readings and the relative resistance values for several of the fine-textured pavement specimens are tabulated in 
Table 8 of Appendix C. Mixes made from both Greencastle limestone and West Lafayette sands are included. The addition of a factor of +50 to each oscilloscope reading converted the results to a relative reflectance scale and eliminated all negative signs. Assuming that the black asphalt caused no reflection and that the asphalt had worn from the aggregate surfaces, the relative reflectance would correspond numerically to the percent of the surface composed of exposed aggregate. The relationship found experimentally between reflectance and relative skid resistance is shown by Figure 21.

The reflectance readings for the fine mixes were very low, indicating, under the stated assumptions, a range of approximately 20 to 45 percent exposed aggregate. The relative resistance values are seen in Figure 21 to increase as the area of exposed aggregate, represented by the reflectance values, decreases. The relationship shown in Figure 20 indicates that relative resistance values increase as area increases. One explanation for this seemingly complete reversal of the expected results could be that asphalt is not worn from the very small particles before they are expelled. This continual expulsion of particles would prevent the development of a surface composed of light-colored exposed aggregate, and there would be no light-colored area to be measured by the photoelectric-cell. For fine mixes, then, the photoelectric-cell might better be used to measure the rate at which particles are expelled with less reflection indicating ability to maintain skid resistance.

That part of the data representing sand mixes shows more variation than that for fine limestone. Probably the wide range of colors 


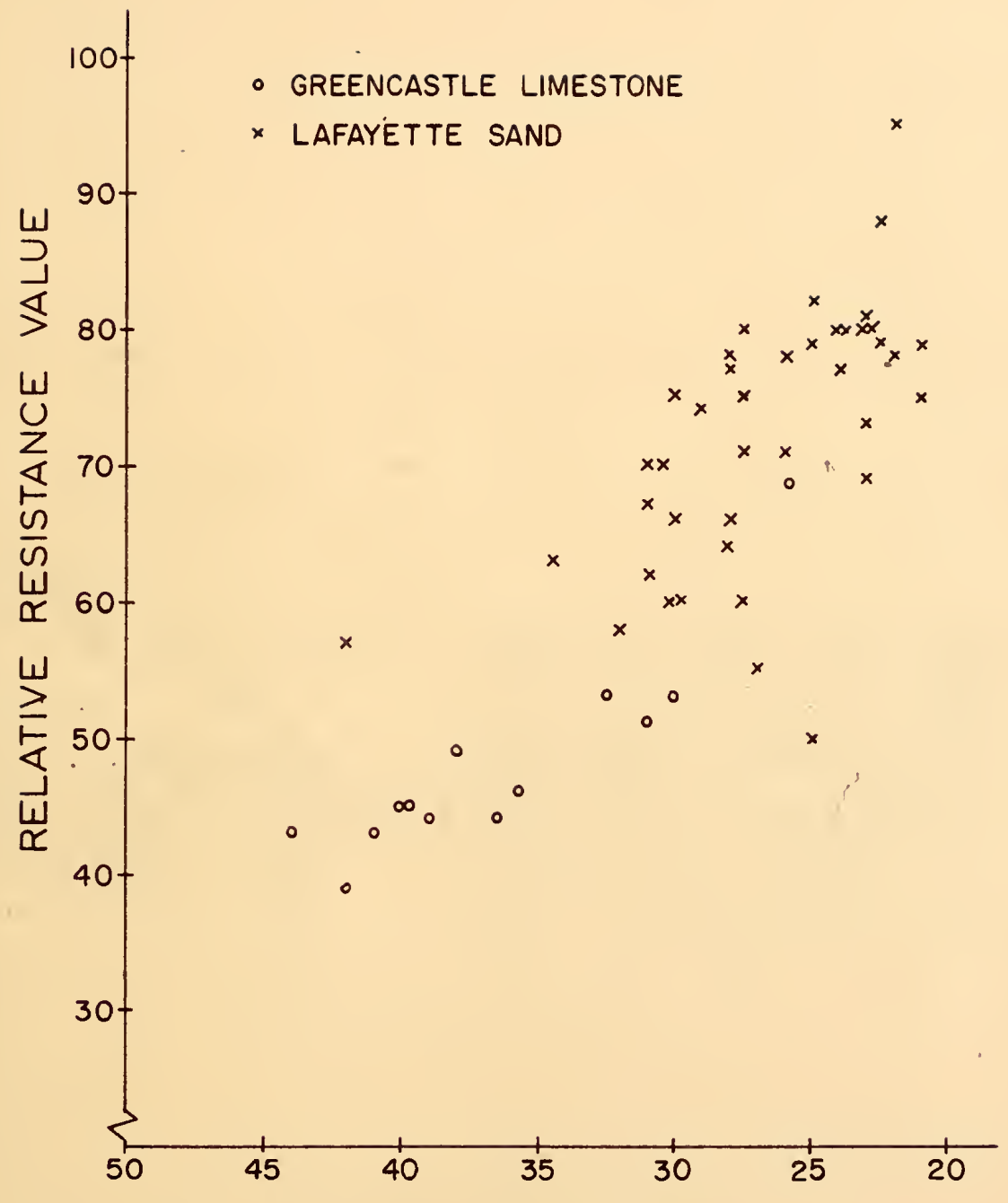

RELATIVE REFLECTANCE FROM OSCILLOSCOPE

FIG. 21 VARIATION IN SKID RESISTANCE WITH REFLECTANCE OF FINE BITUMINOUS MIXTURES 
present in the West Lafayette sand affects the amount of light reflected.

Coarse limestone mixes gave a different condition from that observed on fine mixes as the aggregate remained in place and the asphalt was worn away. Under this condition, the photoelectric-cell measures the area of the exposed aggregate. Light measurements on two core specimens of an asphalt-limestone pavement were compared to planimeter measurements. The first core surface tested by reflected light measured 73 percent of the total sample surface as exposed aggregate, the second $77 \frac{1}{2}$ percent. Planimeter measurements of the same cores gave $74 \frac{1}{2}$ and 79 percents, respectively. These few measurements indicate that such a method of measurement has possibilities.

Certain difficulties must be overcome before skid resistance can be effectively estimated from data of this kind. A continuous surface of the texture and color of the aggregate would be required in order to zero the meter used with the photoelectric-cell. Also a curve similar to Figure 20 relating relative resistance value to aggregate area in contact with the tire would be needed for the material to be tested. 
EFFECT OF AGGREGA TE EDGES

ON SKIDDING RESISTANCE OF PAVEMEN TS

The skid resistance between rubber and pavement is due to interference of both micro- and macro-size irregularities. Much of the macro-size interference must occur at the particle boundaries. If skid resistance is to be planned into paving mixes, the relative importance of these two types of interference must be determined. When the size of aggregate approaches its own roughness, then the two types of interference become one type. As this size is in the range of 0.01 inches or smaller, very few mixes will be sufficiently fine to have a mafority of this size of particles.

An approach to this problem was made by considering the data in Table 6 of Appendix $C$ which is for the tests of the specimen composed of small cores of rock (see CO-1, Figure 16). As the axes of the small cores were placed radially in the mold, each revolution of the shoe struck the same length of edges regardless of the extent to which the specimen had been ground or polished. However, as the area was increased, the angle between the surface and the side of the cores increased (see Figure 20). This, of course, suggests the possibility that the increase in relative resistance value was due to the change in attack angle of the edges of the particles instead of to increased area. The attack angle of the edges increased as a sine function (see Figure 20). In this figure it is apparent that, as the cores 
are worn slightly, the relative resistance value increases rapidly as the attack angle increases slowly, but when the wear becomes greater, the change in relative resistance is small and the angle change large. This lack of direct correlation tends to show that the increase in attack angle of the edges did not cause the increase in relative resistance values.

Several other specimens were prepared using different shapes of limestone fragments (see Figure 16). The patterns were chosen so as to keep the area of rock in contact with the test shoe constant but to vary the quantity and orientation of the edges. The specimens were tested at only one normal load. Table 8 of Appendix C lists the shapes and other physical data. The resulting relative resistance values are plotted on Figure 20 and substantiate the results obtained from the small cores. Two of these specimens may be directly compared to specimen CO-1 for which Figure 20 was prepared. Specimen RS-8 (see Figure 16) has nearly the same area and the same length of radial edges as specimen $\mathrm{CO}-1$. The relative resistance value of specimen RS-8 when corrected to $28 \mathrm{psi}$ is only three units of relative resistance away from the curve for specimen $\mathrm{CO}-1$. The fact that the attack angle $\propto$ of the edges of specimen RS-8 was greater than for specimen CO-1 may explain this minor difference. Specimen RS-16 was similar to specimen RS-8 with the exception that there were twice as many inches of edges on specimen RS-16 as on specimen RS-8. This doubling of the length of the edges increased the relative resistance value two units. While this change is in the direction anticlpated its magnitude is small. 
For further verification of this edge effect, the edges of specimens $\mathrm{CO}-2$, $\mathrm{CU}-2$ and $\mathrm{RS}-16$ were eliminated by filling the voids with plastic aluminum cement which had nearly the same skid resistance as the limestone. After polishing, the specimens were again tested. The pressure was reduced slightly due to the increased area, but the values were corrected to constant pressure of $28 \mathrm{psi}$ by the correction used in plotting Figure 20. The values then fell reasonably close to those for the solid core (see Figure 20 and Table 9 of Appendix C).

Changes in the orientation of the edges caused unpredictable changes in relative resistance value. Specimen CU-l (Figure 16) was made of one-inch cubes and had eighteen inches of edges. However, the relative resistance value was the same as that for specimen $\mathrm{RS}-16$ which had thirty-six inches of edges. Specimen CO-2 (Figure 16) had approximately twenty-six inches of edges but gave a relative resistance value well above that for specimen $\mathrm{RS}-16$ which had thirty-six inches. These differences are not easily explained. 
EFFECT OF POLISHING AGGREGATE SURFACES

ON SKIDDING RESISTANCE OF PAVEMENTS

There have been many indications that the degree to which an aggregate surface has been polished has a major effect upon the skid resistance of the surface. Both the work reported by Giles (25) and that included here concerning the size of roughness effective in skid resistance indicate asperities of the size of a few thousandths of an inch to be' important. Such roughness is provided by the aggregate surface in many cases, and any tendency for such asperities to become worn or polished reduces the resulting resistance.

There is no apparent need for molding aggregage into bituminous pavement specimens in order to measure the polishing characteristics. Such characteristics are inherent to the aggregate and will be the same whether measured on the stone alone or in a $\mathrm{mix}$ composed of this stone and representing the pavement. If the aggregate is crushed rock, cores cut from the same rock can be prepared and processed easily and the problems of bleeding or raveling of the surface of the test specimen can be avoided completely. For comparison purposes such a method of test has the obvious advantage of comparing the polishing of the aggregate surface only.

Polishing of several stone cores, including Medina sandstone, Bedford dolomite, Richmond limestone, Wheeling limestone and Greencastle limestone, was carried out in stages by using different 
grades of abrasive grit (see Figure 20). The core of Richmond,

- Indiana, limestone is shown in Figure 18 and was typical of all. After each increment of polish, the relative resistance value was determined. All of the cores were first polished with a series of crushed quartz abrasives which were harder than the cores. Other investigators have shown that a set level of polish is established and maintained by a given size abrasive. For this reason, after thirty minutes of polishing effort, the abrasive was changed to the next smaller size. Gradations of the crushed quartz abrasives are listed in Table 11 of Appendix C. The possibility exists that the degree of polish imparted to a core by a given size of grit may be a function of the relative hardness of the abrasive to that of the core. For this reason the cores after completion of all polishing with crushed quartz were roughened and repolished using abrasives made by crushing and sizing the core material.

The relative resistance values for the different cores after polishing by the different abrasives are tabulated in Table 10 of Appendix C. The polishing with each abrasive was carried out in two 15minute periods and skid tests were made after each. For ease in comparing the polish resistance of the cores, the relative resistance values for quartz polishing are graphed in Figure 22 and for selfpolishing in Figure 23. In these figures, as the number of the polishing cycle increased, the size of polishing abrasive became finer.

The cores tested were selected to range, using Mohr's hardness scale, from Greencastle limestone at three to Medina sandstone at five. The internal structure of the rocks used can be seen in the 


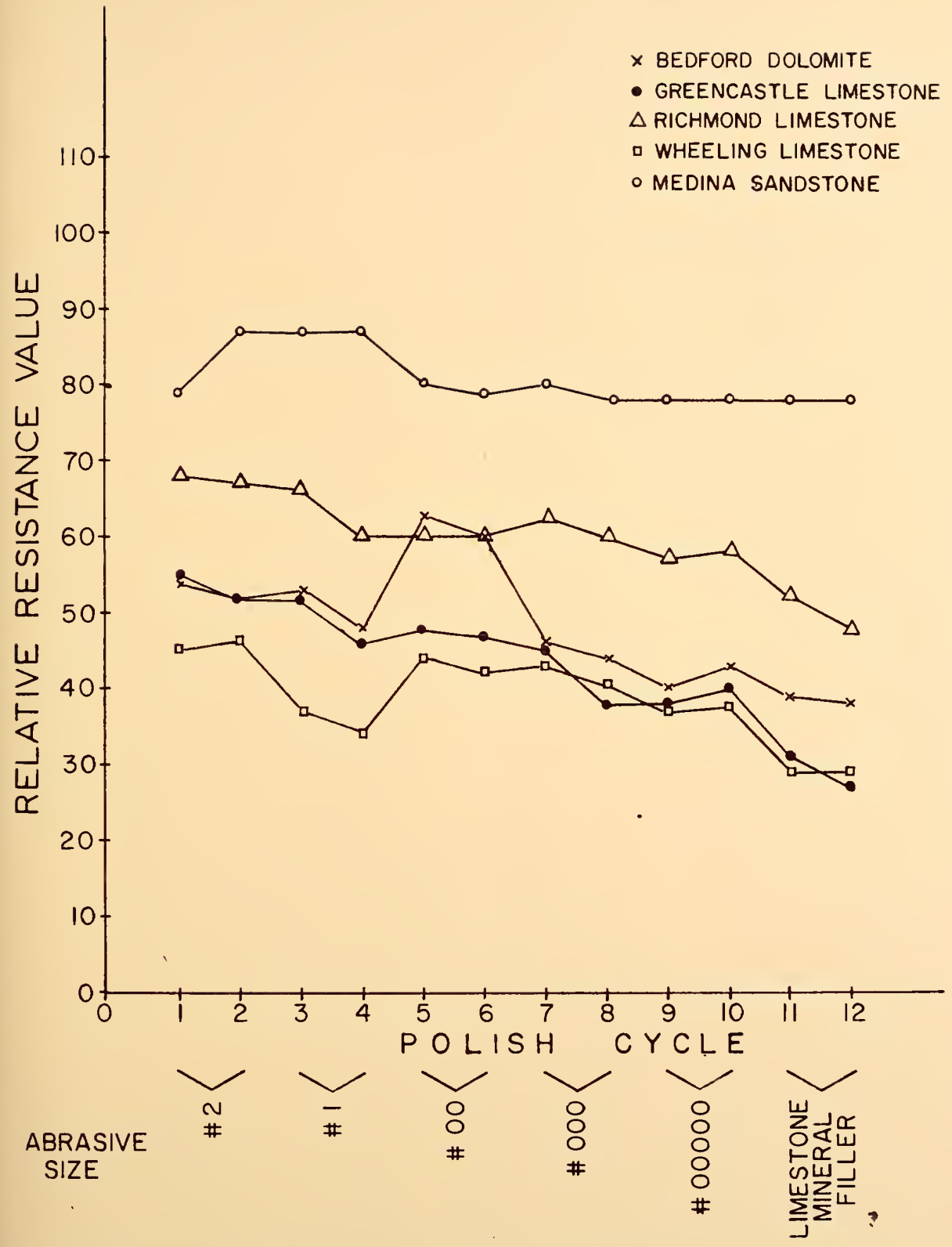

FIG. 22 VARIATION IN SKID RESISTANCE WITH POLISHING CYCLE FOR ROCK CORES (CRUSHED QUARTZ FOR ABRASIVE) 


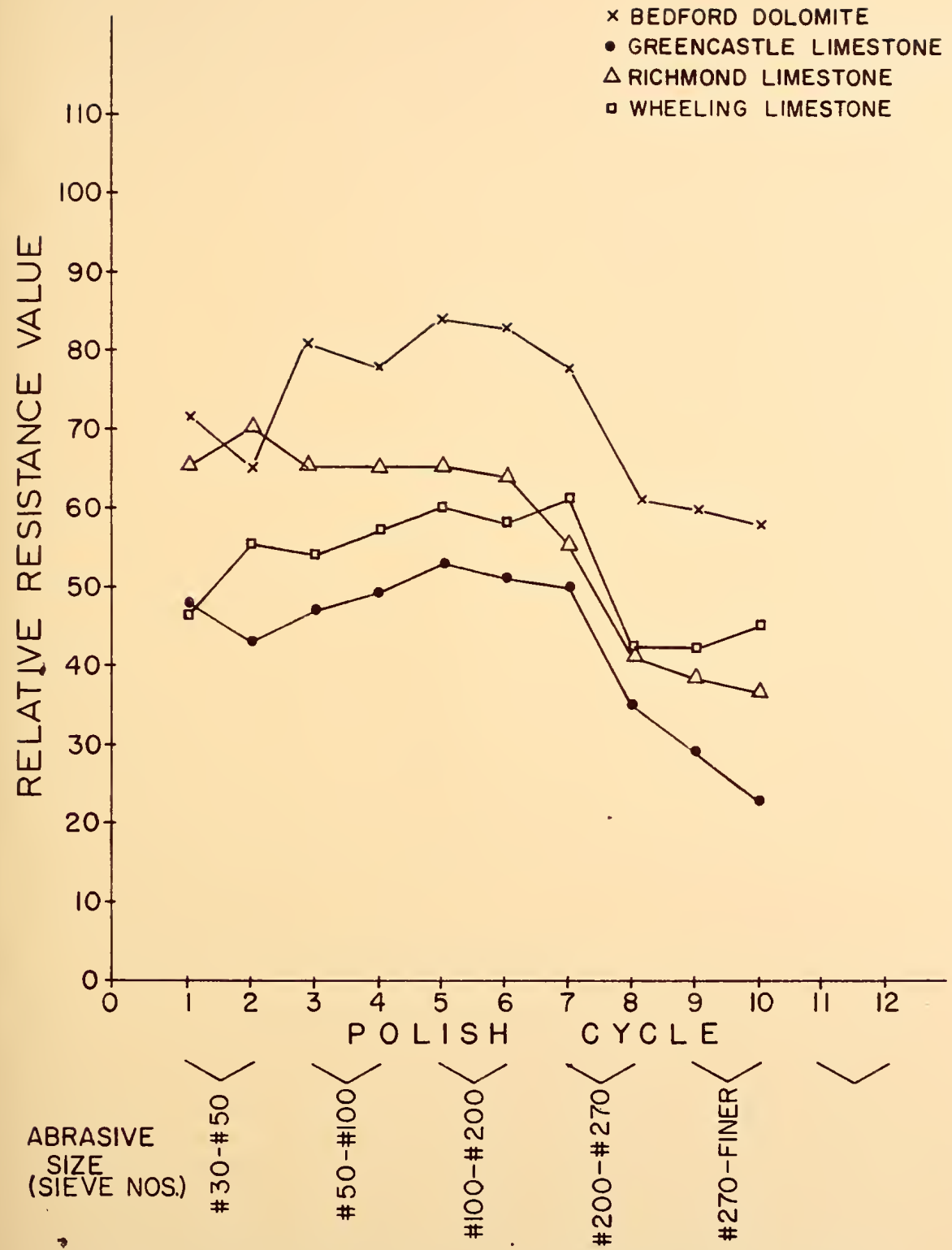

FIG. 23 VARIATION IN SKID RESISTANCE WITH POLISHING CYCLE FOR ROCK CORES (CORE MATERIAL AS ABRASIVE) 
photomicrographs shown in Figure 24. Complete petrographic descriptions are presented in Appendix A.

Comparing Figures 22 and 23, it is found that for the large abrasives used, polishing progressed more rapidly with crushed quartz than with the core material. This was to be expected as at this time the roughness of the core surface was greater than the size of the grit and the hard, sharp grit reduced the asperities faster than the soft, more rounded abrasives. There seems to be a definite trend for the No. $\infty$ quartz to increase the skid resistance. No explanation for this is known. When the fine abrasives were used, the polish progressed more rapidly with the soft abrasives than with the hard. Probably when the asperities have been reduced to a size smaller than the abrasive particles, the hard grains cut or gouge into the surface and tend to maintain a roughness of the same magnitude as the size of the abrasive. Soft particles would not do this as both the particle and the surface under polish would suffer part of the wear. For actual conditions of service on roadways, there seems to be no absolute means of foreseeing the exact nature of the grit that would be present.

Any attempt to compare the resistance to polish of the cores presents the question of what basis should be used for such comparisons. Using the degree of polish obtained by the use of crushed quartz and measured by relative resistance values, the Wheeling and Greencastle limestones are about equal and the Richmond limestone somewhat better. However, using the same material for abrasive as the core, Greencastle is outstanding as the poorest material with the Richmond material next and the wheeling limestone now third. Perhaps 


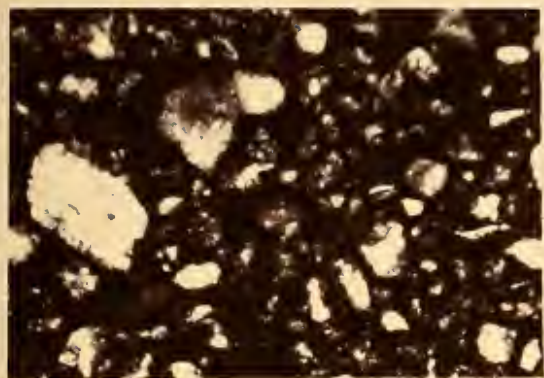

MEDINA SANDSTONE

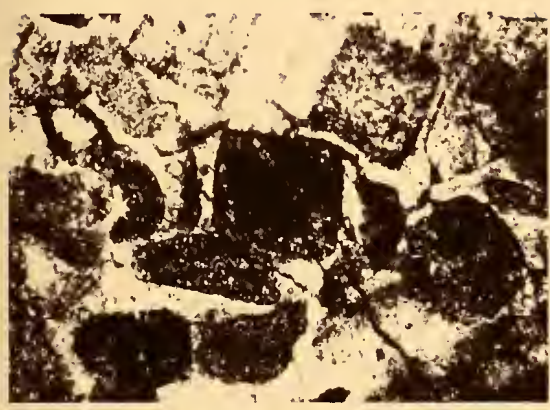

RICHMOND LIMESTONE

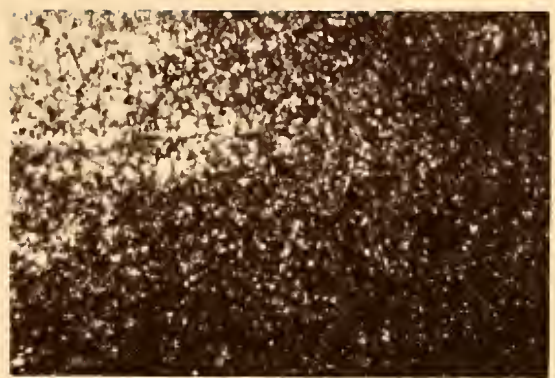

BEDFORD DOLOMITE

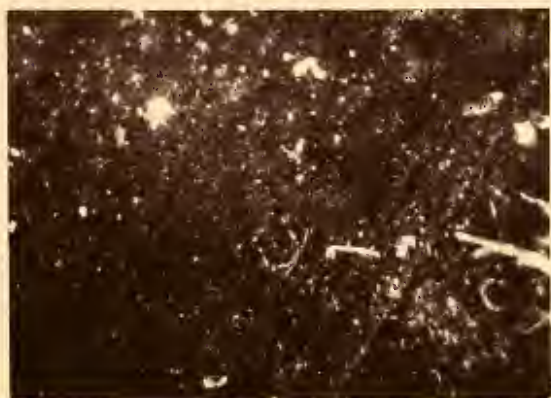

WHEELING LIMESTONE

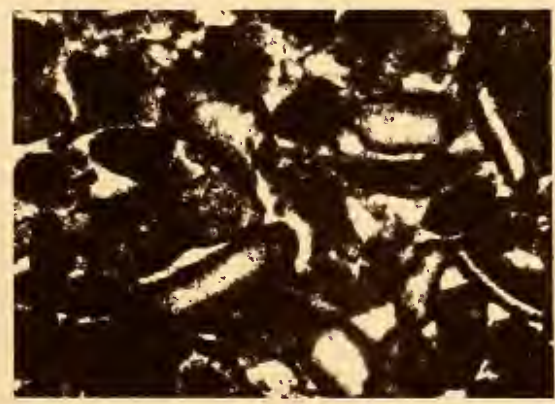

GREENCASTLE LIMESTONE

FIG. 24 PHOTOMICROGRAPHS OF THIN SECTIONS OF ROCK CORES $(9 O X)$ 
the rate of polishing should be used as a comparison, but at what range of polish? It would appear that the use of abrasives of a hardness similar to that of the aggregate should be satisfactory if the material is to be used alone. If the aggregate is to be blended, then use of an abrasive corresponding to the hardest material in the resulting mixture might be justified.

These tests point out the superiority of sandstone for skid resistance. The stone used here was very hard and did not show the particle expulsion type wear frequently assigned to sandstone. In fact, during the tests no apparent wear occurred on the sandstone although by the same procedure some of the limestones were worn away $3 / 16$ of an inch. The Bedford dolomite also resisted wear well and did not polish to the extent that the limestones did. 
USE OF BRUSH SURFACE ANALYZER

FOR PREDICTING SKIDDING RESISTANCE OF PAVEMENTS

Inspection of many pavements in service reveals the fact that coarse bituminous surfaces wear by erosion of the bituminous matrix from between the pieces of coarse aggregate. As this erosion progresses, more and more of the applied loads and the corresponding friction must be carried by the coarse aggregate. Obviously the friction characteristics of the pavement gradually become those of the coarse aggregate.

Frictional resistance can be considered as due to two factors: an inherent part due to the nature of the sliding materials, and a part due to mechanical interlock. The first of these should remain constant for a given material and type of tire rubber. The second should vary directly with the roughness of the surface. If these assumptions are true, the relative resistance value for a particular aggregate should vary directly with surface roughness.

It would be advantageous to have some means of determining the basic roughness of aggregates. Ideally, such a method should be quick, economical, reliable, and simple. The Brush Surface Analyzer appeared to fit these conditions. This instrument was developed for measuring surface roughness of machined surfaces.

The Brush Surface Analyzer is shown in Figure 25 and consists of a motor-driven pickup unit, an amplifier, and a recorder. The pickup 


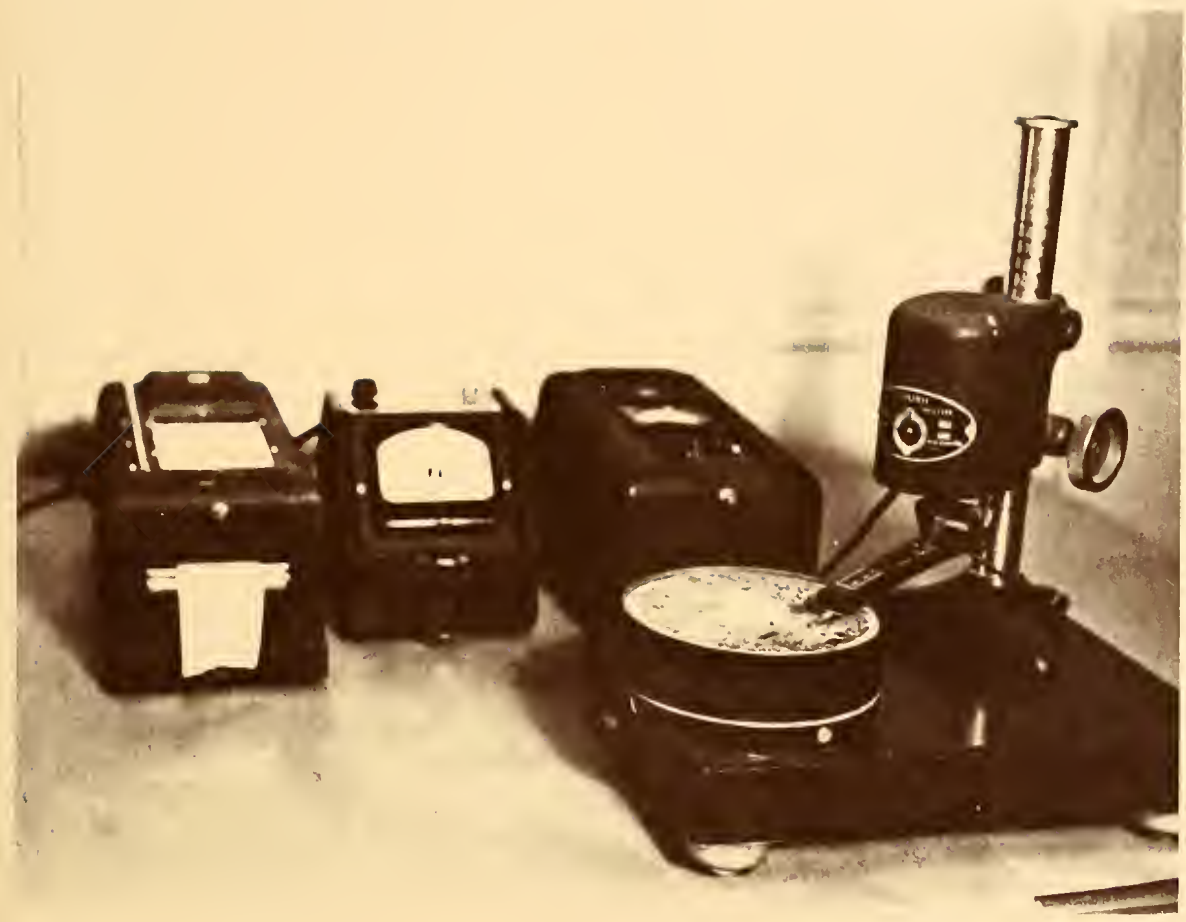

Figure 25. Brush Surface Analyzer 
resembles a phonograph arm in that it has a diamond stylus which moves up and down over the roughness and generates an electric signal. This signal is fed into the amplifier and, after magnification, activates the recorder. When sliding over the surface to be measured the tracer arm is supported by a small smooth shoe, thus establishing a base level to which the actual movement of the needle is referenced. The traversing is accomplished by a motor-driven cam which moves the arm through a two-millimeter stroke at a very slow speed. The oscillograph draws a line on a moving paper tape. This line corresponds to an enlarged image of the profile of the surface traversed. See Figure 26. The sensitivity of this instrument is such that it can measure roughness in the range of one to 300 microns.

This instrument was not satisfactory for measuring the surface of the fine sand mixes. The unit load under the sharp-pointed diamond is high and the needle tended to follow the soft bituminous binder material instead of traveling up and over the sand grains. Speeding up the rate of travel eliminated this trouble but caused new problems. The momentum of the needle after impact with the sand grains caused over run of the mechanism and the profile was exaggerated.

Measurements were attempted for the surface texture of rock cores at different degrees of polish. After each polish, each core was traversed at three locations near the center of the test area. When the polishing was completed, recorded tapes were available for a range of relative reistance values from 27 to 84 . All attempts to $f$ ind a means of correlating the shape of the profiles recorded on the tape to the relative resistance value measured at the same degree of polish have failed. Relative size, distribution, frequency, differences in height, 


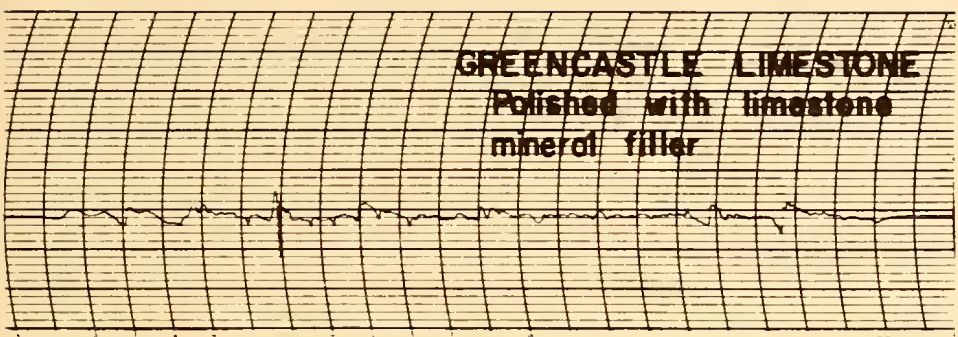

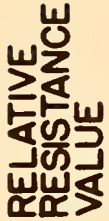

27
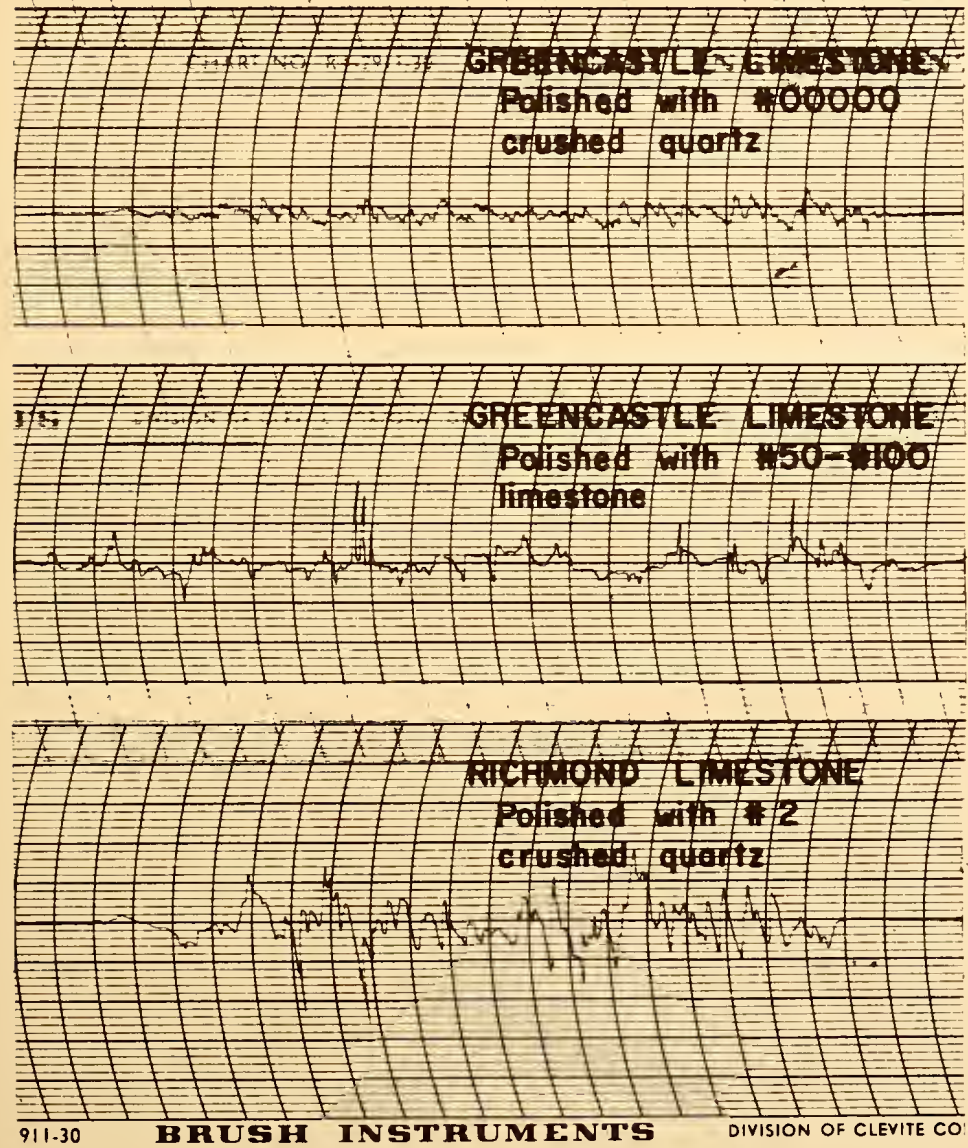

\section{FIG. 26 OSCILLOGRAMS FROM THE BRUSH SURFACE ANALYZER}


or combinations of these factors do not always correspond to the relative resistance values. Measurements of these factors are listed in Table 12 of Appendix C.

Visually, differences can be seen between the profiles shown in Figure 26. Generally speaking the profiles for surfaces of low relative resistance are characterized by subdued, rounded peaks. The profiles of most surfaces of high resistance show strong, sharp peaks. The peaks frequently appear to be closer together on the profiles of highly resistant surfaces than on surfaces of low resistance. While this relationship seems to be true in general, occasional surfaces give profiles which when ranked by relative resistance values do not fit smoothly into these concepts.

Several explanations for the fact that only partial agreement was found between surface roughness as measured by the Brush Surface Analyzer and relative resistance values could be advanced. Possibly the roughness meter did not measure the true roughness. The high needle pressure may have forced the tip to follow soft material and thus avoid the sharp peaks. However, the recorded profiles appear to include the peaks. Another possibility is that the relative resistance values varied from the correct value due to variations in conditions. Changes in ambient temperature and in the number of tests performed before the shoe is redressed are two such conditions. The peculiar manner in which relative resistance values varied with degree of polish in Figures 22 and 23 points to the possibility that some other variable was acting. The difficulties inherent in controlling conditions during skid testing, make it highly desirable to pursue the measurement of roughness as a measure of skid resistance. 
SUMMARY OF PESUITS

The skidding resistance of a fine bituminous mixture is affected by many surface factors both of the aggregate and of the mix. These factors are closely inter-related and any change in one may result in a change in the effect of another. In the laboratory testing program upon which this dissertation is based, each specimen contained only one type of aggregate. No blending of aggregate other than to control gradation was attempted. All measurements of skid resistance were made by means of the laboratory skid-test machine and should be considered as relative measurements. They should not be interpreted either as absolute values or as coefficients of friction. The measurements were made with water constantly supplied to the surfaces. The angular velocity of the test specimen was held constant at 2,500 rpm. Due to the rotary motion between the test shoe and the specimen, the actual skidding speed varied from approximately $27 \mathrm{ft}$. per sec. at the inner edge of the test area to $55 \mathrm{ft}$. per sec. at the outer edge. The following summary of results is presented:

1. For every series of gradations based on a particular maximum size of Lafayette sand, the skid-resistance value increased substantially as the fineness modulus decreased. The greatest change occurred in the series using No. 4 - No. 8 material as the maximum size. For this material the relative resistance value increased from 45 at a fineness modulus of 5.25 to a value of 81 at a fineness modulus of 3.3 . 
The rates of increase in relative resistance value for all maximum sizes used were nearly identical. As the maximum size decreased, the total change in resistance values became smaller because of the accompanying decrease in the possible range of fineness modulus.

2. Silica sand gave higher relative resistance values than the two Indlana sands used. The difference was small at the No. 4 - No. 8 size and increased as the sand mixes became finer. The importance of silica content then depends on gradation. Changing the fineness modulus of the silica-sand mix from 5.55 to 2.55 caused a greater change in relative resistance than did changing the silica content of the mix from 99 percent to 60.9 percent. The Greencastle limestone sand was always lower in skid resistance than the silica and glacial sands throughout the range of sizes used.

3. Angular silica sands gave higher relative resistance values initially than round silica sands of the same size, but the angular silica polished more rapidly and ultimately gave lower values. Artificially rounded limestone sand and angular limestone sand gave nearly identical results.

4. As the maximum size sand particles used in the mixes decreased, the relative resistance values increased. A limit for this trend was found for the crushed silica sand, and presumably exists for any other material, beyond which the relative resistance values decreased. The optimum relative resistance value for the crushed silica sand occurred for the $\mathrm{mix}$ in which No. 30 to No. 50 size material predominated and was also the maximum size used. This corresponds to a height of roughness of 0.009 inches spaced at 0.018 inches. For round sands, the 
optimum height of roughness is indicated to be less than that for the crushed material.

5. Changing the penetration grade of asphalt used from 65 to 143 did not cause a change in the relative resistance values of the fine bituminous mixes made from Lafayette sand.

6. Increasing the area of stone in contact with the test shoe, while holding the total test load constant, increased the relative resistance value. This result was determined using a variable area of coarse aggregate and was most pronounced in the range of $20-50$ percent aggregate in contact with the test shoe. Attempts to make similar measurements on fine mixes by using light reflection as a measure of aggregate area were not entirely successful, but the degree to which a fine bituminous surface reflects light appears to be related to the relative resistance value for the surface.

7. As was to be expected, an increase in normal pressure on the surface tested gave an increase in relative resistance value. The rate of increase was essentially the same for a solid limestone core as for a limestone specimen surface made of discrete pieces.

8. Changes in the angle between the plane on the side surface of the aggregate piece and the plane of the pavement surface did not correlate with changes in relative resistance values. An increase in the total length of aggregate edges in the specimen surface did raise the relative resistance values slightly.

9. Efforts to polish a core specimen of hard sandstone did not result in lower relative resistance values. The same polishing effort applied to a limestone core specimen reduced the relative resistance value by as much as fifty percent. The use of different abrasives 
changed the rate of polish. Hard abrasives resulted in rapid polish when the texture of the surface being polished was greater than the abrasive size. Soft abrasives produced more rapid polish than hard when the size of the asperities making up the surface texture was less than the abrasive size.

10. Profiles showing aggregate roughness as plotted by the Brush Surface Analyzer had different characteristics depending on the aggregate and the degree of polish at the time of measurement. Generally, the recorded profile can be used visually for an indication of skid resistance. 


\section{CONCLUSIONS}

The conclusions presented here are based entirely on a theoretical review of friction and the laboratory study made on the factors discussed. The trends found in the results have not at this time been verified by field tests. It is entirely possible that differences between the laboratory methods and the actual field conditions have led to misleading conclusions. Within the limitations of the test procedures and for the range of materials and conditions utilized, the following conclusions are considered valid.

The skid resistance of fine bituminous pavements can be largely controlled by the gradation of the $m i x$. If the maximum size aggregate is below the No. 4 sieve, the skid resistance will increase for finer mixes. The greatest change was observed in the mixes containing No. 4 - No. 8 material as the maximum size, but this was probably due to the greater change in fineness modulus possible as compared to the finer mixes. As the ultimate resistance reached for all Lafayette sand mixes was nearly the same, it is concluded that, as a given size of fine material is added to coarse mixes in order to lower the fineness modulus, the skid resistance of the mix gradually approaches that of the fine particles.

It is concluded that there is an optimum size of fine particle for any given aggregate which will produce maximum skid resistance under fixed conditions of test. For the conditions used in this study, 
this size is approximately 0.018 inches (asperity height of 0.009 inches) for crushed silica sand. In general, the optimum size for round sands is somewhat smaller.

For mixes using material with fineness modulus of approximately four or less, test results show that sand with a high silica content produces mixtures with superior skid resistance as compared to the other materials used. For fine mixes using material with fineness modulus greater than four, the relative resistance value for a specimen made from the high-silica sand is nearly the same as that for a like gradation of West lafayette sand. Glacial sands of the same gradation but containing widely different percentages of material insoluble in acid had relative resistance values of the same magnitude. Therefore, it is concluded that a wide range in silica content of natural sand has little effect on relative resistance values.

It is concluded that the shape of the sand particles has a greater effect on polish resistance than on the actual magnitude of skid resistance. Surfaces, which are initially skid resistant and are composed of hard aggregate, will remain skid resistant longer if the aggregate has a rounded shape when used. Regardless of shape, soft aggregate is not highly skid resistant. If angular when used, the soft material will quickly polish to a rounded shape. On the basis of this study, these conclusions with respect to particle shape must be limited to fine bituminous mixes.

For the test speed used in this study, it is concluded that surface asperities 0.004 inches or greater in height supply a degree of relief on the specimen surface sufficient to permit drainage of water from under the rubber shoe as required for contact between rubber and 
aggregate. If the rebound rate of the rubber used is sufficiently great, this conclusion should be valid at higher speeds and for smaller asperities.

According to the results of this laboratory study, within the range of penetration of 65 to 143 the grade of asphalt used has no direct effect upon skid resistance. Viscosity does affect compaction and thus indirectly the skid resistance. Lower compaction would result in less aggregate area in the pavement surface and lower skid resistance. Penetration may also affect skid resistance by varying the durability or resistance of the paving mix to weathering. If the rate at which sand particles leave the surface is altered, the skid resistance will also change.

The skid resistance of a surface containing coarse aggregate is dependent partially on gradation. If the same aggregate is to be used for all sizes, the $\mathrm{mix}$ which results in the greatest area of aggregate surfaces in contact with the tire should be used. When the coarse and fine aggregate are different, some experimentation may be required to determine whether more sand matrix or more coarse aggregate will give the best result. The relative importance of material versus gradation is a function of both type of material and particle size.

It is probable that all aggregate will polish to some extent. In order to maintain skid resistance over an extended period of time, a hard, polish-resistant aggregate is desirable. However, the hard aggregates normally available will eventually polish. If the parti? cles are expelled gradually, the deterioration of the skid-resistant properties by polishing will be reduced. The optimum rate of expulsion would then depend on the polish resistance of the mineral. 
Some better method of measuring the physical properties which give skid resistance is needed. The Brush Surface Analyzer gives indications of being potentially useful for this purpose since the size of roughness to be measured is within the range of its ability to measure. The difficulty in scaling the results must be overcome before such a method can be put to practical use. 
SUGGESTIONS FOR FUTURE RESEARCH

For many purposes laboratory tests are preferable to field tests. However, the question should be answered as to whether a laboratory test measures the quantity desired. To answer this question, further investigation into the nature of friction should be undertaken. Surely, one or more basic physical characteristics of the sliding surfaces determine the magnitude of frictional resistance. Identifying these factors and finding a measure for them should be the goal of research in this field.

It is conceivable that several years may elapse before the above is accomplished. In order to provide some control in the interim period further work with the existing machine might well be justified.

To meet these two conditions the following suggestions for further research are made:

1. The mechanics of the action of water in the reduction of skid resistance should be studied. Such a study should include measurements of the minimum thickness of water that is effective in reducing skid resistance and how tightly this water is bound to the surface. 2. A method of measuring or evaluating surface texture or roughness at the scale important in skid resistance should be developed (85). The Brush Surface Analyzer as used was not completely satisfactory. Regardless of other work, such measurements will be of importance in finding a solution to the skid-resistance problem. The 
topographic microscope described by Saur (72) or the profile method described by Write (89) might be extended to pavement surfaces. A surface permeameter using air or water could possibly be developed to measure roughness by frictional resistance to flow.

3. Studies should be made to find the rebound rate of rubber. What frequency of deformation can be applied to the rubber and still allow complete rebound to occur between the applications?

4. Rubber as used for a test shoe in laboratory skid resistance machines intended for comparing different surfaces should be studied. Heat and possibly work alter the character of rubber. Test values may be dependent on the history of or prior testing done with the test shoe.

5. The rapidly rotating disk used in the Purdue test machine could act as a centrifugal pump. If removal of water is of major importance, what is the effect of testing with the water under high velocity?

6. A study of polishing as it affects rock cores should be continued. Polish curves for some rocks show a tendency at a certain degree of roughness to develop more skid resistance with increased polishing. This does not seem realistic and should be investigated further. Much more information is needed about factors or characteristics of rocks which determine resistance to polish.

7. Field studies to verify laboratory results should be made periodically. Laboratory tests are designed to give the same relative results as field tests but field tests are needed for true comparisons. 
8. Studies should be undertaken to determine for normal aggregate shapes what part of the skid resistance is due to the nature of the surface of the aggregate particles and what part to aggregate shape.

9. Skidding speed may have an important effect on skid resistance. As the relationship may differ with surface texture, effect of speed during testing should be considered. Research to determine the relationship between speed and skid resistance would aid in future comparisons of results from the different test methods. 


\section{BIBLIOGRAPHY}

1. Agg, T. R., "Tractive Resistance and Related Characteristics on Roadway Surfaces," Bulletin No. 67, Iowa Engineering Experiment Station, 1924.

2. Agg, T. R., "Tractive Resistance of Automobiles and Coefficient of Friction of Pneumatic TIres," Bulletin No. 88, Engineering Experiment Station, Iowa State College, 1928.

3. Bird, G. and Miller, R. A., "Studies in Road Friction II, An Analysis of the Factors Affecting Measurement, "Road Research Technical Paper No. 2, Department of Scientiflc and Industrial Research, London, England, 1937 (H. M. Stationery Office).

4. Bird, G. and Scott, W. J. O., "Studies in Road Friction I, Road Surface Resistance to Skidding," Road Research Technical Paper No. 1, Department of Scientific and Industrial Research, London England, 1936 (H. M. Stationery Office).

5. Blok, H., "Fundamental Mechanical Aspects of Boundary Lubrication," Journal of Society of Automobile Engineers, Vol. 46, p. $54,1940$.

6. Bowden, F. P. and Bastow, S. H., "Physical Properties of Surfaces," Proceedings, Royal Society, London, England, Series A, Vol. 151, pp. 220-233, 1933.

7. Bowden, F. P. and Leben, L., "The Nature of Sliding and the Analysis of Friction," Proceedings, Royal Society, London, England, Series A, Vol. 169, pp. 371-391, 1938.

8. Bowden, F. P. and Ridler, K. E. W., "Physical Properties of Surfaces, III. The Surface Temperature of Sliding Metals, The Temperature of Lubricated Surfaces," Proceedings, Royal Society, Iondon, England, Series A, Vol. 154, pp. 640-656, 1936.

9. Bowden, F. P. and Tabor, D., "The Area of Contact Between Stationary and Between Moving Surfaces," Proceedings, Royal Society, London, England, Series A, Vol. 169, pp. 391-413, 1938.

10. Bradley, B. A. and Allen, R. F., "Factors Affecting the Behaviour of Rubber Tired Wheels on Road Surfaces, " Proceedings, Institution of Automobile Engineers, Vol. 25, pp. 63-92, 1930-31. 
11. Brown, M.G., Milliman, P., and Otto, G., "Michigan's Skid Testing Equipment," Report No. 294, Research Laboratory Division, Office of Testing and Research, Michigan State Highway Department.

12. Croce, K., "Measurements with the 'Stuttgart' Test Apparatus in Germany," Paper presented at the Flrst International Skid Prevention Conference, University of Virginia, 1958. (to be published).

13. Daube, J., "Facteurs Influencing the Coefficient of Transverse Friction," Publication F30/58, Center of Road Research, Brussels, Belgium, $19 \overline{58 .}$

14. Denny, D. F., "The Influence of Load and Surface Roughness on the Friction of Rubber-Like Materials," Proceedings, Physical Society of London, Sec. B, Vol. 66, pp. 721-727, 1953.

15. Derleux, J. B., "The Coefficlent of Friction of Rubber," Rubber Chemistry and Technology, Vol. 8, pp. 44l-442, 1935.

16. Dillard, J. H. and Alwood, R. L., "Field Study of Methods of Providing Sk1d-Resistant Roads," Progress Report No. 1, Virginia Council of Highway Investigation and Research.

17. Dillard, J. H. and Alwood, R. L., "Providing Skid-Resistant Roads in Virginia," Proceedings, The Association of Asphalt Paving Technologists, Vol. 26, pp. 1-22, 1957.

18. Eldredge, K. R. and Tabor, D., "The Mechanl sm of Rolling Friction, I. The Plastic Range," Proceedings, Royal Society, London, England, Series A, Vol. 229, pp. 181-198, 1955.

19. Flnney, E. A. and Brown, M. G., "Relative Skid Resistance of Pavements Based on Michigan's Experience," Report No. 295, Research Laboratory Division, Offlce of Testing and Research, Michigan State Highway Department.

20. Foster, B., "Tests to Determine the Adhesive Power of PassengerCar Tires," Technical Memorandum No. 1416, National Advisory Committee for Aeronautics, 1956.

21. Gehman, S. D., WIlkinson, C. S. Jr., and Daniels, R. D., "Smearing of Vulcanized Rubber," Rubber Chemistry and Technology, Vol. 28, pp. 508-518, 1955.

22. Giles, C. G., "Some European Methods for the Measurement of Skidding Resistance," Paper presented at the First International Skid Prevention Conference, University of Virginta, 1958 (to be published)

23. Giles, C. G., "Some Laboratory Methods for the Investigation of Skidding Problems," Paper presented at the First International Sk1d Resistance Conference, University of Virginia, 1958 (to be published). 
24. Giles, C. G., "Standards of Skidding Resistance, Some European Points of View," Paper presented at the First International Skid Prevention Conference, University of Virginia, 1958 (to be published).

25. Giles, C. G., "The Skidding Resistance of Roads and the Requirements of Modern Traffic," Proceedings, Institution of Civil Eng1neers, Vol. 6, pp. 216-249, 1957.

26. Giles, C. G. and Lander, F. T. W., "The Skid-Resisting Properties of Wet Surfaces at High Speeds," Journal, Royal Aeronautical Society, London, England, Vol. 60, pp. 83-94, 1956.

27. Giles, C. G. and Sabey, B. E., "Accidents Reports and Skidding Accident Sites," Final Report, The Public Works and Municipal Services Congress, London, England, pp. 355-373, 1956.

28. Giles, C. G. and Sabey, B. E., "A Note on the Problem of 'Seasonal Variation" in Skidding Resistance," Paper presented at the First Intermational Skid Prevention Conference, University of Virginia, 1958 (to be published).

29. Giles, C. G. and Sabey, B. E., "Recent Investigations on the Role of Rubber Hysteresis in Skidding Resistance Measurements," Paper presented at the First International Skid Prevention Conference, University of Virginia, 1958 (to be published).

30. Goetz, W. H. and Rice, J. M., "Factors Affecting the Measurement of Skid Resistance," Paper presented at the First International Skid Prevention Conference, University of Virginia, 1958 (to be published).

31. Goodwin, W. A. and Whitehurst, E. A., "A Review of Pavement SIIpperiness Testing in the United States Through Towed Vehicle Techniques," Paper presented at the First International Skid Prevention Conference, University of Virginia, 1958 (to be published).

32. Gough, V. E., "Tyre and Vehicle Behaviour," Automobile Engineer, Vol. 39, pp. 97-106 and pp. 139-145, 1949.

33. Gough, V. E. and Parkinson, D., "Dunlop Fatigue Test for Rubber Compounds," Transactions, Institution of Rubber Industry, Vol. 17, pp. $168-239,1942$.

34. Gray, J. E., "National Crushed Stone Association's Laboratory Method of Evaluating Slipperiness," Paper presented at the First International Skid Prevention Conference, University of Virginia 1958 (to be published).

35. Greenwood, J.A. and Tabor, D., "The Friction of Hard Sliders on Lubricated Rubber, the Importance of Deformation Losses," Proceedings, Physical Soclety of London, Vol. 71, Part 6, No. 462, pp. 989-1001, 1958. 
36. Grime, G. and Giles, C. G., "The Skid-Resisting Properties of Roads and Tyres," Proceedings, Institute of Mechanical Engineers, Automobile Division, Section No. 1, pp. 19-30, 1954-55.

37. Grunau, D. L. and Michael, H. L., "Skid Characteristics of Pavement Surfaces in Indiana," Bulletin No. 139, Highway Research Board, 1956.

38. Hample, W. G., "Friction Study of Aircraft Tire Material on Concrete," Technical Note No. 3294, National Advisory Cormittee for Aeronautics, 1955.

39. Harrin, E. N., "Low Tire Friction and Cornering Forces on a Wet Surface," Technical Note No. 4406, National Advisory Comittee for Aeronautics, 1959.

40. Havens, J. H., "Skid Prevention Studies in Kentucky," Paper presented at the First International Skid Prevention Conference, University of Virginia, 1958 (to be published).

41. Hveem, F. N., Zube, E. and Skog, J. B., "California Type Skid Resistance Tester for Field and Laboratory Use," Paper presented at the First International Skid Prevention Conference, University of Virginia, 1958 (to be published).

42. Johannsen, A. and Stephenson, E. A., "On the Accuracy of the Rosiwal Method," Journal of Geology, Vol. 27, pp. 212-220, 1919.

43. Lleó, A. and Escalera, J. L., "The Apparatus of the 'Laboratorio Del Transporte', Madrid, for Measuring Road Surface Friction," Paper presented at the First International Skid Prevention ConFerence, University of Virginia, 1958 (to be published).

44. Lodge, A. S. and Howell, H. G., "Friction of an Elastic Solid," Proceedings, Physical Society of London, Section B, Vol. 67, pp. 89-97, 1954.

45. Maclean, D. J. and Shergold, F. A., "The Polishing of Roadstone In Relation to the Resistance to Skidding of Bituminous Road Surfacings, " Road Research Technical Paper No. 43, Department of Scientific and Industrial Research, London, England, 1958 (H. M. Stationery Office).

46. Markwick, A. H. D. and Starks, H. J. H., "Stresses Between Tire and Road," Journal, Institution of Civil Engineers, London, England, Vol. 16, pp. 309-325, 1941.

47. Martin, G. E., "Apparatus for Determining Skid Resistance of Pavements," Proceedings, Highway Research Board, Vol. 17, pp. 121-134, 1937. 
48. Martin, G. E., "Report of Committee on Ant1-Skid Properties of Road Surfaces," Proceedings, Highway Research Bosrd, Vol. 19, pp. 126-128, 1939.

49. Martin, G. E., "Skid Resistance of Tar Road Surfaces," Proceedings, Highway Research Board, Vol. 14, pp. 217-219, 1934.

50. McConnell, W. A., "Traction and Braking Characteristics of Vehicles," Paper presented at the First International Skid Prevention Conference, University of Virginia, 1958.(to be published).

51. McKesson, C. L., "SIippery Pavements--Causes and Treatments," Proceedings, The Association of Asphalt Paving Technologists, Vol. 18, pp. 1-18, 1949.

52. McLaughlin, J.F. and Goetz, W. H., "Permeability, Vold Content, and Durability of Bituninous Concrete," Proceedings, Highway Research Board, Vol. 34, pp. 274-286, 1955.

53. Michael, H. L., "Effect of Pavement Type and Composition on Slipperiness, A Summary of Research in Indiana," Paper presented at the First International Skid Prevention Conference, University of Virginia, 1958 (to be published).

54. Mills, J. P. Jr. and Skelton, W. B., "Virginia Accident Information Relating to Skidding," Paper presented at the First International SkId Prevention Conference, University of V1rginta, 1958 (to be published).

55. Morgan, A. D., "Correlation of Roughometer and Skid Tests with Pavement Type, Design, and Mix," Bulletin No. 37, Highway Research Board, pp. 38-56, 1951.

56. Moyer, R. A., "A Review of the Variable Affecting Pavement Slipperiness," Paper presented at the First International Skid Prevention Conference, University of Virginia, 1958 (to be published).

57. Moyer, R. A., "Discussion of Report of Committee on Design," Proceedings, Highway Research Board, Vol. 14, pp. 223-224, 1934.

58. Moyer, R. A., "Motor Vehicle Operating Costs, Road Roughness, and Slipperiness of Various Bituminous and Portland Cement Concrete Surfaces," Proceedings, Highway Research Board, Vol. 22, pp. 1352,1942 .

59. Moyer, R. A., "Recent Developments in the Measurement of Road Roughness and Skid-Resistance," Proceedings, The Association of Asphalt Paving Technologists, Vol. 20, pp. 42-96, 1951.

60. Moyer, R. A., "Skidding Characteristics of Automobile Tires on Roadway Surfaces and Their Relation to Highway Safety," Bulletin No. 120, Iowa Englneering Station, Ames, Iowa, 1934. 
61. Moyer, R. A., "Skidding Characteristics of Road Surfaces," Proceedings, Highway Research Board, Vol. 13, pp. 123-168, 1933.

62. Moyer, R. A. and Shupe, J. W., "Roughness and Skid-Resistance Measurements of Pavement in California," Bulletin No. 37, Highway Research Board, pp. 1-35, 1951.

63. Nichols, F. P. Jr., "Further Studies on Skid Resistance of Virginia Pavements," Paper presented at the First International Skid Prevention Conference, University of Virginia, 1958 (to be published).

64. Norman, O. K., "Braking Distances of Vehicles From High Speeds," Proceedings, Highway Research Board, Vol. 32, pp. 421-436, 1953.

65. Olley, M., "Nat1onal Influences on American Passenger Car Design," Proceedings, Institution of Automotive Engineers, Vol. 32, pp. 531$546,1937-38$.

66. Orchard, D. F., "A Laboratory Invest1gation of Sk1dding on Roads," Paper No. 5530, Journal of Institution of Civil Engineers, Vol. 27, pp. 279-215, 1946-47.

67. Paustian, R. G., "Tractive Resistance as Related to Roadway Surfaces and Motor Vehicle Operation," Bulletin No. 119, Engineering Experiment Station, Iowa State College, 1934.

68. Pike, E. C., "Coefficients of Friction," Journal, Royal Aeronautical Soclety, London, England, Vol. 53, pp. 1085-1094, 1949.

69. Roth, F. L., Driscoll, R. L., and Holt, W. L., NFrictional Properties of Rubber," Journal of Research of the National Bureau of Standards, Vol. 28, pp. 439-461, 1942.

70. Ruefer, A. L., "Test Installations of Thin Silica Sand Asphalt Resurfacing," Bulletin No. 188, H1ghway Research Board, pp. 1-12, 1958.

71. Sabey, B. E., "Pressure Distribution Beneath Spherical and Conical Shapes Pressed into a Rubber Plane and Their Bearing on Coefficlents of Friction Under Wet Conditions," Proceedings, Physical Soc1ety, London, England, Vol. 71, pp. 979-988, 1958.

72. Saur, R. L., "Topographic Microscope," Review of Scientific Instruments, Vol. 29, p. 1023, 1958.

73. Sawyer, R. H., Batterson, S. A., and Harrin, E. N., "Tire-ToSurface Friction Especially Under Wet Conditions," Memorandum, 2-23-59L, National Aeronautics and Space Administration.

74. Schallamach, A., "The Load Dependence of Rubber Friction," Proceedings, Physical Society, London, England, Vol. 65, Sec. B., Part 9, p. 658, 1952. 
75. Shupe, J. W. and Goetz, W. H., "A Laboratory Method for Determining the Skidding Resistance of Bituminous Paving Mixtures,"

Proceedings, American Society for Testing Materials, Vol. 58, pp. 1282-1305, 1958.

76. Shupe, J. W. and Goetz, W. H., "A Laboratory Method of Evaluating Slipperiness," Paper presented at the First International Skid Prevention Conference, University of Virginia, 1958 (to be published).

77. Shupe, J. W. and Goetz, W. H., "A Laboratory Investigation of Pavement Slipperiness," Paper presented at the 38th Annual Meeting of the Highway Research Board, 1959 (to be published).

78. Shupe, J. W., "A Laboratory Investigation of Factors Affecting the Slipperiness of Bituminous Paving Mixtures, "Report, Joint Highway Research Project, Purdue University, 1958 (unpublished).

79. Shupe, J. W. and Lounsbury, R. W., "Polishing Characteristics of Mineral Aggregates," Paper presented at the First International Skid Prevention Conference, University of Virginia, 1958 (to be published).

80. Skeels, P. C., Stonex, K. A., and Finney, E. A., "Road Surface Friction from the Standpoint of Automotive and Highway Engineers," Proceedings, The Association of Asphalt Paving Technologists, Vol. 25, pp. 353-378, 1956.

81. Stinson, K. W. and Roberts, C. P., "Coefficient of Friction Between Tires and Road Surfaces," Proceedings, Highway Research Board, Vol. 13, pp. 169-184, 1933.

82. Tabor, D., "The Importance of Hysteresis Losses in the Friction of Lubricated Rubber," Paper presented at the First International Skid Prevention Conference, University of Virginia, 1958 (to be published).

83. Tabor, D., "The Mechanism of Rolling Friction, II Elastic Range," Proceedings, Royal Society, London, England, Series A, Vol. 229, pp. 198-220, 1955.

84. Trout, J. P. Jr., "NACA Research on Friction Measurements," Paper presented at the First International Skid Prevention Conference, University of Virginia, 1958 (to be published).

85. Verbeck, G. J., "The Camera Lucida Method for Measuring Air Voids in Hardened Concrete," Journal, American Concrete Institute, Vol. 18, No. 9, pp. 1025-1039, 1947.

86. Whitehurst, E. A. and Goodwin, W. A., "Pavement Slipperiness in Tennessee," Proceedings, Highway Research Board, Vol. 34, pp. 194$209,1955$. 
87. Wh1tehurst, E. A. and Goodwin, W. A., "Tennessee's Method of Laboratory Evaluation of Potential Pavement Slipperiness," Paper presented at the First International Skid Prevention Conference, University of Virginia, 1958 (to be published).

88. Williams, E. G. and Gregg, L. E., "Evaluation of Sandstone as an Aggregate in Plant Mix," Proceedings, The Association of As phalt Paving Technologists, Vol. 22, pp. 92-106, 1953.

89. Write, P. J.F., "A Method of Measuring the Surface Texture of Aggregate," Magazine of Concrete Research, Vol. 7, No. 2l, pp. 151-160, November 1955.

90. Zuk, W., "The Dynamics of Veh1cle Skid Deviation as Caused by Road Conditions," Paper, Virginia Council of Highway Investigation and Research, Charlottesville, Virginia, June 1958. 
․․… 


\section{Materials}

Brief descriptions are presented here for the materials used in the test specimens. The descriptions for the fine aggregates and the rock cores were prepared by Professor R. W. Lounsbury of Purdue University.

Fine Aggregates

Lafayette Sand Western Indiana Gravel Company, West Lafayette, Indiana

Glacial sand washed from terrace deposit of gravel

Approximately $60 \%$ quartz $20 \%$ carbonates

$10 \%$ feldspar

Richmond Sand Western Indiana Gravel Company, Richmond, Indiana

Glacial sand

Approximately $35 \%$ quartz

$45 \%$ carbonates

$10 \%$ feldspar

Silica Sand

Perry Silica Sand Company, Chillicothe, Ohio

Located approximately five miles south of the

limit of glaciation and, from topographic

location, probably is tertiary sand 
Rock Cores

Greencastle

Greencastle, Indiana Gray-green oolitic limestone

The texture of this rock is oolitic. It consists of ovate oolites of calcite 0.1 to $0.9 \mathrm{~mm}$. Iong in a sparse calcite matrix. Within the oolites calcite grains average about $0.02 \mathrm{~mm}$. In size. Notable graygreen color changes occur from one horizon to another in the beds which may vary from a fraction of an inch to two inches in thickness.

Richmond

Richmond, Indiana

Gray-green medium-grained limestone with dolomite lenses

The rock is a medium-grained bioclastic limestone. The clasts are chiefly fossil fragments up to $0.1 \mathrm{~mm}$. in size, and vary considerably in shape. Rectangular, ovate, rod-shaped and even circular clasts of calcite occur in a matrix of calcite. Lenses and stringers of very fine dolomite up to an inch thick are intercalated in the limestone.

Wheeling Wheeling, West Virginia Very fine-grained limestone Its texture is aphanitic, and its composition is calcite grains less than $0.01 \mathrm{~mm}$. In diameter. Set in this matrix are occasional traces of small shell fragments about 0.1 to $0.2 \mathrm{~mm}$. Iong. Thickness of the thin beds is usually less than $1 \mathrm{~mm}$. 
Bedford

Bedford, Pennsylvania

Fine gray dolomite

This rock has a crystalline granular texture, and consists of interlocking dolomite grains of approximately $0.02 \mathrm{~mm}$. diameter. Some of the larger grains range up to $0.1 \mathrm{~mm}$. , and there is some detrital quartz. The rock is thin-bedded in laminae generally less than $1 / 16$ inch thick.

Medina Medina, New York Fine red sandstone

This rock has a clastic texture, and consists chiefly of angular to subangular quartz grains in a hematitic cement. Largest quartz grains are about $0.3 \mathrm{~mm}$. in diameter, but the average grain size is about $0.1 \mathrm{~mm}$. A small amount of feldspar is present as a detrital mineral and there is some calcite in the cement. The bedding is thin, usually a fraction of an inch in thickness, and some crossbedding is present. 


\section{Asphalts}

The asphalts used were supplied by the Texas Company, Port Neches, Texas. The following data for the three grades of asphalt used were supplied by the Texas Company:

Texaco Paving Cement, grade

Specific Gravity, $77^{\circ}$ F

Softening Point, Ring and $\mathrm{Ball},{ }^{\mathrm{O}} \mathrm{F}$

Ductility, $77^{\circ} \mathrm{F}, 1 \mathrm{~cm} . / \mathrm{min} ., \mathrm{cm}$.

Penetration

$77^{\circ} \mathrm{F}, 100$ grams, 5 seconds

Penetration

$32^{\circ} \mathrm{F}, 100$ grams, 5 seconds

Penetration

$115^{\circ} \mathrm{F}, 100$ grams, 5 seconds

Flash Point, $C O C$, OF

Loss, $50 / 5 / 325^{\circ} \mathrm{F}, \%$

Penetration of Residue

$77^{\circ} \mathrm{F}, \%$ of Original

Solubility in $\mathrm{C} \mathrm{Cl}_{4}$, \%

Oliensis Spot Test

$\begin{array}{ccc}65 & 96 & 130 \\ 1.019 & 1.010 & 1.008 \\ 125 & 118 & 109 \\ 200+ & 200+ & 148\end{array}$

65

93

143

20

28

Soft Soft Soft

$570 \quad 565 \quad 570$

$\begin{array}{lll}0.02 & 0.03 & 0.02\end{array}$

92

91

90

$99.82 \quad 99.86 \quad 99.83$

Neg. Neg. Neg. 
APPENDIX B

TEST PROCEDURES 


\section{Preparation of Test Specimens}

Nost of the fine material arrived at the laboratory directly from outside storage and so was first placed in the aggregate drying oven. After drying, the fine aggregate was passed through the series of sieves listed in Table 13 of Appendix C using a ten-minute period in a Ro-Tap sieve shaker. Angular fine aggregate was prepared by crushing larger pieces through an Iler Improved Grinder manufactured by the Fen Machine Company of Cleveland, Ohio. This machine is a rotary disk type pulverizer. The crushed material was then sieved in the same manner as the sand.

For each specimen, the weights of materials required were weighed with an accuracy of \pm 0.1 percent. The material and an adequate amount of as phalt were heated to $325^{\circ} \mathrm{F}$. in a closed oven. When this temperature was reached, the aggregate was placed in a preheated mixing bowl and the asphalt then weighed into it. Mixing was carried out for two minutes at slow speed in a 6-at. modified Hobart electric mixer.

Most of the specimens were made in two layers in order to save on the amount of sieving required to secure the fine sizes of aggregate. The bottom one inch of the mold was filled with a base course of 50 percent $1 / 2$ to $3 / 8$ inch gravel, 50 percent sand passing a No. 8 sieve and $51 / 2$ percent by weight of the aggregate of $85-100$ penetration asphalt. The upper layer consisted of one inch of the mix under test. This use of two layers also permitted the testing of some fine mixes that would not have been stable in thick layers. 
Compaction as carried out by Shupe (78) gave somewhat erratic results when applied to the fine mixes, apparently depending on the energy expended by the vibrator operator. Various means of securing a standard degree of compation were tried and the results are listed in Table 14 of Appendix C. The small jack frame and Cleveland vibrator shown in Figure 27 were used for the standard method of compaction because of ease and rapidity of the operation and satisfactoriness of the results. The compaction pressure was held at 48 psi for thirty seconds to give the particles an opportunity to reorient and was then increased to 275 psi for thirty seconds, with the vibrator operating throughout. During this compaction the mix surface was confined under a 1/2-inch plate, 1/8-inch smaller in diameter than the inside diameter of the mold.

In detail the molding procedure was:

1. Place material uniformly into the hot mold

2. Place preheated plate on surface of specimen

3. Move assembly of mold, $\operatorname{mix}$ and plate into the jacking frame and plumb the vibrator

4. Raise jack pressure to 150 psi on the gauge

5. Vibrate for 30 seconds

6. Raise jack pressure to 750 psi on the gauge

7. Vibrate for 30 seconds

8. Cool for $1 \mathrm{hr} .15 \mathrm{~min}$.

9. Roll for two mirutes in the Mini-track under 100 pounds laad

The rolling was intended to close up the surface and orient the particles parallel to the surface. Flexing of the tapered rubber rollers used on coarse mixes caused part of the roller to slip. This 


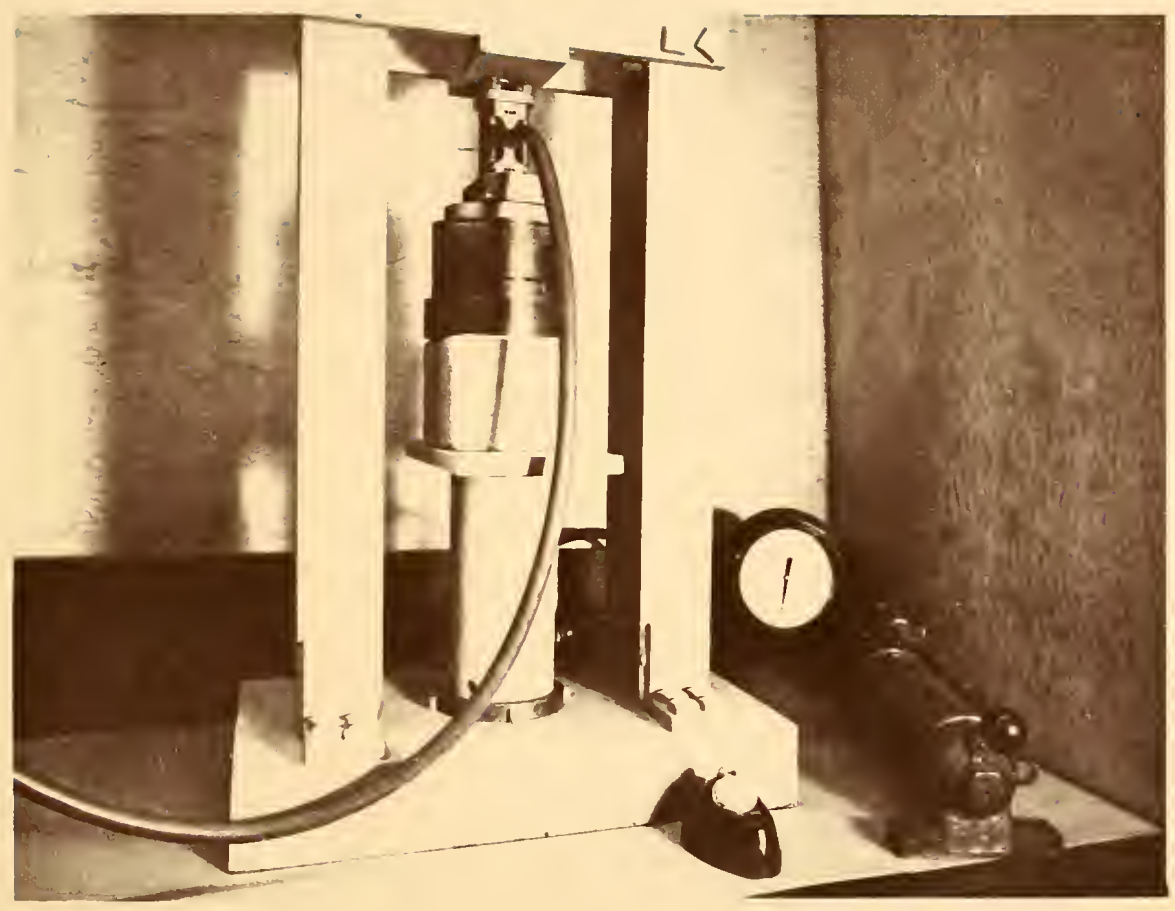

Figure 27. Equipment for Molding Laboratory Specimens 
did not affect coarse mixes but did tend to abraid the fine surfaces. For this reason steel rollers were substituted which could slip without causing damage (see Figure 28). After rolling, the specimens were cooled overnight at room temperature.

\section{Testing}

All skid-resistance measurements of the specimens were carried out in the skidding resistance machine developed by Shupe (78). See Figure 29. Several modifications were made to the machine which did not change the basic principle but did simplify operation. The machine consists basically of a means of pushing a rubber test shoe against a rapidly spinning pavement specimen and measuring the frictional drag or torque on the shoe. Skid-resistance determinations were made on each specimen in an 'as rolled' condition and again after the specimen surface had been polished.

The test shoes used for coarse surfaces had elght slots $3 / 8$ ths of an inch wide to permit water to be distributed to the pavement surface. This meant that at the extreme radius of the testing shoe approximately two inches of rubber passed over every point in the pavement between rewettings by water in the slots. The water was removed from the fine pavement surfaces efficiently enough to cause both the pavement and the shoe to overheat. To remedy this situation the shoes were redesigned to have sixteen slots $3 / 16$ th of an inch wide (see Figure 30). Some trouble was still encountered with a few of the finer surfaces. There seems to be no reason that the redesigned shoe should not be used for coarse surfaces. 


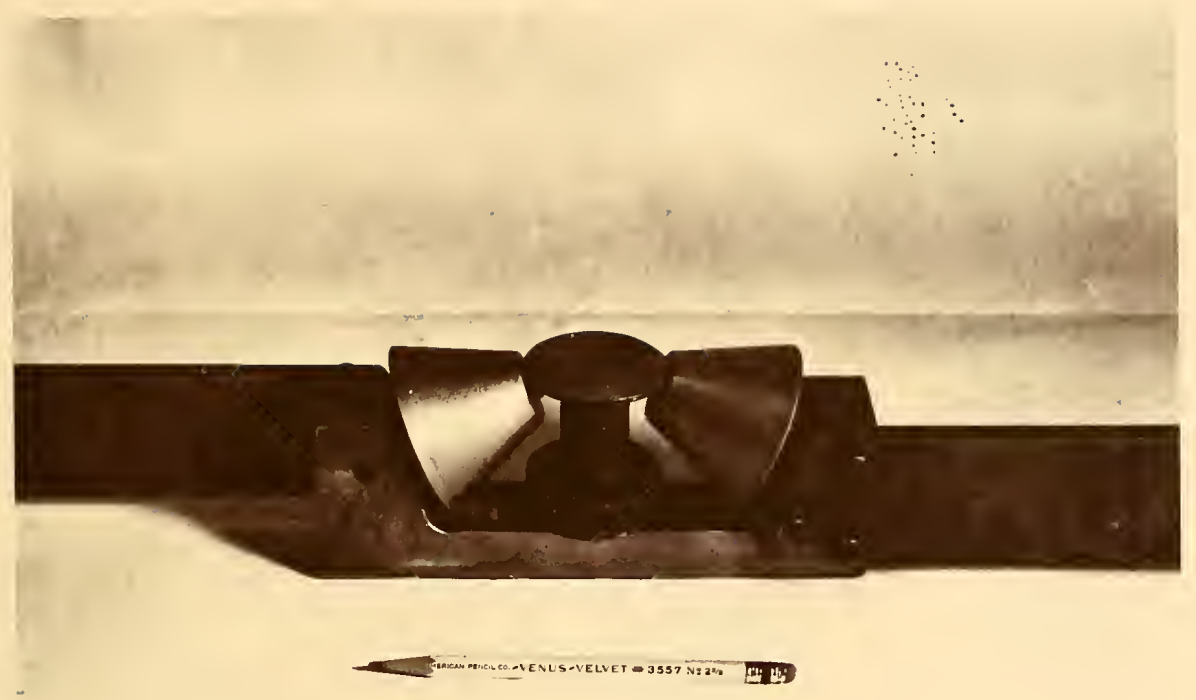

Figure 28. Laboratory Rollers 


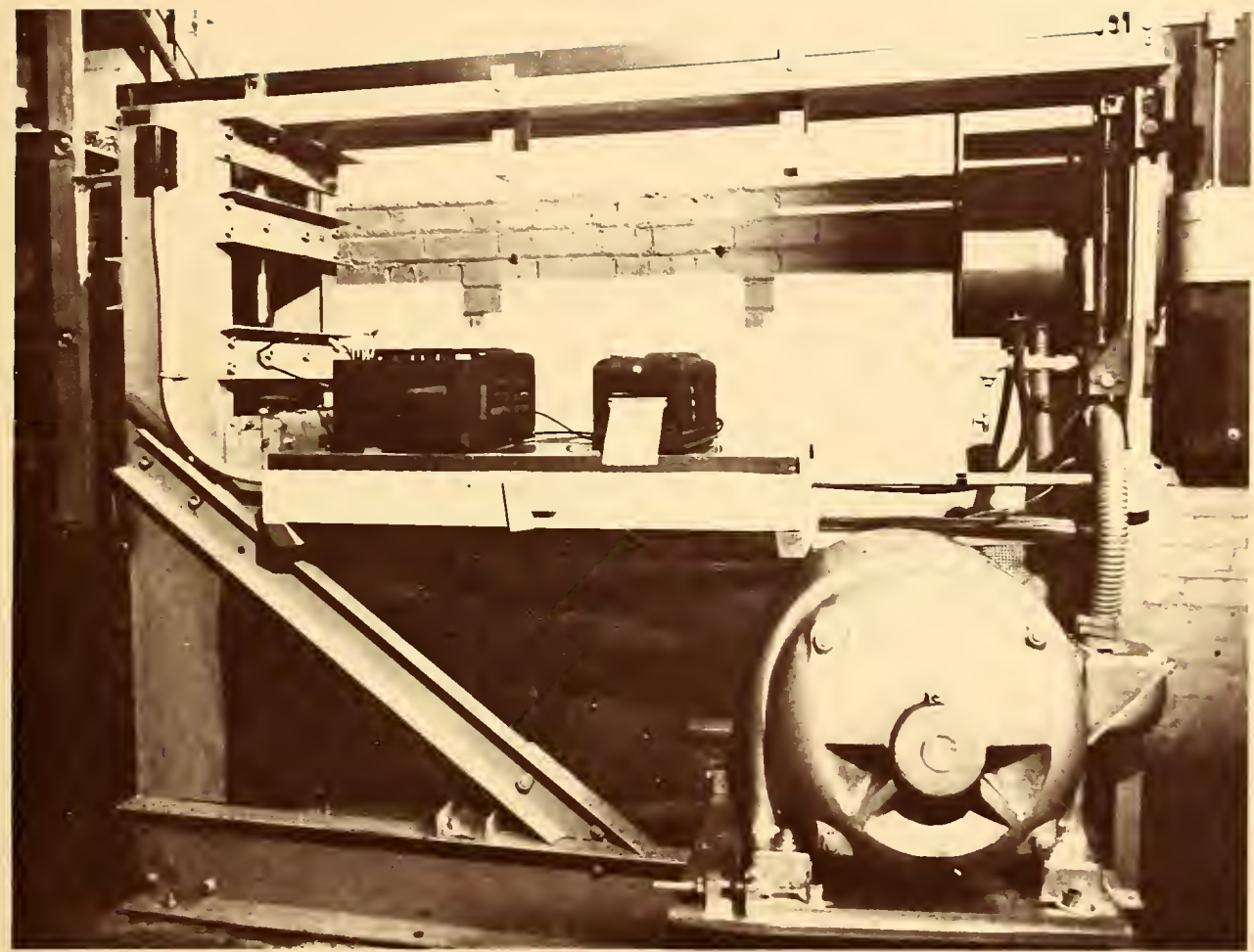

Figure 29. Laboratory Skid Resistance Machine 
Figure 30. Test Shoes Used in the Laboratory Skid Resistance Machine 
The machine was originally planned to have an operator manually raise and lower the test load. Although the lever system reduced the magnitude of the load required, it was still necessary to handle a weight of approximately fifty pounds. Many of the fine sand surfaces withstood skidding forces well but were destroyed if the weight was dropped, forcing the shoe suddenly onto the sand surface. Consequently, an air-operated cylinder was installed to raise the test load and beam. By placing the air cylinder under the beam, air pressure was used only for raising and holding the beam. By leaving a small bleeder valve constantly open the air pressure in the cylinder quickly faded when the valve in the air supply line was closed. Thus when the air was turned of $f$, springs retracted the air piston and the beam floated free retaining all of the advantages of a constant load as supplied by a dead weight system. The rate of load application was readily controlled by a needle valve in the bleeder line. For the tests reported in this study, the load on the test shoe was built up during a onesecond interval and was held for two seconds giving a test-load cycle of three seconds.

Attempts to calibrate the recorder against a standard pavement sample were not satisfactory. By so doing, the calibration reflected any change in the standard surface due to accumulative polish from repeated calibration skids. To avoid this variation the recorder was calibrated each day against a standard high-precision resistor. This is an arbitrary standard but one that did not change. Using a 125,000 ohm resistor and the attenuation set to give five major divisions on the tape resulted in the same calibration as used by Shupe (78). 
All tests on the fine bituminous mixes were performed at a test load of approximately 406 pounds or $28 \mathrm{psi}$ on the test surface. The tests on the rock cores and the edge series were conducted at a total load of 463.7 pounds which corresponds to a pressure of 32 psi for the solid cores.

\section{Polishing}

When planning equipment for polishing skid-resistance specimens, some consideration should be given to the action of loaded rubber tires as applied to the polishing of pavements. The tread area of a normal tire is in the form of an arc between the two sidewalls. As the tire is placed on a smooth surface and loaded, the arch must change to a straight line and the sidewalls must conform to a smaller radius of curvature than was present in the unloaded condition. Considering bending of a transverse section through the tire trear, it is obvious that the tread surface is on the compression side and the fabric on the tension side. If the fabric prevents elongation of the tension side, then shortening must occur on the compression side and a tendency is present for parts of the tread surface to move laterally with respect to the pavement surface.

The diameter of the tire measured at the edge of the tread is smaller than that at the center of the tread. As the wheel rolls on the pavement, the center of the tread will strike the pavement at a point ahead of where the edges strike and leave the pavement at a point behind that where the edges leave. It is then evident that some parts of the tread must be constantly sliding longitudinally on the pavement. Due to the random spacing of vehicles within the lane width, 
much of the pavement must be subjected to both transverse and longitudinal scuffing. If a laboratory polishing procedure is to give skid results of the correct relative value, then the polishing action must be such that the abrasive does not leave scoring in one direction. Skidding at right angles to such scoring would set up a chattering action and skidding parallel would have much the effect of riding on rails. Either result would be deceptive.

The method of polishing specimens in the skid machine did leave scoring in a circular pattern which would then be parallel to the direction of skidding during the test. For this reason a new polishing procedure was developed based on the use of a small rotating polishing shoe carried in the chuck of a drill press. See Figures 31 and 32. The pavement sample was placed on a free-turning table with the center of rotation located such that the polishing shoe covered the width of the annular test area. During the polishing, the shoe rotated about its own axis and the friction between the shoe and the specimen caused the specimen to rotate about its axis, giving a compound motion that caused the pavement to be subjected to polish in all directions.

It was necessary to arbitrarily choose both a time and load for this polishing action. For this purpose a group of mixes was prepared and the relative resistance values compared after different times of polishing. The polishing times and corresponding relative resistance values are given in Table 15 of Appendix C. Figure 33 shows the relationship of polishing time to relative resistance value. Zero on the time scale indicates tests carried out on the specimens in an 'as rolled' condition. At first, polishing raised the resistance of all the specimens. Continued polishing caused a gradusl decrease in the 


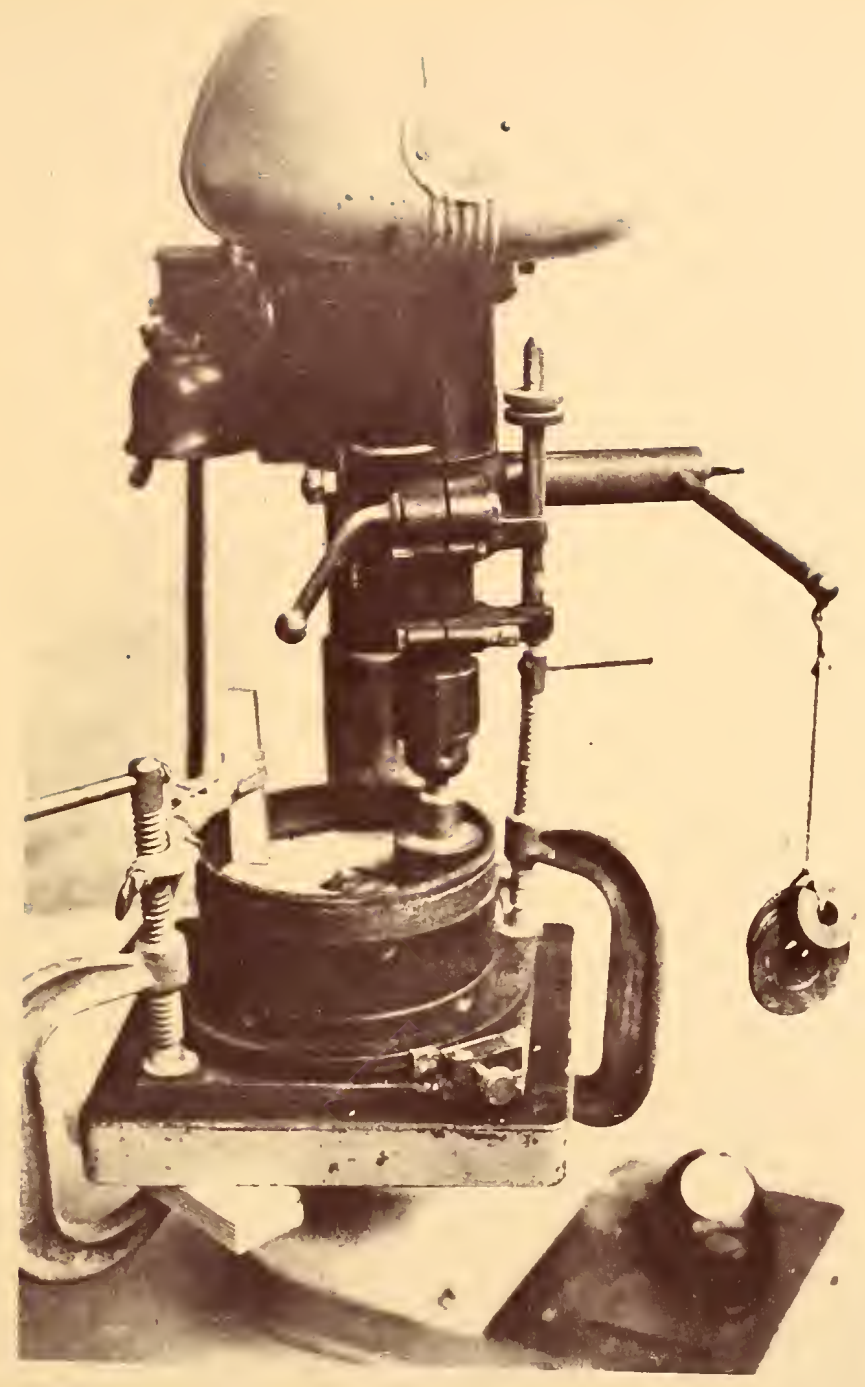

1

Figure 31. Drill Press Setup for Polishing 

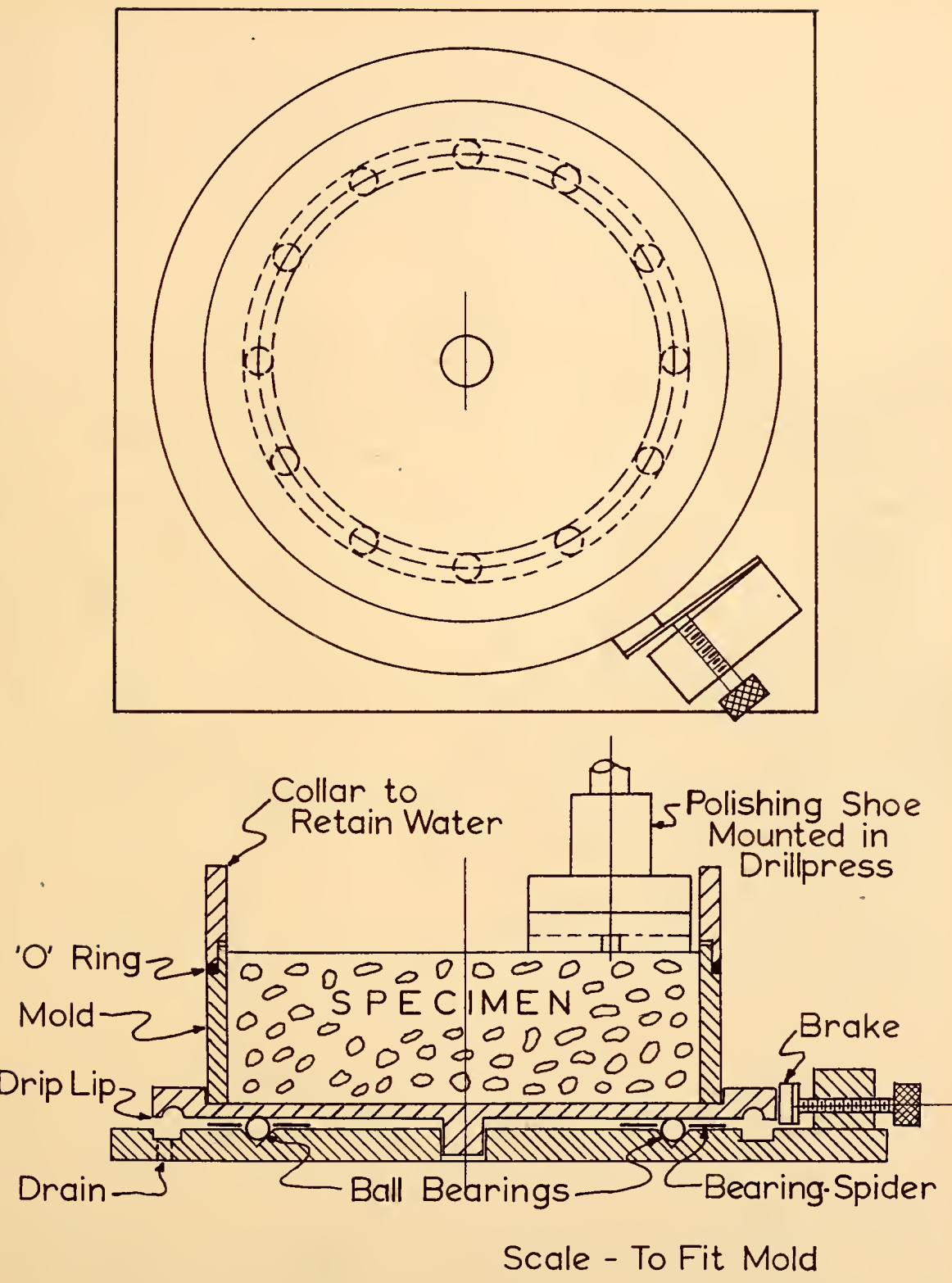

FIG. 32 DIAGRAM OF POLISHING TURNTABLE 


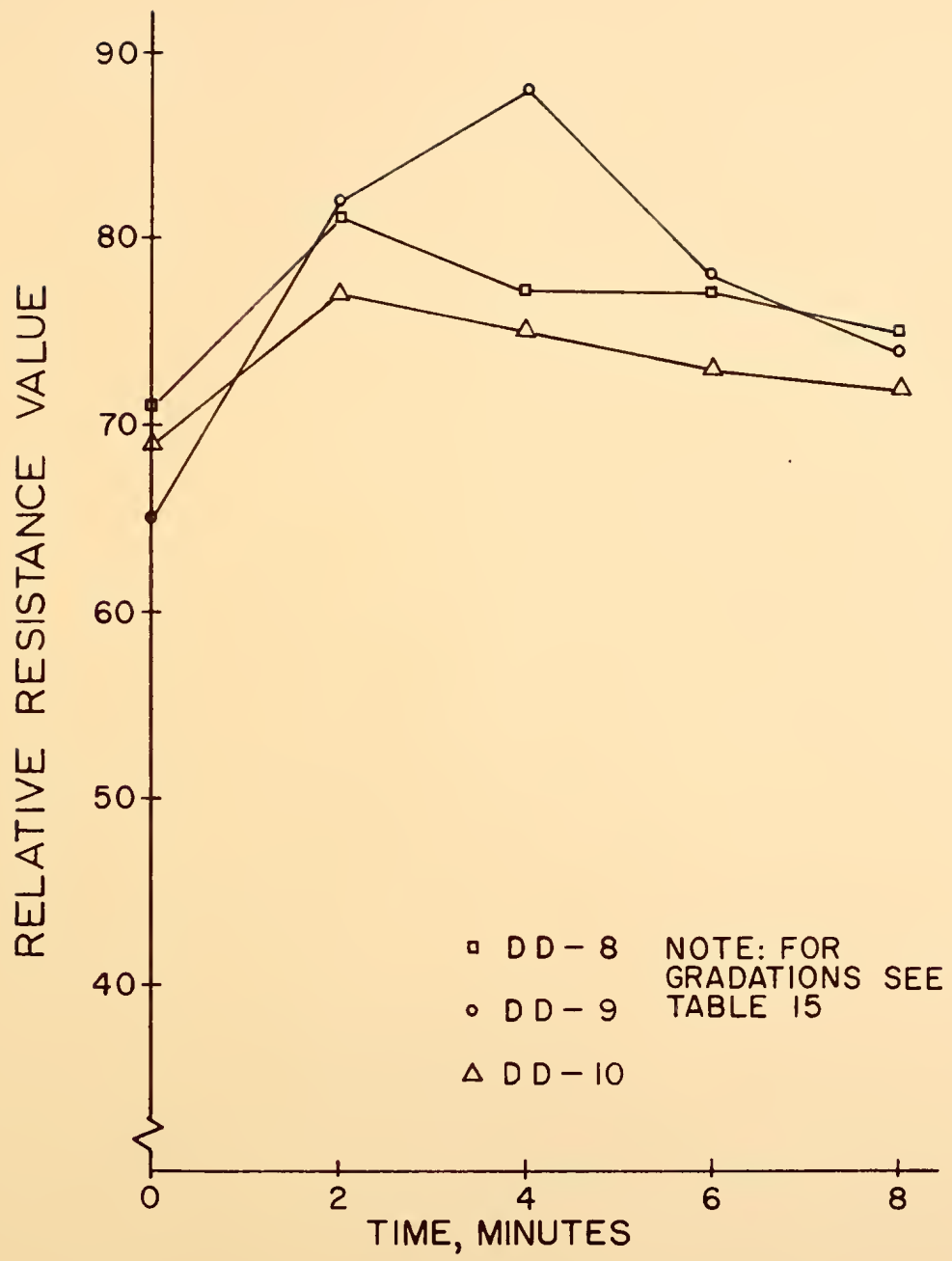

FIG. 33 VARIATION IN SKID RESISTANCE WITH TIME OF POLISHING 
relative resistance values. From this curve it was decided to test the specimens after both four minutes and eight minutes of polish. No. 000 crushed quartz was used for the first polish and No. 00000 crushed quartz for the second. Water was used as a cooling and lubricating agent throughout all polishing to prevent overheating.

Details of the polishing equipment are shown in Figure 32. The drill press spindle turned at $875 \mathrm{rpm}$ while a vertical force of 5.5 pounds forced the shoe against the specimen. The rate at which the specimen turned was controlled by varying the brake pressure applied to the edge of the rotating plate. The polishing shoe makes the same number of passes over any given portion of the specimen regardless of the rate at which the table rotates. In practice the braking force on the table was increased until the table slowed to a speed at which the abrasive and water slurry was not thrown from the mold collar.

The quartz abrasives stated above were used for all sand asphalt mixes. Gradations of the quartz abrasives are given in Table 11 of Appendix C. For the rock-core polishing study, other abrasives were used as noted.

\section{Test Conditions}

Certain shortcomings or questionable factors concerning the laboratory skid-testing machine came to light during this study. These factors are mentioned here as an aid to future investigators who may continue this work. The basic design of the machine does not permit ready modification to alter these factors.

Spinning the pavement sample at high speed creates the problem of excessively high centrifugal forces set up within the sample mass. 
Laboratory molded specimens of low stability tend to flow outward causing the surface to bulge near the mold. If tested in this bulged condition, the distribution of the normal pressure and, consequently, of the friction forces from the test shoe is unknown. It is then impossible to compare test results as the torque measured by the calibrated electronic system will be affected by the effective moment arm of the frictional force.

Frequently, field cores from deslicking mixes could not stand the centrifugal force. The thin layer of sand mix was thrown of $f$ before tests could be completed. These same mixes served satisfactorily in the field with no visual crowding or shoving under heavy traffic.

Spinning the pavement causes undesired forces in the water applied to the surface. Drag between the pavement and this water sets up a slinging action much like that developed by the impeller of a centrifugal pump. It is possible that the water film is not continuous at all points on the test specimen. Under such a pumping action cavitation may occur at outer areas of the specimen. The water travels radially across the pavement surface at high velocity. As the velocity set up in surface water under the pressure of a rubber tire may be important in determining skid resistance, the condition cited here may be an important consideration in the use of this type of apparatus.

At 2,500 rpm, a three-second test cycle, and a sixteen-segment test shoe, each point in the specimen is subjected to a minimum of 2,000 sheảr forces per test. This is very severe testing as compared to field tests.

The shape of the segmented test shoe possibly causes undesired effects. Each segment is tapered in such a way that the width at the 
outer end is approximately three times that at the inner ends. As the shoe is made of rubber, the deformation of any point on the surface of the shoe is a function of lateral support as well as normal pressure. Consequently, for each rubber sector, the narrow end deforms more readily than the wide end. Under this condition normal pressure between the test shoe and a flat surface cannot be uniformly distributed. The greater pressure occurs at the outer edge of the shoe.

The test shoe is made of thick rubber backed by a one-half inch steel plate. The mounting of this shoe fixes the backing plate rigidly in a plane perpendicular to the axis of the rotating chuck which carries the pavement specimen. Any uneveness or cant in the surface of the test specimen causes uneven bearing of the shoe on the surface which, in turn, results in erroneous relative resistance values.

Ambient temperature has some effect on the test results. Characteristics of both bituminous and rubber materials are modified by changes in temperature. 
APPENDIX C

TEST DATA 


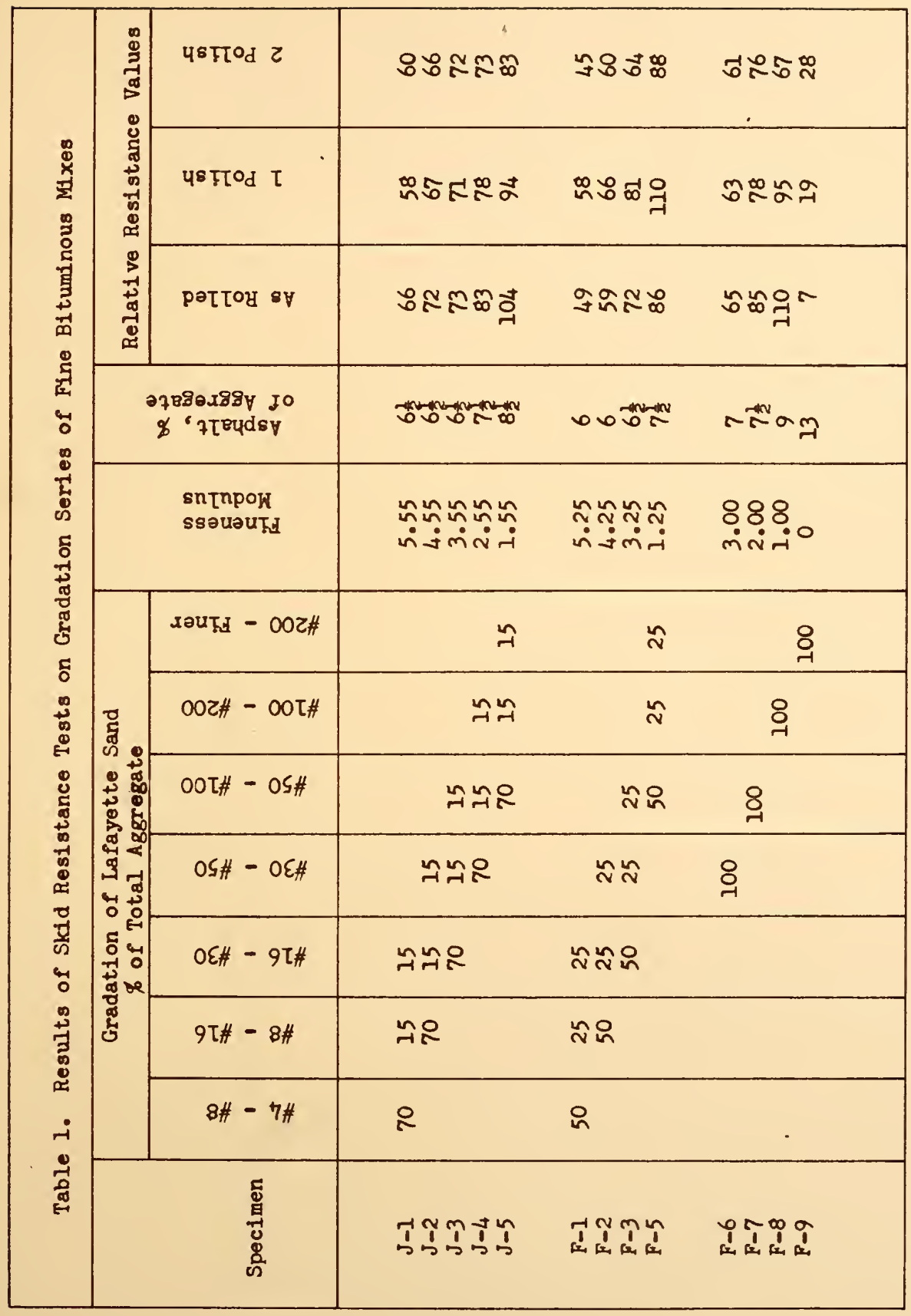




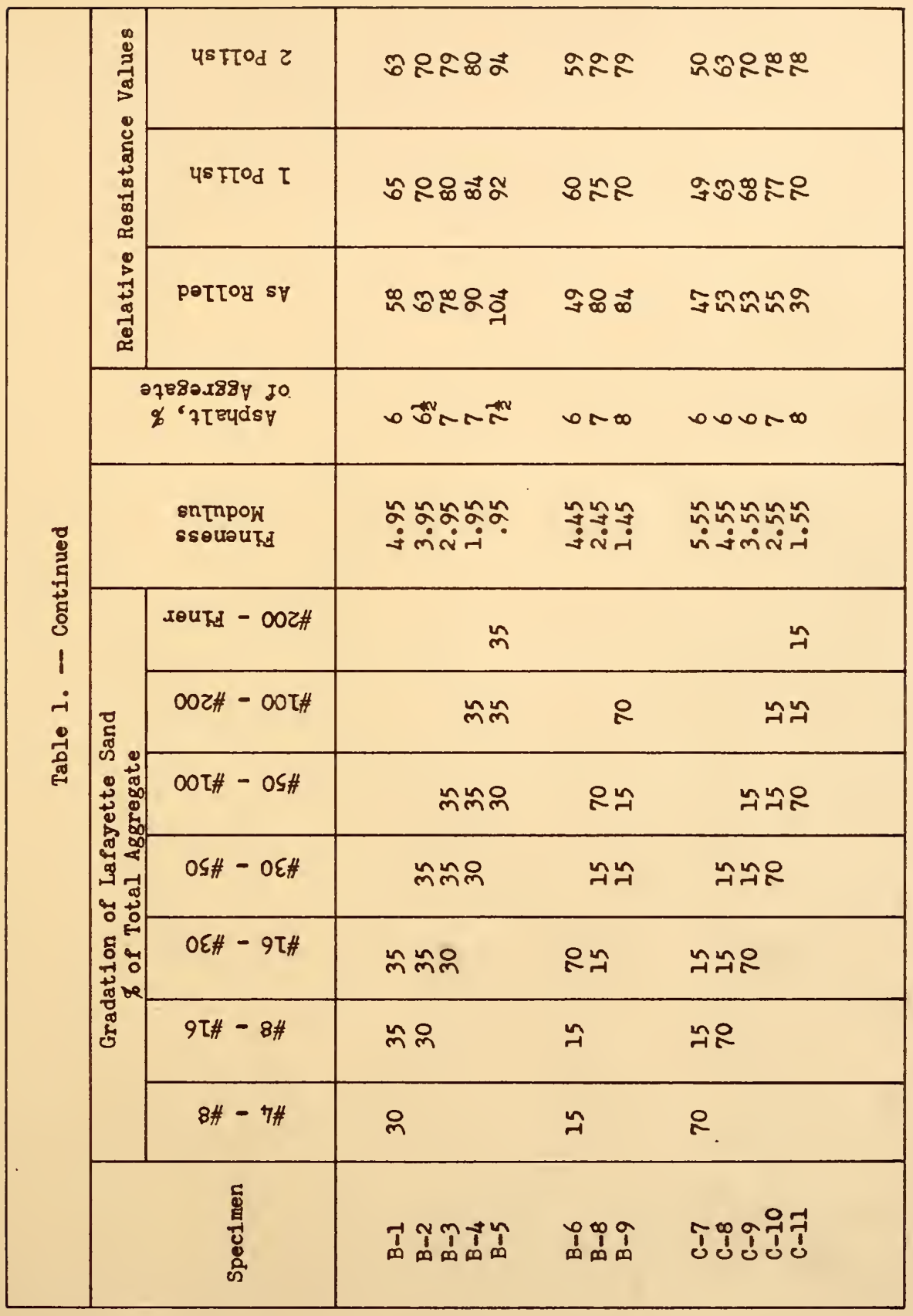




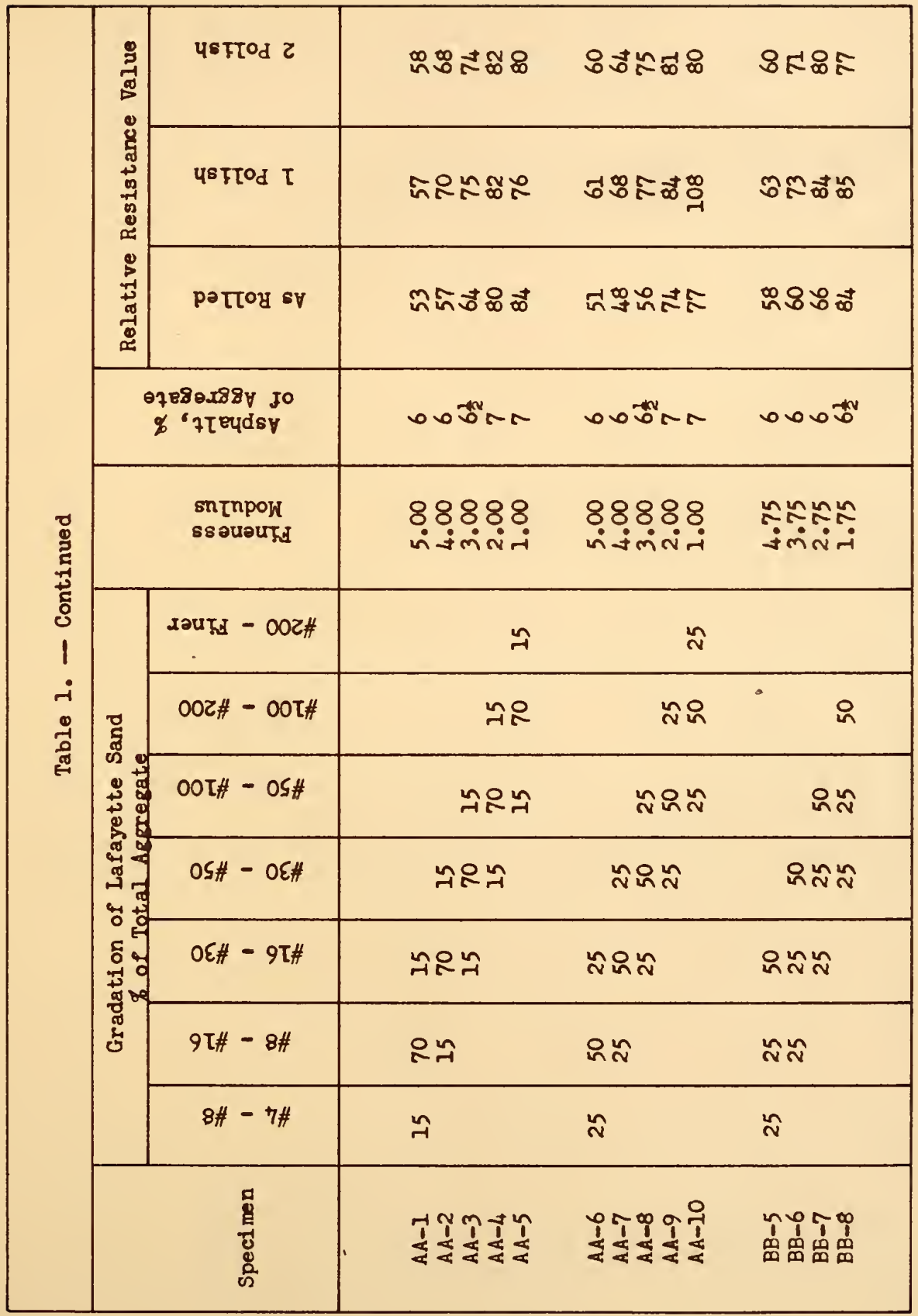




\begin{tabular}{|c|c|c|c|c|c|c|}
\hline \multirow{13}{*}{ 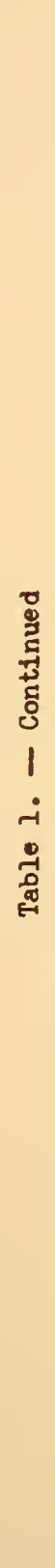 } & \multirow{3}{*}{ } & पsfTOd Z & ㅁo & 웅요욤 & 요요 & $\preccurlyeq \curvearrowleft$ \\
\hline & & पs frod T & స్- & 종 -1 & $\approx-100$ & 또 \\
\hline & & portơ sy & సం: & ヘヘฐ゚゚ & ธิ์ & $7 \infty$ \\
\hline & \multicolumn{2}{|c|}{ 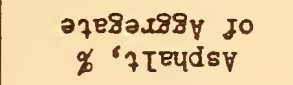 } & Nno & IN०0000 & 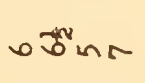 & 0 in \\
\hline & \multicolumn{2}{|r|}{$\begin{array}{l}\text { sn[noon } \\
\text { ssautut] }\end{array}$} & $\begin{array}{l}\text { nmin } \\
\text { imiñ }\end{array}$ & 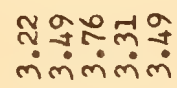 & 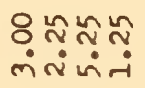 & $\begin{array}{l}m \tilde{n} \\
\text { in }\end{array}$ \\
\hline & \multirow{7}{*}{ 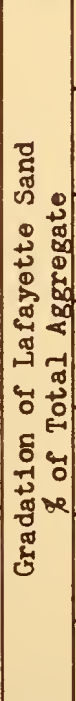 } & sauts - $\infty$ Z\# & & & \multicolumn{2}{|l|}{$\stackrel{n}{*}$} \\
\hline & & 00z\# - & in & & \multicolumn{2}{|l|}{$\stackrel{\sim}{\sim}$} \\
\hline & & DOTH - OS\# & ก8 & జ్నిన్ని & $\stackrel{n}{\sim}$ 요 & กิโ \\
\hline & & OSH - OE\# & స్+ి & జేనిన్ని & 8 & กิร \\
\hline & & OE\# - 9โ\# & mo & ลีสสสี & $\approx$ & $\underset{\sim}{\infty} \underset{\sim}{\sim}$ \\
\hline & & 9 โโ\#-8\# & స్nn & $\underset{\sim}{\infty} \tilde{N}$ & \multicolumn{2}{|l|}{$\stackrel{n}{\sim}$} \\
\hline & & $8 \#-7 \#$ & $\stackrel{2 n}{n}$ & $\sigma \underset{\pi}{\infty}$ & 윳 & లిజే \\
\hline & & 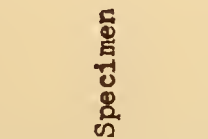 & 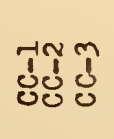 & 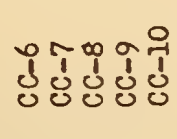 & 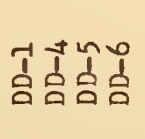 & 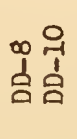 \\
\hline
\end{tabular}




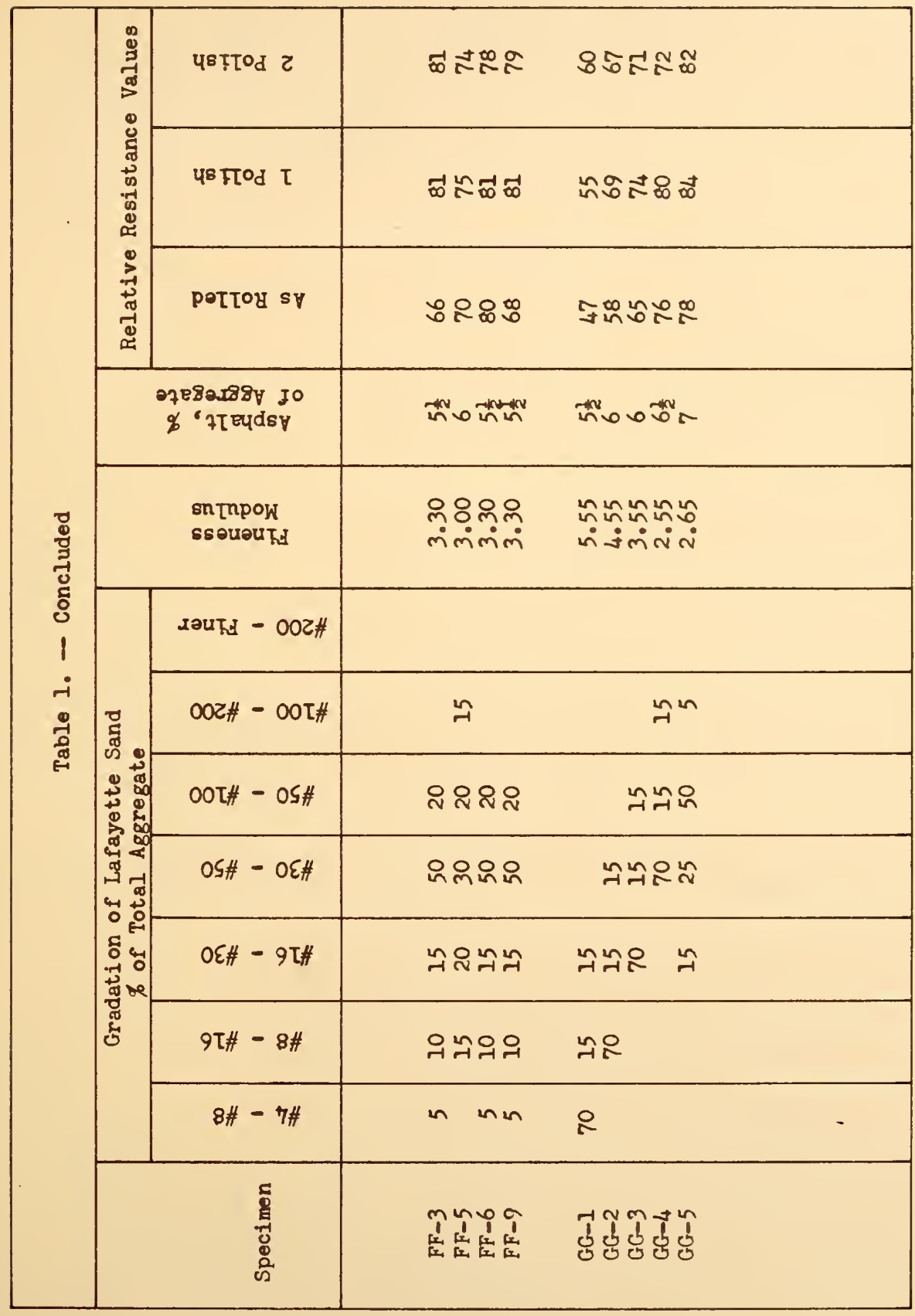




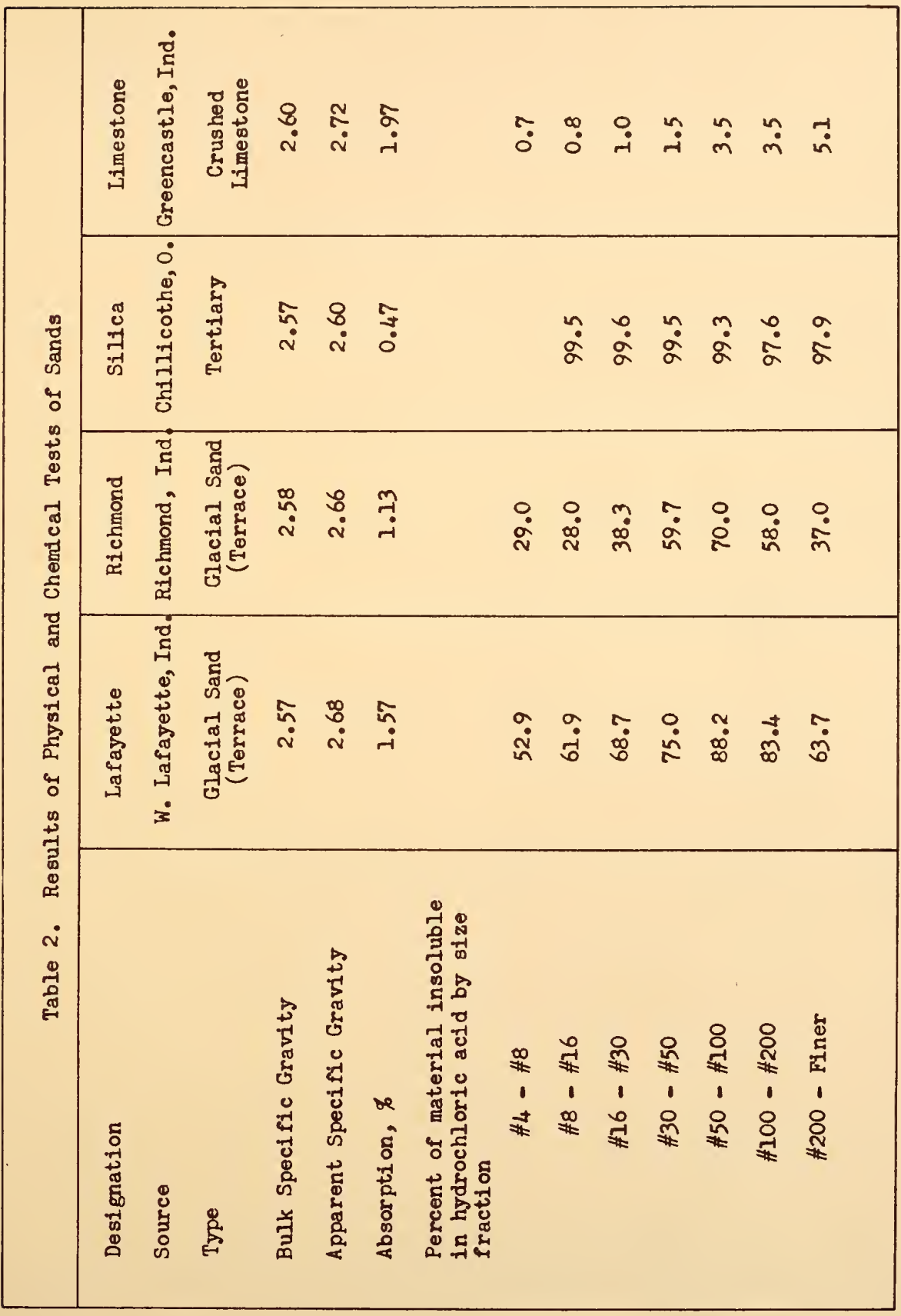




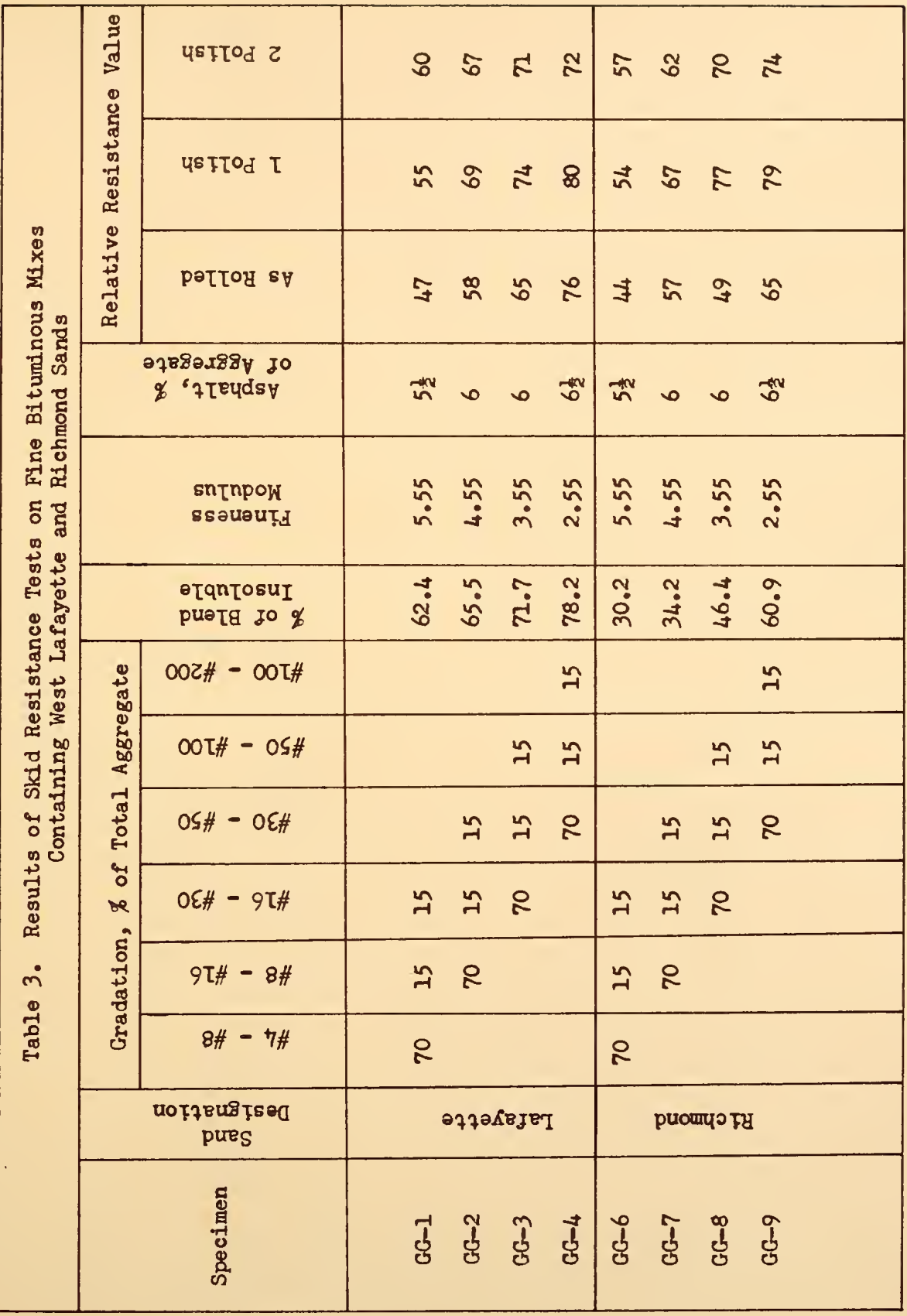




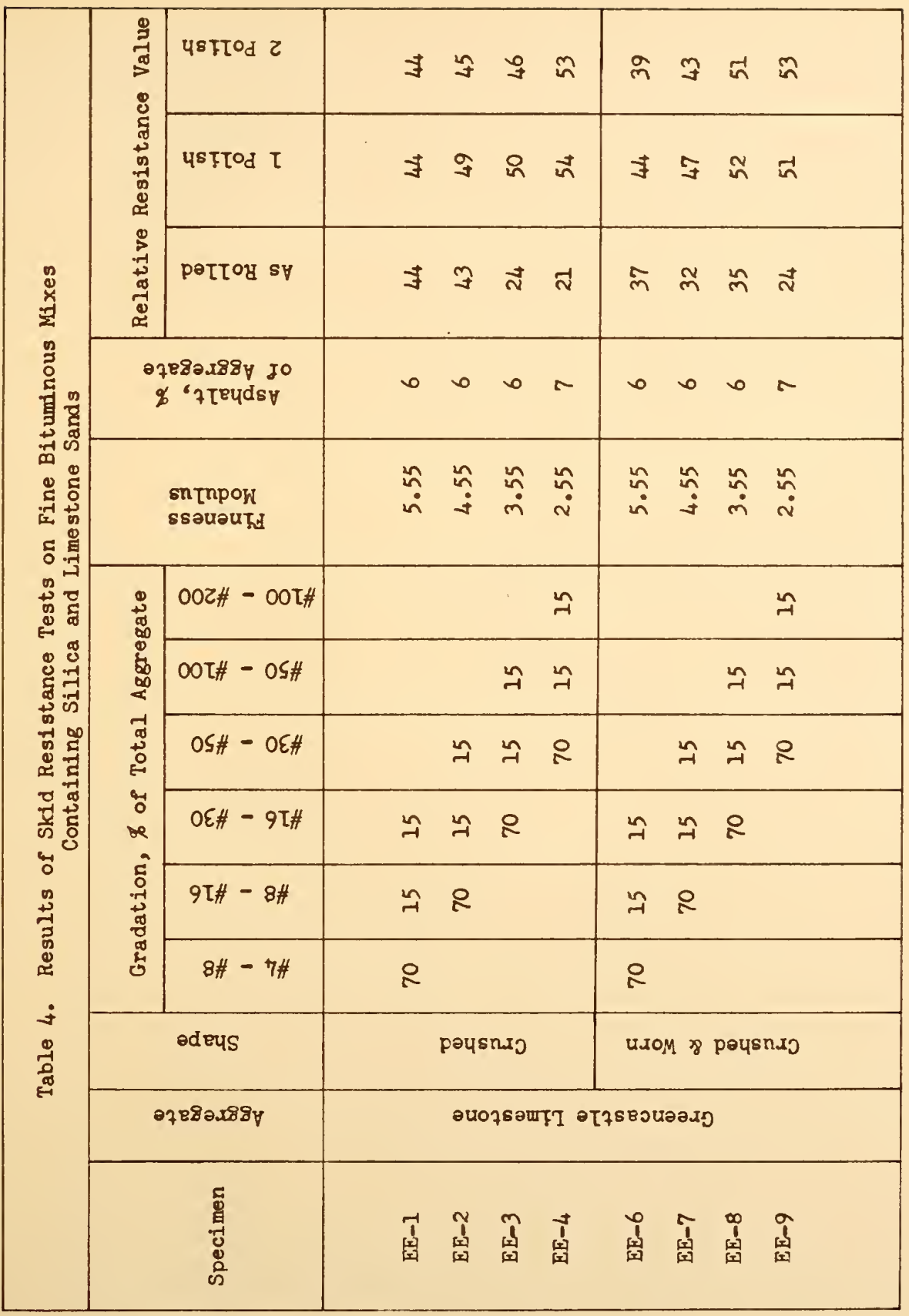




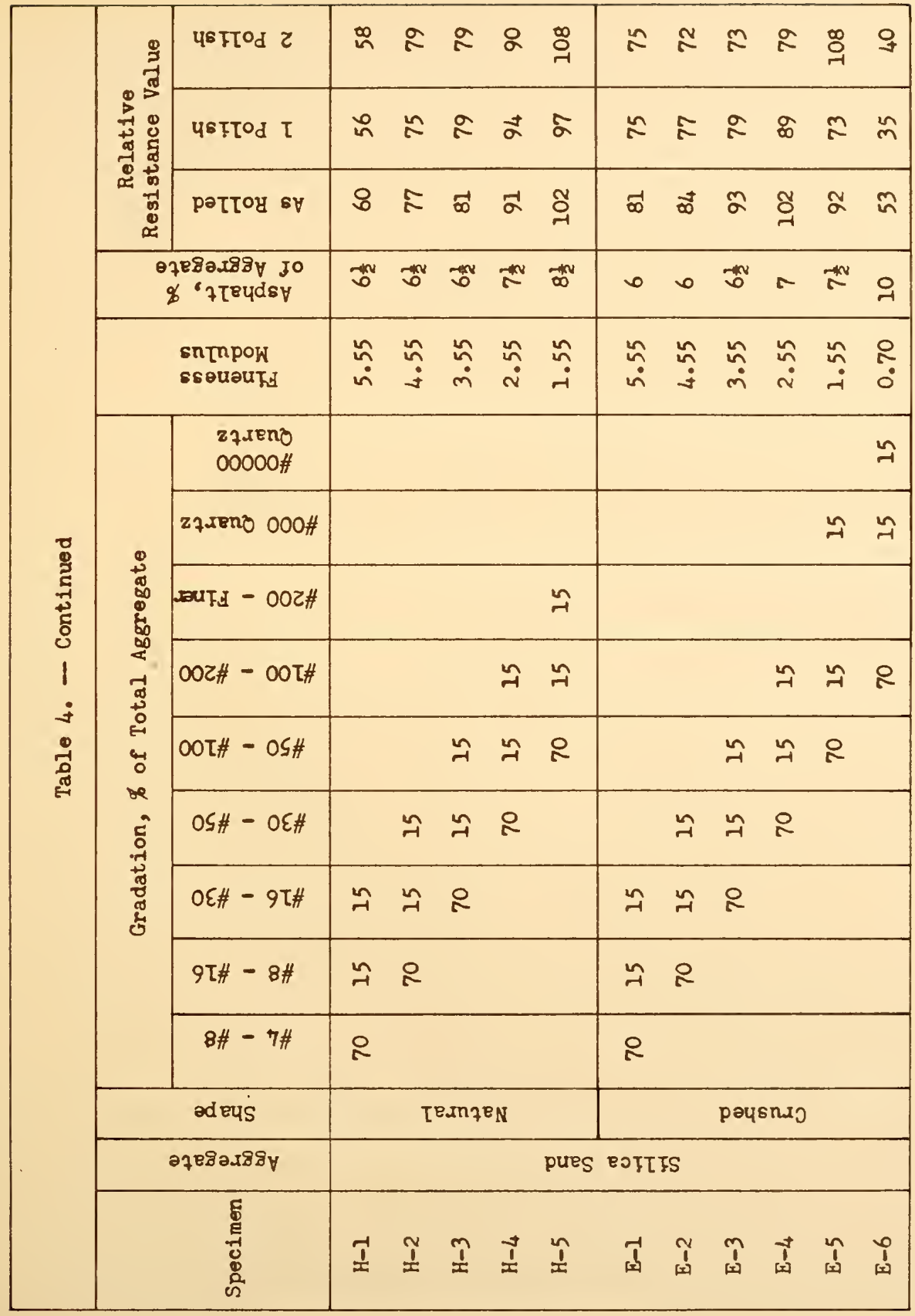




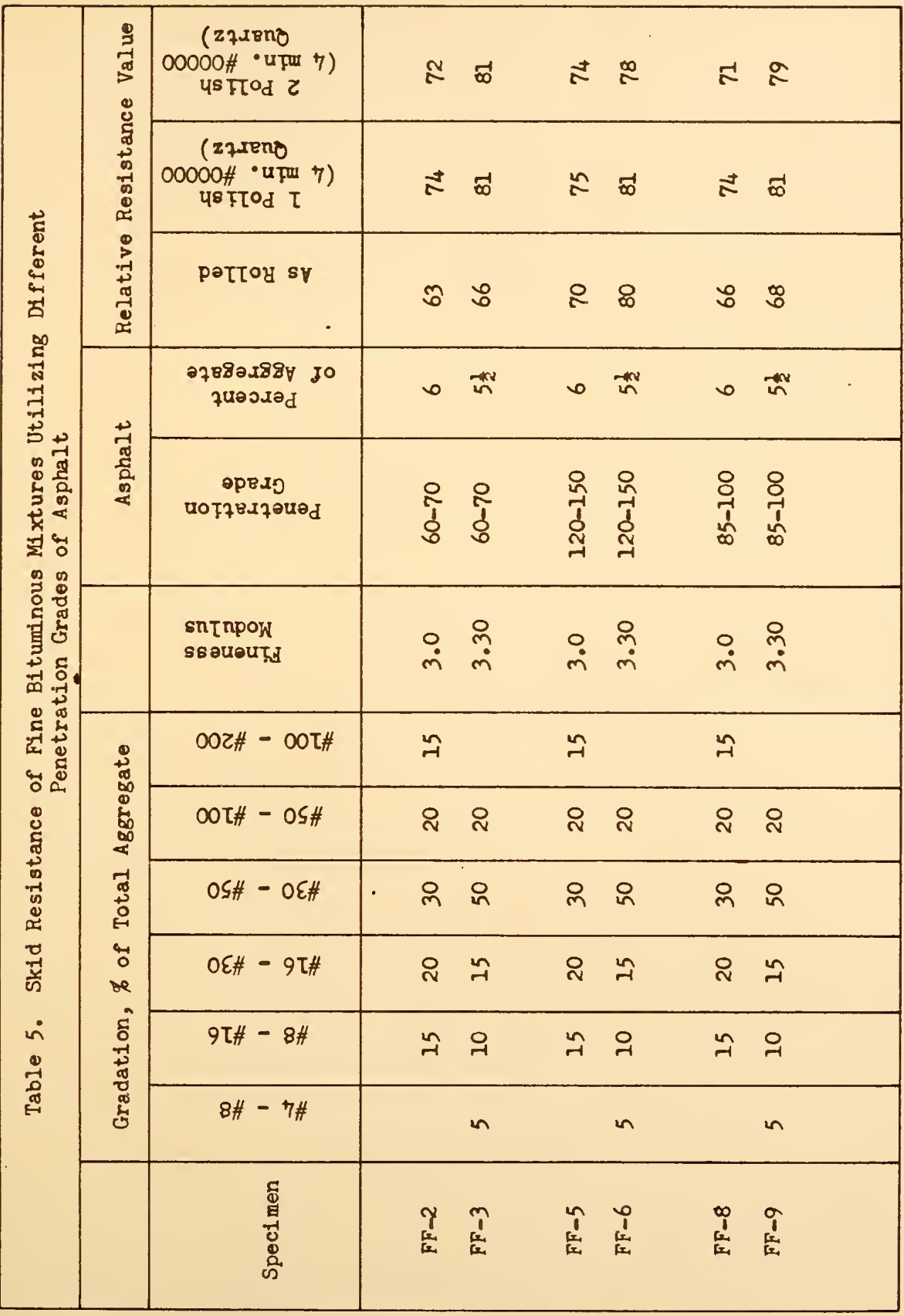


Table 6. Skid Resistance Test Results for Different Contact Areas Between Test Shoe and Limestone

\begin{tabular}{|c|c|c|c|c|c|}
\hline $\begin{array}{l}\text { Test } \\
\text { Gree. }\end{array}$ & $\begin{array}{ll}\text { ad } & 463.72 \mathrm{lb} \\
\text { stle Limestone }\end{array}$ & & $\begin{array}{l}\text { e Area } \\
\text { ished wit }\end{array}$ & $\begin{array}{l}14.45 \mathrm{sq} \\
\mathrm{h} \# 000 \mathrm{Qz}\end{array}$ & $\begin{array}{l}\text { in. } \\
\text { dartz }\end{array}$ \\
\hline \multirow[b]{2}{*}{ Specimen } & \multirow[b]{2}{*}{ Area pattern } & \multirow{2}{*}{$\begin{array}{l}\text { Area of rock } \\
\text { under test } \\
\text { shoe (sq.in.) }\end{array}$} & \multirow{2}{*}{$\begin{array}{c}\text { Pressure } \\
\text { psi }\end{array}$} & \multicolumn{2}{|c|}{$\begin{array}{c}\text { Relative } \\
\text { Resistance Value }\end{array}$} \\
\hline & & & & Mea sured & $\begin{array}{l}\text { Corrected } \\
\text { to } 28 \text { ps } 1\end{array}$ \\
\hline \multirow[t]{10}{*}{$\mathrm{CO}-2$} & $\begin{array}{l}0.66 \text { inch dia. } \\
\text { cores lying } \\
\text { flat }\end{array}$ & $\begin{array}{c}\text { no flat area } \\
3.71\end{array}$ & 164.48 & $\begin{array}{l}28 \\
30\end{array}$ & 7 \\
\hline & & 4.53 & 133.5 & 31 & 10 \\
\hline & 1 & 5.24 & 115.0 & 35 & 18 \\
\hline & & 6.16 & 98.0 & 38 & 24 \\
\hline & & 6.54 & 92.5 & 38 & 25 \\
\hline & & 7.20 & 84.0 & 41 & 30 \\
\hline & & 8.10 & 74.7 & 43 & 35 \\
\hline & & 8.63 & 70.0 & 44 & 36 \\
\hline & & 9.35 & 64.8 & 46 & 39 \\
\hline & & 10.69 & 57.0 & 46 & 40 \\
\hline \multirow[t]{3}{*}{$\mathrm{CU}-2$} & $\begin{array}{l}\frac{1}{2} \text {-inch cubes } \\
\text { on edge }\end{array}$ & no flat area & & 67 & \\
\hline & & 3.66 & 165.0 & 45 & 18 \\
\hline & & 5.5 & 110.0 & 44 & 28 \\
\hline
\end{tabular}


Table 7. Relative Resistance Values at Different Pressures for Greencastle Ifmestone and Medina Sandstone

\begin{tabular}{|c|c|c|c|c|c|}
\hline \multicolumn{2}{|c|}{$\begin{array}{l}\text { Solid Limestone } \\
\text { Core, Contact } \\
\text { Area }=14.45 \text { in }^{2}\end{array}$} & \multicolumn{2}{|c|}{$\begin{array}{l}\text { Solid Sandstone } \\
\text { Core, Contact } \\
\text { Area }=14.45 \text { in }^{2}\end{array}$} & \multicolumn{2}{|c|}{$\begin{array}{l}\text { Multiple Iimestone } \\
\text { Cores, Contact } \\
\text { Area }=8.2 \text { in }^{2}\end{array}$} \\
\hline $\begin{array}{c}\text { Pressure } \\
\text { (psi) }\end{array}$ & $\begin{array}{l}\text { Relative } \\
\text { Resistance } \\
\text { Value }\end{array}$ & $\begin{array}{c}\text { Pressure } \\
\text { (ps1) }\end{array}$ & $\begin{array}{l}\text { Relative } \\
\text { Resistance } \\
\text { Value }\end{array}$ & $\begin{array}{c}\text { Pressure } \\
\text { (psi) }\end{array}$ & $\begin{array}{c}\text { Relative } \\
\text { Resistance } \\
\text { Value } \\
\end{array}$ \\
\hline \multicolumn{6}{|c|}{ Static } \\
\hline 16.7 & 67 & 16.7 & 36 & 29.7 & 47 \\
\hline 24.6 & 86 & 24.6 & 50 & 43.3 & 58 \\
\hline 32.2 & 110 & 32.3 & 76 & 56.8 & 80 \\
\hline 44.5 & 130 & 44.5 & 128 & 77.5 & 120 \\
\hline 54.0 & 150 & 54.0 & 158 & 95.5 & 152 \\
\hline 65.0 & 170 & 65.0 & 192 & 114.5 & 195 \\
\hline \multicolumn{6}{|c|}{ Dymanic $(2,500 \mathrm{rpm})$} \\
\hline 16.7 & 15 & 16.7 & 30 & 29.7 & 28 \\
\hline 24.6 & 24 & 24.6 & 45 & 43.3 & 35 \\
\hline 32.3 & 27 & 32.3 & 59 & 56.8 & 38 \\
\hline 44.5 & 30 & 44.5 & 74 & 77.5 & 49 \\
\hline 54.0 & 32 & 54.0 & 87 & 95.5 & 55 \\
\hline 65.0 & 35 & 65.0 & 102 & 114.5 & 59 \\
\hline
\end{tabular}


Table 8. Results of Reflected light Measurements on Fine Bituminous Surfaces

\begin{tabular}{|c|c|c|c|c|c|c|c|c|}
\hline \multicolumn{3}{|c|}{ Greencastle IImestone } & \multicolumn{6}{|c|}{ West Iafayette Sand } \\
\hline 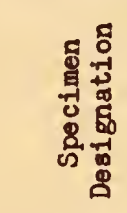 & 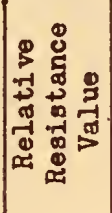 & 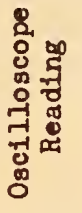 & 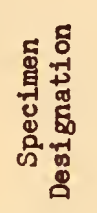 & 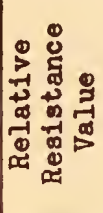 & 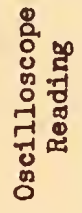 & 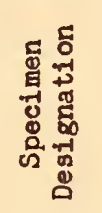 & 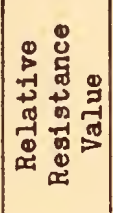 & 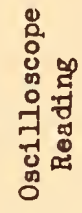 \\
\hline EE-1 & 44 & $-13 \frac{1}{2}$ & GG-1 & 60 & -20 & $\mathrm{CC}-6$ & 79 & -29 \\
\hline $\mathrm{EE}-2$ & 45 & -10 & $G G-2$ & 67 & -19 & $\mathrm{CC}-7$ & 78 & -28 \\
\hline$E E-3$ & 46 & -14 & $G G-3$ & 71 & $-22 \frac{1}{2}$ & $c c-8$ & 79 & $-27 \frac{1}{2}$ \\
\hline EE-4 & 53 & -20 & $G G-6$ & 57 & -8 & $\mathrm{CC}-9$ & 80 & -26 \\
\hline$E E-6$ & 39 & -8 & $G G-7$ & 62 & -19 & CC-10 & 79 & -25 \\
\hline EE-7 & 43 & -6 & $G G-8$ & 70 & -19 & $\mathrm{BB}-5$ & 60 & -20 \\
\hline EE-8 & 51 & -19 & $A A-1$ & 58 & -18 & $\mathrm{BB}-6$ & 71 & -24 \\
\hline EE-9 & 53 & $-17 \frac{1}{2}$ & $A A-3$ & 74 & -21 & $\mathrm{BB}-7$ & 80 & $-22 \frac{1}{2}$ \\
\hline $\mathrm{K}-1$ & 44 & -11 & $A A-7$ & 64 & -22 & $\mathrm{BB}-8$ & 77 & -22 \\
\hline$K-2$ & 45 & -10 & $A A-8$ & 75 & $-22 \frac{1}{2}$ & $c-7$ & 50 & -25 \\
\hline $\mathrm{K}-3$ & 49 & -12 & $A A=9$ & 81 & -27 & $C-8$ & 63 & $-15 \frac{1}{2}$ \\
\hline $\mathrm{K}-4$ & 43 & -9 & $\mathrm{DD}-1$ & 69 & -27 & $c-9$ & 70 & -19 \\
\hline \multirow[t]{8}{*}{$k-5$} & 69 & -24 & $\mathrm{DD}-4$ & 80 & -27 & $c-10$ & 78 & -22 \\
\hline & & & $D D-5$ & 60 & $-22 \frac{1}{2}$ & $C-11$ & 82 & -25 \\
\hline & . & & $D D-6$ & 87 & -26 & $J-1$ & 55 & -23 \\
\hline & & & $D D-8$ & 77 & -26 & $J-2$ & 66 & -20 \\
\hline & & & DD-10 & 75 & -20 & $J-3$ & 73 & -27 \\
\hline & & & CC-1 & 66 & -22 & $J-4$ & 75 & -29 \\
\hline & & & $\mathrm{CC}-2$ & 78 & -24 & $J-5$ & 95 & -28 \\
\hline & & & $\mathrm{CC}-3$ & 80 & -27 & & & \\
\hline
\end{tabular}


Table 9. Skid Resistance of Surfaces Composed of Controlled-Shape Rock Fragments

Greencastle Limestone

Test Load 463.72 pounds
Shoe Area $14.45 \mathrm{sq}$. in.

Polished with \#000 crushed quartz

\begin{tabular}{|c|c|c|c|c|c|c|c|c|}
\hline \multirow[b]{3}{*}{ Specimen } & \multirow[b]{3}{*}{ Shape } & \multirow{3}{*}{ 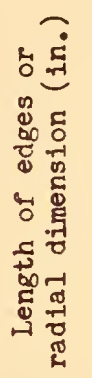 } & \multirow{3}{*}{ 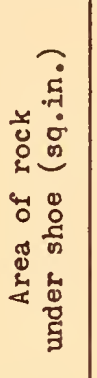 } & \multirow{3}{*}{ 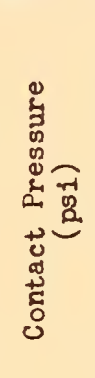 } & \multicolumn{4}{|c|}{$\begin{array}{c}\text { Relative } \\
\text { Resistance Value }\end{array}$} \\
\hline & & & & & \multicolumn{2}{|c|}{$\begin{array}{l}\text { Aggregate } \\
\text { Interstices } \\
\text { Open }\end{array}$} & \multicolumn{2}{|c|}{$\begin{array}{l}\text { Aggregate } \\
\text { Interstices } \\
\text { Filled }\end{array}$} \\
\hline & & & & & 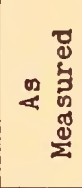 & 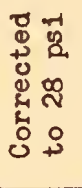 & 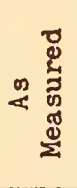 & 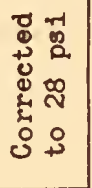 \\
\hline $\mathrm{CO}-2$ & $\begin{array}{l}0.66 \text { inch cores } \\
\text { lying flat }\end{array}$ & 20.64 & 0.0 & & 28 & & & \\
\hline $\mathrm{CO}-2$ & as above & 20.95 & 10.69 & 57 & 46 & 40 & & \\
\hline CU-1 & $\begin{array}{l}1 \text { inch square } \\
\text { cubes, flat, } \\
\frac{1}{4} \text { in. spacing }\end{array}$ & 18.8 & 12.11 & 50 & 50 & 46 & 46 & 45 \\
\hline$R S-26$ & $\begin{array}{l}\text { Solid core, } \\
243 / 16 \text { inch } \\
\text { radial slots }\end{array}$ & 36.0 & 12.1 & 50.3 & 50 & 46 & 44 & 43 \\
\hline RS-8 & $\begin{array}{l}\text { Solid core } \\
123 / 8 \text { inch } \\
\text { radial slots }\end{array}$ & 18.0 & 12.1 & 50.3 & 48 & 44 & & \\
\hline $\mathrm{CO}-1$ & $\begin{array}{l}0.66 \text { inch cores } \\
\text { on end }\end{array}$ & 25.85 & 14.01 & 43.4 & 57 & 53 & 52 & 51 \\
\hline CU-2 & $\begin{array}{l}0.5 \text { inch cubes } \\
\text { on edge }\end{array}$ & 30.5 & 0.0 & & 67 & & & \\
\hline $\mathrm{CU}-2$ & as above & 30.5 & 5.5 & 110 & 44 & 28 & & \\
\hline $\mathrm{SC}$ & Solid core & 0 & 28.85 & 32.1 & & & 44 & 43 \\
\hline $\begin{array}{l}\text { A luminum } \\
\text { Cement }\end{array}$ & Solid surface & 0 & 18.85 & 32.1 & & & 48 & 47 \\
\hline
\end{tabular}




\begin{tabular}{|c|c|c|c|c|c|}
\hline \multicolumn{6}{|c|}{$\begin{array}{c}\text { Table 10. Relative Resistance Values Resulting from Varying } \\
\text { the Degree of Polish of Stone Cores }\end{array}$} \\
\hline & \multicolumn{5}{|c|}{ Relative Resistance Values } \\
\hline $\begin{array}{r}15 \text {-minute polish } \\
\text { with each abra- } \\
\text { sive listed below }\end{array}$ & $\begin{array}{l}\text { Sandstone } \\
\text { Medina, } \\
\text { New York }\end{array}$ & \begin{tabular}{|c|} 
Limestone \\
Greencastie, \\
Indiana
\end{tabular} & \begin{tabular}{|l|} 
Limestone \\
Wheeling, \\
W.Virginis \\
\end{tabular} & $\begin{array}{l}\text { Limestone } \\
\text { Richmond, } \\
\text { Indians } \\
\end{array}$ & $\begin{array}{c}\text { Dolonite } \\
\text { Bedford, } \\
\text { Penn. }\end{array}$ \\
\hline$\# 2$ quartz & 79 & 55 & 45 & 68 & 54 \\
\hline \#2 quartz & 87 & 52 & 46 & 67 & 52 \\
\hline \#1 quartz & 87 & 52 & 37 & 66 & 53 \\
\hline \#1 quartz & 87 & 46 & 34 & 60 & 48 \\
\hline$\# 00$ quartz & 80 & 46 & 44 & 60 & 63 \\
\hline \#00 quartz & 79 & 48 & 42 & 60 & 60 \\
\hline$\# 000$ quartz & 80 & 47 & 45 & 47 & 62 \\
\hline$\# 000$ quartz & 78 & 45 & 40 & 44 & 60 \\
\hline$\# 00000$ quartz & 78 & 38 & 37 & 40 & 57 \\
\hline \#00000 quartz & 78 & 40 & 37 & 43 & 58 \\
\hline Miñmeratopiler & 78 & 31 & 29 & 39 & 52 \\
\hline Minerastopler & 77 & 27 & 27 & 38 & 48 \\
\hline $\begin{array}{l}\text { Abrasive material } \\
\text { same as core, sieve } \\
\text { size fractions }\end{array}$ & & & & & \\
\hline$\# 30-\# 50$ & & 48 & 46 & 65 & 72 \\
\hline$\# 30-\# 50$ & & 43 & 55 & 70 & 65 \\
\hline$\# 50-\# 100$ & & 47 & 54 & 65 & 81 \\
\hline$\# 50-\# 100$ & & 49 & 57 & 65 & 78 \\
\hline$\# 100-\# 200$ & & 53 & 60 & 65 & 84 \\
\hline$\# 100-\# 200$ & & 51 & 58 & 63 & 83 \\
\hline$\# 200-\# 270$ & & 50 & 61 & 55 & 78 \\
\hline$\# 200-\# 270$ & & 35 & 42 & 41 & 61 \\
\hline$\# 270$ - Finer & - & 29 & 42 & 38 & 60 \\
\hline$\# 270$ - F1ner & & 23 & 46 & 37 & 58 \\
\hline
\end{tabular}


Table 11. Summary of Abrasives Used for Pollshing

\begin{tabular}{|c|c|c|c|c|c|}
\hline \multirow{2}{*}{$\begin{array}{c}\text { Material } \\
\text { and } \\
\text { Grade }\end{array}$} & \multicolumn{5}{|c|}{ Percent of material between sieves numbered } \\
\hline & $\# 30-\# 50$ & $\# 50-\# 100$ & $\# 100-\# 200$ & $\# 200-\# 270$ & $\# 270-P a n$ \\
\hline Crushed Quartz & & & & & \\
\hline$\# 2$ & 95 & 5 & & & \\
\hline \#I & & 100 & 85 & 5 & \\
\hline$\# \infty$ & & 10 & 85 & 5 & \\
\hline$\# 000$ & & & 17 & 6 & 77 \\
\hline \#00000 & & & & 10.5 & 89.5 \\
\hline Mineral Filler & & 4.8 & 10.6 & 28.8 & 55.8 \\
\hline
\end{tabular}


Table 12. Sumnary of Measurements of Surface Roughness by the Brush Surface Analyzer

\begin{tabular}{|c|c|c|c|c|c|c|c|}
\hline \multirow[b]{2}{*}{ 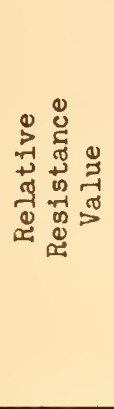 } & \multicolumn{4}{|c|}{$\begin{array}{c}\text { Height of Profile Peaks, } \\
\text { Chart Divisions }\end{array}$} & \multirow[b]{2}{*}{ 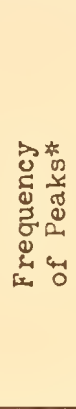 } & \multirow[b]{2}{*}{ 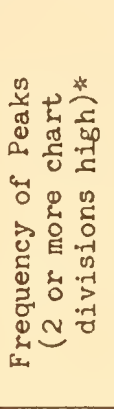 } & \multirow[b]{2}{*}{ 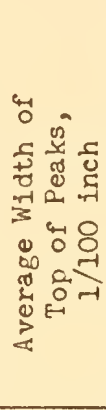 } \\
\hline & 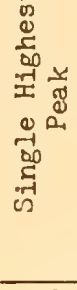 & 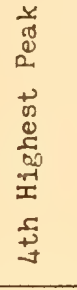 & 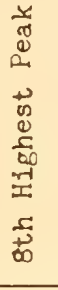 & 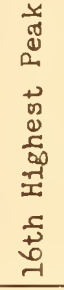 & & & \\
\hline 27 & $3 \frac{1}{2}$ & 1 & 1 & $\frac{1}{2}$ & 13 & 6 & 3 \\
\hline 31 & 4 & 2 & $I_{2}^{2}$ & 1 & 13 & 4 & 3 \\
\hline 37 & 3 & 2 & $1 \frac{1}{2}$ & 1 & 17 & 12 & 3 \\
\hline 40 & 1 & 1 & 1 & 1 & 13 & 6 & 7 \\
\hline 45 & 3 & 2 & 2 & 1 & 10 & 7 & 2 \\
\hline 50 & $15 \frac{1}{2}$ & 5 & $3 \frac{1}{2}$ & 2 & 12 & 11 & 2 \\
\hline 55 & $11 \frac{1}{2}$ & $6 \frac{2}{4}$ & 4 & 2 & 12 & 8 & 1 \\
\hline 60 & $8 \frac{1}{4}$ & $2 \frac{1}{2}$ & 2 & 2 & 16 & 10 & 4 \\
\hline 65 & 6 & $3 \frac{1}{4}$ & $2 \frac{1}{2}$ & 2 & 13 & 12 & 2 \\
\hline 70 & $7 \frac{1}{2}$ & $5 \frac{1}{2}$ & 4 & 2 & 7 & 8 & 2 \\
\hline 72 & 3 & 2 & 1 & 1 & 15 & 8 & 3 \\
\hline 78 & $3 \frac{1}{2}$ & 2 & $1 \frac{1}{2}$ & $1 \frac{1}{4}$ & 13 & 9 & 2 \\
\hline 81 & 5 & 3 & $2 \frac{1}{4}$ & 2 & 13 & 10 & 3 \\
\hline 83 & 5 & 3 & 2 & 3 & 20 & 8 & 1 \\
\hline 84 & 3 & 3 & $2 \frac{1}{2}$ & 2 & 20 & 13 & 2 \\
\hline
\end{tabular}

*The unit for frequency of peaks is the number of peaks in one 0.1 -inch traverse. On the paper tape profiles this is 20 longitudinal units. 


\begin{tabular}{|c|c|c|}
\hline \multirow{2}{*}{ Table 13. Summary of Sieve Sizes Used for Fine Aggregate } \\
\hline \multirow{2}{*}{ Sieve Designation } & \multicolumn{2}{|c|}{ Sieve Opening } \\
\cline { 2 - 3 } & Millimeters & Inches \\
\hline $3 / 8$ inch & 9.52 & 0.375 \\
$\# 4$ & 4.76 & 0.187 \\
$\# 8$ & 2.38 & 0.0937 \\
$\# 16$ & 1.19 & 0.0469 \\
$\# 30$ & 0.59 & 0.0232 \\
$\# 50$ & 0.297 & 0.0127 \\
$\# 100$ & 0.149 & 0.0059 \\
$\# 200$ & 0.074 & 0.0029 \\
\hline
\end{tabular}


Table 14. Skid Resistance of Differently Compacted Specimens

\begin{tabular}{|c|c|c|c|c|c|}
\hline Sieve Size & $\begin{array}{c}\text { Gradation } \\
\text { \% of Total Aggregate }\end{array}$ & \multirow{3}{*}{ 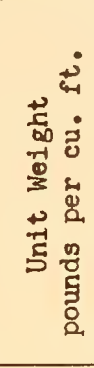 } & \multicolumn{3}{|c|}{$\begin{array}{c}\text { Relative } \\
\text { Resistance Values }\end{array}$} \\
\hline $\begin{array}{c}\# 8-\# 16 \\
\# 16-\# 30 \\
\# 30-\# 50 \\
\# 50-\# 100 \\
\# 100-\# 200 \\
\# 200-\text { Finer } \\
\end{array}$ & 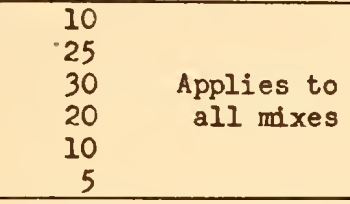 & & 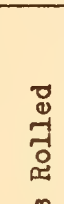 & 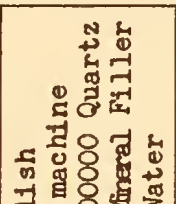 &  \\
\hline Specimen & $\begin{array}{c}\text { Compaction at Time } \\
\text { of Molding }\end{array}$ & & $<$ & 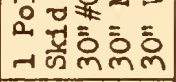 & $N$ \\
\hline$Q-1$ & $\begin{array}{l}\text { Wibrate by hand } \\
30 \text { sec. plus } 30 \mathrm{sec} \text {. }\end{array}$ & 119.5 & 76 & 64 & 64 \\
\hline Q-2 & $\begin{array}{l}\text { Vibrate in frame } \\
30 \mathrm{sec} \text {. at } 48 \mathrm{psi} \\
30 \mathrm{sec} . \text { at } 275 \mathrm{psi}\end{array}$ & 116.3 & 82 & 69 & 66 \\
\hline$Q-3$ & $\begin{array}{l}\text { Vibrate in frame } \\
300 \mathrm{sec} \text { at } 48 \mathrm{psi}\end{array}$ & $114 \cdot 4$ & 80 & 69 & 65 \\
\hline$Q-4$ & $\begin{array}{l}\text { Vibrate in frame } \\
30 \mathrm{sec} \text {. at } 48 \mathrm{psi} \\
30 \mathrm{sec} \text {. at } 735 \mathrm{psi}\end{array}$ & 116.0 & 83 & 72 & 67 \\
\hline$Q-5$ & $\begin{array}{l}\text { Static load } \\
120 \mathrm{sec} \text { at } 110 \mathrm{psi}\end{array}$ & 113.5 & 82 & 68 & 65 \\
\hline$Q-6$ & $\begin{array}{l}\text { Static load } \\
120 \text { sec. at } 550 \text { psi }\end{array}$ & 115.4 & 81 & 69 & 67 \\
\hline$Q-7$ & $\begin{array}{l}\text { Static load } \\
120 \mathrm{sec} \text {. at } 110 \mathrm{psi}\end{array}$ & 116.7 & 79 & 68 & 65 \\
\hline$Q-8$ & $\begin{array}{l}\text { Static load } \\
120 \text { sec. at } 110 \text { psi } \\
\text { cooled under load }\end{array}$ & 115.3 & 80 & 70 & 68 \\
\hline$Q-9$ & $\begin{array}{l}\text { Vibrate in frame } \\
30 \mathrm{sec} \text {. at } 48 \mathrm{psi} \\
30 \mathrm{sec} \text {. at } 275 \mathrm{psi}\end{array}$ & 116.4 & 76 & 65 & 63 \\
\hline
\end{tabular}




\begin{tabular}{|c|c|c|c|}
\hline $\begin{array}{r}\text { Table 15. Skid Resistan } \\
\text { for Diffe }\end{array}$ & $\begin{array}{l}\text { of Specimen } \\
\text { nt Lengths o }\end{array}$ & $\begin{array}{l}\text { is Pollshed } \\
\text { of Time }\end{array}$ & \\
\hline Specimen Designation & $\mathrm{DD}-7$ & DD-9 & DD-10 \\
\hline Sieve Number & \multicolumn{3}{|c|}{ Gradation, $\%$ of Total Aggregate } \\
\hline$\# 4-\# 8$ & 36 & 45 & 54 \\
\hline$\# 16-\# 30$ & 18 & 15 & 12 \\
\hline$\# 30-\# 50$ & 23 & 20 & 17 \\
\hline$\# 50-\# 100$ & 23 & 20 & 17 \\
\hline Asphalt, $\mathscr{f}$ of Aggregate & 6 & $5 \frac{1}{2}$ & $5 \frac{1}{2}$ \\
\hline Pollshing Procedure & \multicolumn{3}{|c|}{ Relative Resistance Value } \\
\hline As rolled & $n$ & 65 & 68 \\
\hline $\begin{array}{l}1 \text { Pollsh, } 2 \text { min. in drill } \\
\text { press } \# 00000 \text { crushed } \\
\text { quartz }\end{array}$ & 81 & 82 & 77 \\
\hline 2 Pollish, as above & 77 & 88 & 75 \\
\hline 3 Poltsh, as above & 77 & 78 & 73 \\
\hline 4 Polish, as above & 75 & 74 & 72 \\
\hline $\begin{array}{l}5 \text { Polish, skid machine } \\
30 \mathrm{sec} ., \text { \#00000 quartz } \\
30 \mathrm{sec} ., \text { mineral filler } \\
30 \text { sec., water }\end{array}$ & 69 & 71 & 69 \\
\hline
\end{tabular}


VITA

Jack Edward Stephens was born on August 17, 1923, in Eaton, Ohio.

He entered Miami University at Oxford, Ohio, in 1941. In 1942 he enlisted in the United States Army and upon returning from the European theater of operation was discharged in 1946. He then completed his undergraduate work at the University of Connecticut receiving the degree of Bachelor of Science in Engineering in 1947.

After one year as an instructor of Civil Engineering at the University of Connecticut, he accepted a position with the Connecticut Highway Department as a junior highway engineer. While with that department he did inspection work on many structures along the SheltonDerby-Ansonia Expressway and also attended the Yale Graduate School.

He returned to the University of Connecticut as an Assistant Professor of Civil Engineering in 1950. He received the MSE from Purdue University in 1955. The summer of 1955 he pursued graduate study at the University of California on an Automotive Safety Foundation Fellowship, and in 1956 he continued graduate study at Purdue University with the aid of an Asphalt Institute Fellowship.

He has been on sabbatical leave from the University of Connecticut during 1958-59 while continuing graduate work at Purdue University under an Automotive Safety Foundation Fellowship. 
He is a member of Sigma Xi, Tau Beta Pi, Chi Epsilon, Phi Kappa Phi, Phi Eta Sigma, the American Society of Civil Engineers, the Association of Asphalt Paving Technologists, the Highway Research Board and the Connecticut Society of Civil Engineers. He is registered as a Land Surveyor and Professional Engineer in the State of Connecticut.

His publications are:

Gant, E. V., Stephens, J. E., and Moulton, L. K., "Measurement of Forces Produced in Piles by Settlement of Adjacent Soil," Bulletin No. 173, Highway Research Board, p. 20, 1958.

Sawyer, H. A. Jr. and Stephens, J. E., "Under-Reinforced Concrete Beans Under Long-Term Load," Journal, American Concrete Institute, Vol. 29, p. 21, July 1957. 

